\title{
Electrochemically Induced Synthesis of Sulfonylated $N$-Unsubstituted Enamines from Vinyl Azides and Sulfonyl Hydrazides
}

\author{
Olga M. Mulina, a Nataliya V. Zhironkina, ${ }^{\text {a,b }}$ Stanislav A. Paveliev, ${ }^{\text {a }}$ \\ Dmitry V. Demchuk, ${ }^{a}$ Alexander O. Terent'ev a,b* \\ ${ }^{a}$ N. D. Zelinsky Institute of Organic Chemistry, Russian Academy of Sciences, 47 Leninsky \\ prospect, Moscow, 119991, Russian Federation \\ Fax: +7 49913553 28; e-mail:terentev@ioc.ac.ru \\ ${ }^{\mathrm{b}}$ D.I. Mendeleev University of Chemical Technology of Russia, 9 Miusskaya square, \\ Moscow, 125047, Russian Federation

\section{SUPPORTING INFORMATION}

\section{Table of Contents}

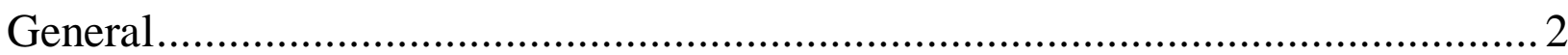

Electrochemical reaction of vinyl azides with sulfonyl hydrazides ........................ 4

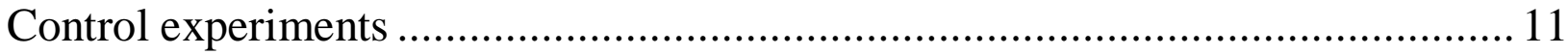

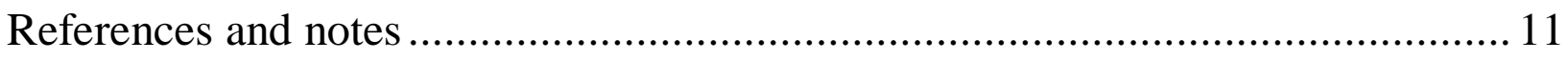

NMR spectra of synthesized compounds ......................................................... 13 


\section{General}

NMR spectra were registered on Bruker Avance II $300 \mathrm{MHz}$ instrument. Chemical shifts were measured relative to residual solvent peaks as an internal standard set to $\delta 7.25$ and $\delta 77.0$ $\left(\mathrm{CDCl}_{3}\right), \delta 2.50$ and $\delta 39.51\left(\mathrm{DMSO}-\mathrm{d}_{6}\right)$. High resolution mass spectra (HRMS) were measured on a Bruker maXis instrument equipped with an electrospray ionization (ESI) ion source. ${ }^{[1]}$ The measurements were done in a positive ion mode (interface capillary voltage $4500 \mathrm{~V}$ ); the mass ratio was from m/z 50 to $3000 \mathrm{Da}$; external/internal calibration was done with Electrospray Calibrant Solution. A syringe injection was used for solutions in $\mathrm{CH}_{3} \mathrm{CN}$ (flow rate $3 \mu \mathrm{L} / \mathrm{min}$ ). Nitrogen was applied as a dry gas; interface temperature was set at $180^{\circ} \mathrm{C}$. The TLC analyses were carried out on standard silica gel chromatography plates. The melting points were determined on a Kofler hot-stage apparatus. Column chromatography was performed on silica gel (60-200 mesh).

p-Toluenesulfonohydrazide (2a), benzenesulfonohydrazide (2t), methanesulfonohydrazide (2u), 4-chlorobenzenesulfonyl chloride, 4-bromobenzenesulfonyl chloride, 4-fluorobenzenesulfonyl chloride, 4-iodobenzenesulfonyl chloride, 4-methoxybenzenesulfonyl chloride, 4acetamidobenzenesulfonyl chloride, 4-nitrobenzenesulfonyl chloride, 3-nitrobenzenesulfonyl chloride, 2,4,6-trimethylbenzenesulfonyl chloride, naphthalene-2-sulfonyl chloride, thiophene-2sulfonyl chloride, 2,5-dimethylthiophene-3-sulfonyl chloride, isothiazole-5-sulfonyl chloride, styrene, 1-methyl-4-vinylbenzene, 1-methyl-3-vinylbenzene, 1-tert-butyl-4-vinylbenzene, 1chloro-4-vinylbenzene, 1-fluoro-4-vinylbenzene, 1-methoxy-3-vinylbenzene, 1-(chloromethyl)4-vinylbenzene, (E)-prop-1-enylbenzene, tetrabutylammoniumtetrafluoroborate, $\mathrm{NH}_{4} \mathrm{I}, \mathrm{NH}_{4} \mathrm{Br}$, KI, TBAI, $\mathrm{LiClO}_{4}, \mathrm{Na}_{2} \mathrm{SO}_{4}, \mathrm{Br}_{2}, \mathrm{NaN}_{3}, \mathrm{ICl}, t$-BuOK, KOH, THF, DMSO, DMF, DCM, MeCN, $\mathrm{Et}_{2} \mathrm{O}, \mathrm{NEt}_{3}$, petroleum ether (PE, 40/70), ethyl acetate (EA) were purchased from commercial sources and were used as is.

4-Chlorobenzenesulfonyl hydrazide (2j), 4-bromobenzenesulfonyl hydrazide (2k), 4fluorobenzenesulfonyl hydrazide (2l), 4-iodobenzenesulfonyl hydrazide (2m), 4methoxybenzenesulfonyl hydrazide (2n), 4-acetamidobenzenesulfonyl hydrazide (o, 4nitrobenzenesulfonyl hydrazide (2p), 3-nitrobenzenesulfonyl hydrazide (2q), 2,4,6trimethylbenzenesulfonyl hydrazide (2r), naphthalene-2-sulfonyl hydrazide (2s), 2,5dimethylthiophene-3-sulfonyl hydrazide (2v), isothiazole-5-sulfonyl hydrazide (2w) were synthesized according to the literature through the reaction between corresponding sulfonyl chlorides and hydrazine hydrate. ${ }^{1}$ (1-Azidovinyl)benzene (1a), 1-(1-azidovinyl)-4methylbenzene (1b), 1-(1-azidovinyl)-3-methylbenzene (1c), 1-(1-azidovinyl)-4-tertbutylbenzene (1d), 1-(1-azidovinyl)-4-chlorobenzene (1e), 1-(1-azidovinyl)-4-fluorobenzene (1f) were synthesized according to the literature through the bromination of corresponding styrenes followed by the reaction of dibromides with $\mathrm{NaN}_{3}{ }^{2}{ }^{2}$ 1-(Azidomethyl)-4-(1-azidovinyl)benzene (1h) was synthesized according the same procedure ${ }^{2}$ from 1-(chloromethyl)-4-vinylbenzene as a result of simultaneous azidation of formed dibromide and nucleophilic substitution of chlorine atom. 1-(1-Azidovinyl)-3-methoxybenzene (1g) and (Z)-(1-azidoprop-1-enyl)benzene (1i) were 
synthesized according to the literature through the reaction between styrenes and $\mathrm{ICl} / \mathrm{NaN}_{3}$ system followed by dehydroiodination with $t$-BuOK. ${ }^{3}$

Cyclic voltammetry (CV) was implemented on an IPC-Pro M computer-assisted potentiostat manufactured by Econix (scan rate error 1.0\%; potential setting $0.25 \mathrm{mV}$; scan rate $100 \mathrm{mV} \mathrm{s}-1$ ). The experiments were performed in a $25 \mathrm{~mL}$ five-neck glass conic electrochemical cell with a water jacket for thermostatting. CV curves were recorded using a three-electrode scheme. The working electrode was a disc glassy-carbon electrode $(\mathrm{d}=3 \mathrm{~mm})$. A platinum wire served as an auxiliary electrode. $\mathrm{An} \mathrm{Ag} / \mathrm{Ag}^{+}$electrode was used as the reference electrode and was linked to the solution by a porous glass diaphragm. The solutions were kept under thermally controlled conditions at $25 \pm 0.5{ }^{\circ} \mathrm{C}$ and deaerated by bubbling argon. Electrochemical experiments were performed under an argon atmosphere. The working electrode was polished before recording each CV curve. In a typical case, $10 \mathrm{~mL}$ of solution was utilized. The compound concentration was $0.05 \mathrm{M}$.

For the electrosynthesis of compounds 3a-3w graphite and stainless steel plates from Russian commercial suppliers were used as electrodes (graphite grade: EUT-2; stainless steel grade: AISI 304):

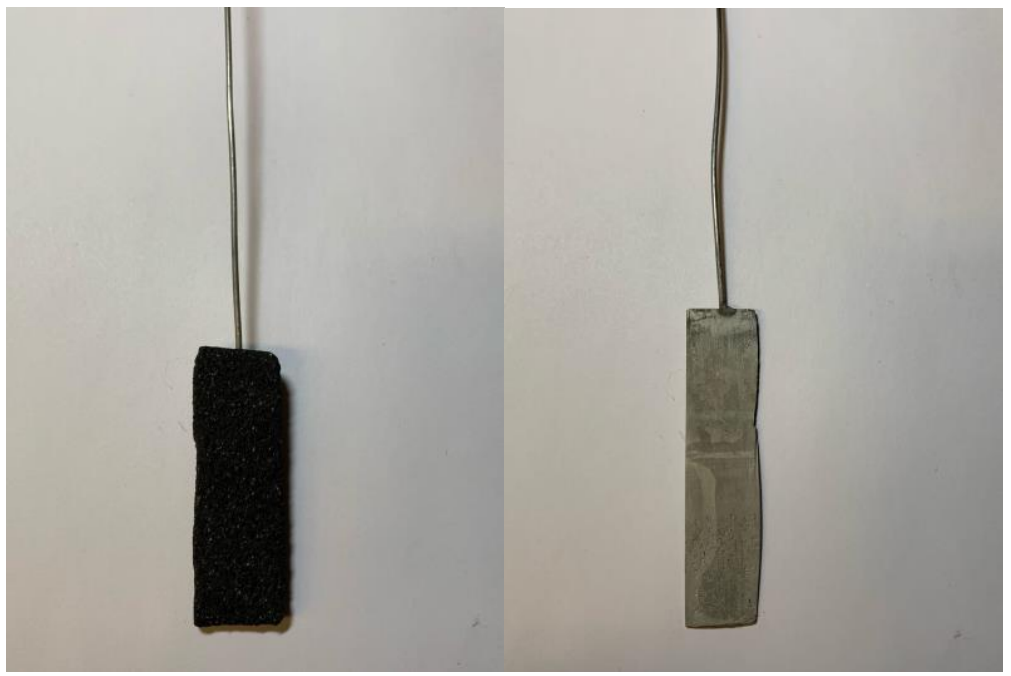

The reactions were performed in a common chemical tube:

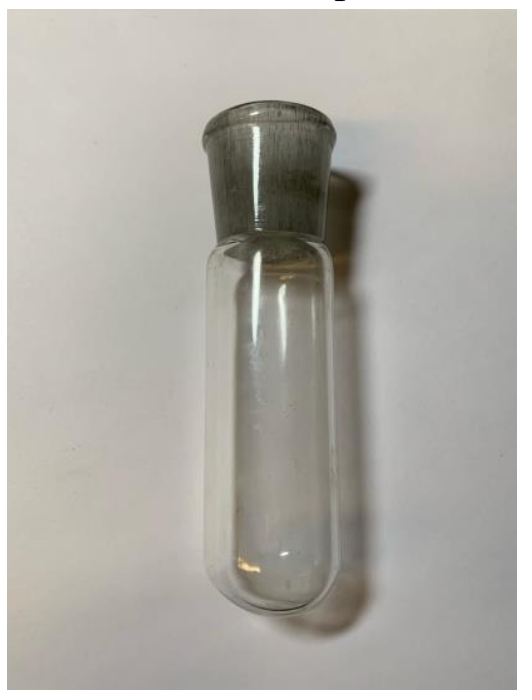


Undivided electrochemical cell equipped with graphite plate anode and stainless steel plate cathode with reaction mixture during electrolysis under constant current conditions:

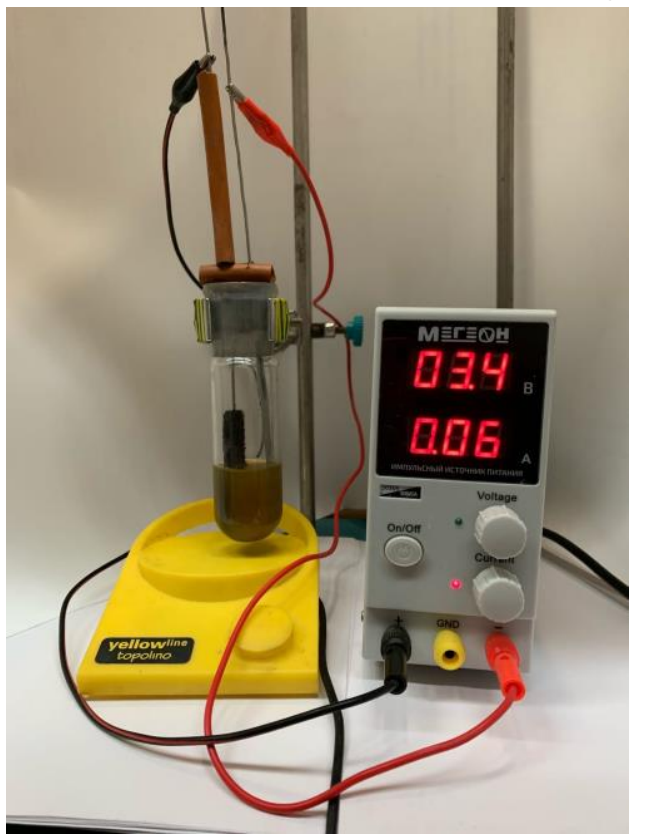

Divided electrochemical cell equipped with a membrane from cintered glass:

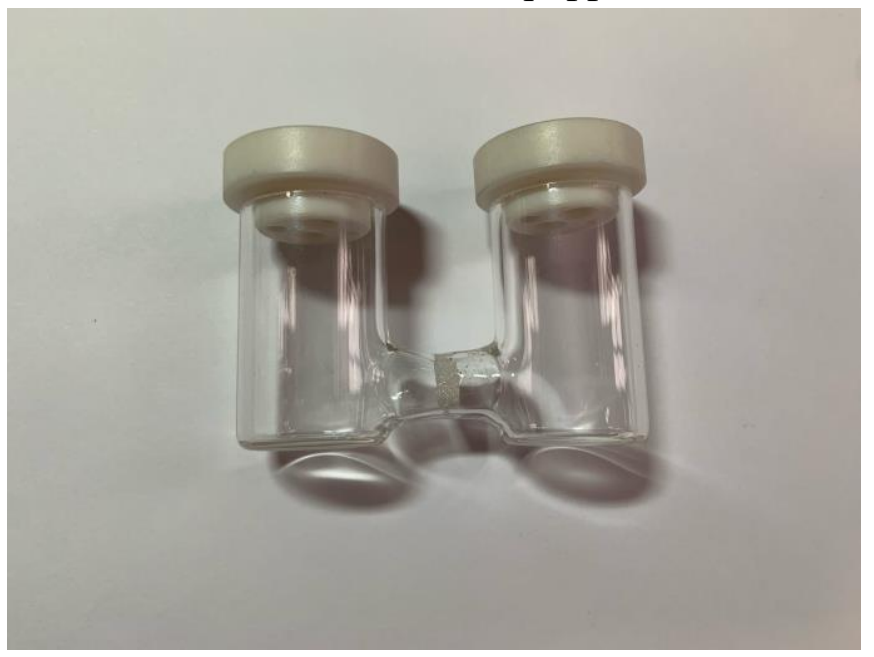

Before all electrochemical reactions the electrodes were put into $5 \mathrm{M}$ solution of $\mathrm{KOH}$ and this mixture was electrolyzed for 10 minutes at $\mathrm{j}=200 \mathrm{~mA} / \mathrm{cm}^{2}$. After that the polarity of electrodes was changed and the mixture was electrolyzed under these conditions again. After electrolysis the electrodes were washed with running water and then with acetone. All these procedures help to clean the electrodes from the impurities from the previous electrolysis, which can dramatically affect the reaction efficiency especially in the case of graphite electrode application.

\section{Electrochemical reaction of vinyl azides with sulfonyl hydrazides}

General procedure 1. Optimization of the reaction conditions for synthesis of 3a from vinyl azide 1a and sulfonyl hydrazide 2a (Table 1): An undivided cell was equipped with a graphite plate anode $\left(3 \mathrm{~cm}^{2}\right)$ and a stainless steel plate cathode $\left(3 \mathrm{~cm}^{2}\right)$ and connected to a DC regulated power supply. The solution of (1-azidovinyl)benzene $1 \mathbf{a}(1 \mathrm{mmol}, 145 \mathrm{mg}), p$ - 
toluenesulfonyl hydrazide 2a (1-2 mmol, 186-372 mg), and supporting electrolyte (0.5-2 mmol, 73-290 mg) in $20 \mathrm{~mL}$ of $\mathrm{H}_{2} \mathrm{O}$-THF (1:1), DMSO or DMSO-THF (1:1) was electrolyzed under constant current conditions ( $\mathrm{I}=20-120 \mathrm{~mA}, \mathrm{j}=7-40 \mathrm{~mA} / \mathrm{cm}^{2}$ at room temperature, $\tau=45 \mathrm{~min}$ $4.5 \mathrm{~h}$ ) under magnetic stirring. After that the reaction mixture was diluted with $0.3 \mathrm{M}$ solution of $\mathrm{Na}_{2} \mathrm{~S}_{2} \mathrm{O}_{3}(50 \mathrm{~mL})$ and washed with EA $(5 \times 10 \mathrm{~mL})$, which was used for the washing of electrodes after the reaction. Combined organic layer was washed with $1 \mathrm{M}$ solution of $\mathrm{Na}_{2} \mathrm{~S}_{2} \mathrm{O}_{3}(10 \mathrm{~mL})$, water $(10 \mathrm{~mL})$, and brine $(10 \mathrm{~mL})$, dried over $\mathrm{Na}_{2} \mathrm{SO}_{4}$ and concentrated under reduced pressure. The desired product 3a was isolated by chromatography with elution using PE-EA in a gradient

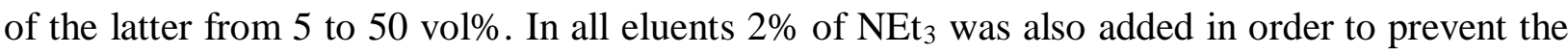
product from hydrolysis.

General procedure 2.Electrosynthesis of products 3a-3w (Schemes 2 and 3). An undivided cell was equipped with a graphite plate anode $\left(3 \mathrm{~cm}^{2}\right)$ and a stainless steel plate cathode $\left(3 \mathrm{~cm}^{2}\right)$ and connected to a DC regulated power supply. The solution of vinyl azide 1a-1i (1 mmol), sulfonyl hydrazide $\mathbf{2 k - 2 w}(1.5 \mathrm{mmol})$ and supporting electrolyte $\mathrm{NH}_{4} \mathrm{I}(1 \mathrm{mmol})$ in 20 $\mathrm{mL}$ of DMSO-THF (1:1) was electrolyzed using constant current conditions $(\mathrm{I}=60 \mathrm{~mA}, \mathrm{j}=20$ $\mathrm{mA} / \mathrm{cm}^{2}$ at room temperature, $\tau=1.5 \mathrm{~h}$ ) under magnetic stirring. After that the reaction mixture was diluted with $0.3 \mathrm{M}$ solution of $\mathrm{Na}_{2} \mathrm{~S}_{2} \mathrm{O}_{3}(50 \mathrm{~mL})$ and washed with $\mathrm{EA}(5 \times 10 \mathrm{~mL})$, which was used for the washing of electrodes after the reaction. Combined organic layer was washed with 1 $\mathrm{M}$ solution of $\mathrm{Na}_{2} \mathrm{~S}_{2} \mathrm{O}_{3}(10 \mathrm{~mL})$, water $(10 \mathrm{~mL})$, and brine $(10 \mathrm{~mL})$, dried over $\mathrm{Na}_{2} \mathrm{SO}_{4}$ and concentrated under reduced pressure. The desired products 3a-3w were isolated by chromatography with elution using PE-EA in a gradient of the latter from 5 to 50 vol\%. In all eluents $2 \%$ of $\mathrm{NEt}_{3}$ was also added in order to prevent the products from hydrolysis.

Procedure for scaling up of enamine 3a electrosynthesis (Scheme 4). An undivided cell was equipped with a graphite plate anode $\left(4.5 \mathrm{~cm}^{2}\right)$ and a stainless steel plate cathode (4.5 $\mathrm{cm}^{2}$ ) and connected to a DC regulated power supply. The solution of vinyl azide 1a (5 mmol, $726 \mathrm{mg})$, -toluenesulfonyl hydrazide $2 \mathbf{a}(7.5 \mathrm{mmol}, 1397 \mathrm{mg})$ and supporting electrolyte $\mathrm{NH}_{4} \mathrm{I}(5 \mathrm{mmol}, 725 \mathrm{mg}$ ) in $30 \mathrm{~mL}$ of DMSO-THF (1:1) was electrolyzed using constant current conditions ( $\mathrm{I}=90 \mathrm{~mA}, \mathrm{j}=20 \mathrm{~mA} / \mathrm{cm}^{2}$ at room temperature, $\tau=5 \mathrm{~h}$ ) under magnetic stirring. After that the reaction mixture was diluted with $0.3 \mathrm{M}$ solution of $\mathrm{Na}_{2} \mathrm{~S}_{2} \mathrm{O}_{3}(50 \mathrm{~mL})$ and washed with EA $(5 \times 10 \mathrm{~mL})$, which was used for the washing of electrodes after the reaction. Combined organic layer was washed with $1 \mathrm{M}$ solution of $\mathrm{Na}_{2} \mathrm{~S}_{2} \mathrm{O}_{3}(10 \mathrm{~mL})$, water $(10 \mathrm{~mL})$ and brine (10 $\mathrm{mL}$ ), dried over $\mathrm{Na}_{2} \mathrm{SO}_{4}$ and concentrated under reduced pressure. The desired product 3a was isolated with $63 \%$ yield $(861 \mathrm{mg}$ ) by chromatography with elution using PE-EA in a gradient of the latter from 5 to $50 \mathrm{vol} \%$. In all eluents $2 \%$ of $\mathrm{NEt}_{3}$ was also added in order to prevent the products from hydrolysis.

(Z)-1-phenyl-2-tosylethenamine (3a) ${ }^{4}$<smiles>C/C=C(\N)c1ccccc1</smiles>

White solid. $202 \mathrm{mg}$ (yield 74\%). $\mathrm{R}_{\mathrm{f}}=0.44$ (PE:EA 2:1), $\mathrm{mp}=116.0-118.0^{\circ} \mathrm{C} .{ }^{1} \mathrm{H} \mathrm{NMR}$ $\left(\mathrm{CDCl}_{3}\right), \delta: 2.40(\mathrm{~s}, 3 \mathrm{H}), 5.08(\mathrm{~s}, 1 \mathrm{H}), 5.99(\mathrm{br} \mathrm{s}, 2 \mathrm{H}), 7.28(\mathrm{~d}, J=8.1 \mathrm{~Hz}, 2 \mathrm{H}), 7.35-7.47$ (m, $5 \mathrm{H}), 7.82(\mathrm{~d}, J=8.1 \mathrm{~Hz}, 2 \mathrm{H}) .{ }^{13} \mathrm{C} \mathrm{NMR}\left(\mathrm{CDCl}_{3}\right), \delta: 21.5,92.3,126.0,126.3,128.9,129.5,130.7$, 
136.9, 141.6, 143.0, 156.0. HRMS (ESI) $\mathrm{m} / \mathrm{z}\left(\mathrm{M}+\mathrm{H}^{+}\right)$calculated for $\left[\mathrm{C}_{15} \mathrm{H}_{16} \mathrm{NO}_{2} \mathrm{~S}\right]^{+}: 274.0896$. Found: 274.0904.

(Z)-1-p-tolyl-2-tosylethenamine $(3 b)^{4}$<smiles>Cc1ccc(/C(N)=C/[125I])cc1</smiles>

Yellow solid. $207 \mathrm{mg}$ (yield 72\%). $\mathrm{R}_{\mathrm{f}}=0.48$ (PE:EA 2:1), $\mathrm{mp}=106.0-108.0^{\circ} \mathrm{C} .{ }^{1} \mathrm{H}$ NMR $\left(\mathrm{CDCl}_{3}\right), \delta: 2.35(\mathrm{~s}, 3 \mathrm{H}), 2.40(\mathrm{~s}, 3 \mathrm{H}), 5.06(\mathrm{~s}, 1 \mathrm{H}), 5.91(\mathrm{br} \mathrm{s}, 2 \mathrm{H}), 7.16(\mathrm{~d}, J=8.1 \mathrm{~Hz}, 2 \mathrm{H}), 7.27$ $(\mathrm{d}, J=8.1 \mathrm{~Hz}, 2 \mathrm{H}), 7.34(\mathrm{~d}, J=8.1 \mathrm{~Hz}, 2 \mathrm{H}), 7.81(\mathrm{~d}, J=8.1 \mathrm{~Hz}, 2 \mathrm{H}) .{ }^{13} \mathrm{C} \mathrm{NMR},\left(\mathrm{CDCl}_{3}\right), \delta$ : 21.2, 21.5, 91.7, 126.0, 126.1, 129.5, 129.5, 134.0, 141.1, 141.7, 142.9, 156.0.

\section{(Z)-1-m-tolyl-2-tosylethenamine (3c) ${ }^{4}$}<smiles>[3H]C=C(N)c1cccc(C)c1</smiles>

Brown solid. $152 \mathrm{mg}$ (yield 53\%). $\mathrm{R}_{\mathrm{f}}=0.33$ (PE:EA 2:1), $\mathrm{mp}=39.0-41.0^{\circ} \mathrm{C} .{ }^{1} \mathrm{HNMR}\left(\mathrm{CDCl}_{3}\right)$, $\delta: 2.37(\mathrm{~s}, 3 \mathrm{H}), 2.44(\mathrm{~s}, 3 \mathrm{H}), 5.10(\mathrm{~s}, 1 \mathrm{H}), 5.95$ (br s, 2H), 7.28-7.32 (m, 6H), 7.85 (d, J=8.1 Hz, 2H). ${ }^{13} \mathrm{CNMR},\left(\mathrm{CDCl}_{3}\right), \delta: 21.3,21.5,92.1,123.3,126.0,126.9,128.8,129.5,131.4,137.0$, $138.8,141.7,142.9,156.2$.

\section{(Z)-1-(4-tert-butylphenyl)-2-tosylethenamine (3d)}<smiles></smiles>

White solid. $105 \mathrm{mg}$ (yield 32\%). $\mathrm{R}_{\mathrm{f}}=0.64$ (PE:EA 1.5:1), $\mathrm{mp}=136.5-138.0^{\circ} \mathrm{C} .{ }^{1} \mathrm{H}$ NMR $\left(\mathrm{CDCl}_{3}\right), \delta: 1.29(\mathrm{~s}, 9 \mathrm{H}), 2.40(\mathrm{~s}, 3 \mathrm{H}), 5.09(\mathrm{~s}, 1 \mathrm{H}), 5.96(\mathrm{br} \mathrm{s}, 2 \mathrm{H}), 7.27(\mathrm{~d}, J=8.1 \mathrm{~Hz}, 2 \mathrm{H}), 7.39$ $(\mathrm{s}, 4 \mathrm{H}), 7.81(\mathrm{~d}, J=8.1 \mathrm{~Hz}, 2 \mathrm{H}) .{ }^{13} \mathrm{C} \mathrm{NMR},\left(\mathrm{CDCl}_{3}\right), \delta: 21.5,31.1,34.8,91.6,125.8,125.9$, 126.0, 129.5, 133.9, 141.7, 142.9, 154.2, 156.0. HRMS (ESI) $\mathrm{m} / \mathrm{z}\left(\mathrm{M}+\mathrm{H}^{+}\right)$calculated for $\left[\mathrm{C}_{19} \mathrm{H}_{24} \mathrm{NO}_{2} \mathrm{~S}\right]^{+}: 330.1522$. Found: 330.1524 .

\section{(Z)-1-(4-chlorophenyl)-2-tosylethenamine $(3 e)^{4}$}<smiles>NC(=C[Hg])c1ccc(Cl)cc1</smiles>

Light orange solid. $77 \mathrm{mg}$ (yield 25\%). $\mathrm{R}_{\mathrm{f}}=0.53$ (PE:EA 2:1), $\mathrm{mp}=133.5-135.0^{\circ} \mathrm{C} .{ }^{1} \mathrm{H} \mathrm{NMR}$ $\left(\mathrm{CDCl}_{3}\right), \delta: 2.41(\mathrm{~s}, 3 \mathrm{H}), 5.05(\mathrm{~s}, 1 \mathrm{H}), 5.90(\mathrm{br} \mathrm{s}, 2 \mathrm{H}), 7.28-7.41(\mathrm{~m}, 6 \mathrm{H}), 7.81(\mathrm{~d}, J=8.8 \mathrm{~Hz}$, $2 \mathrm{H}) .{ }^{13} \mathrm{C} \mathrm{NMR},\left(\mathrm{CDCl}_{3}\right), \delta: 21.5,93.1,126.1,127.7,129.2,129.6,135.5,136.8,141.4,143.2$, 154.7.

(Z)-1-(4-fluorophenyl)-2-tosylethenamine (3f) ${ }^{4}$ 
<smiles>N/C(=C\[Hg])c1ccc(F)cc1</smiles>

Yellow solid. $210 \mathrm{mg}$ (yield 72\%). $\mathrm{R}_{\mathrm{f}}=0.38$ (PE:EA 2:1), $\mathrm{mp}=88.0-90.0^{\circ} \mathrm{C} .{ }^{1} \mathrm{H} \mathrm{NMR}\left(\mathrm{CDCl}_{3}\right)$, $\delta: 2.40(\mathrm{~s}, 3 \mathrm{H}), 5.03(\mathrm{~s}, 1 \mathrm{H}), 5.92(\mathrm{br} \mathrm{s}, 2 \mathrm{H}), 7.05(\mathrm{t}, \mathrm{J}=8.8 \mathrm{~Hz}, 2 \mathrm{H}), 7.28(\mathrm{~d}, J=8.1 \mathrm{~Hz}, 2 \mathrm{H})$, 7.42-7.47 (dd, J= 5.1, 8.8 Hz, 2H), $7.81(\mathrm{~d}, J=8.1 \mathrm{~Hz}, 2 \mathrm{H}) .{ }^{13} \mathrm{C} \mathrm{NMR},\left(\mathrm{CDCl}_{3}\right), \delta: 21.5,92.6$, $116.0(\mathrm{~d}, J=22.1 \mathrm{~Hz}), 126.0,128.4(\mathrm{~d}, J=8.8 \mathrm{~Hz}), 129.6,133.0(\mathrm{~d}, J=3.3 \mathrm{~Hz}), 141.4,143.1$, $154.9,164.0(\mathrm{~d}, J=251.0 \mathrm{~Hz})$.

\section{(Z)-1-(3-methoxyphenyl)-2-tosylethenamine (3g)<smiles></smiles>

Yellow solid. $136 \mathrm{mg}$ (yield 45\%). $\mathrm{R}_{\mathrm{f}}=0.32$ (PE:EA 2:1), $\mathrm{mp}=89.5-90.0^{\circ} \mathrm{C} .{ }^{1} \mathrm{H} \mathrm{NMR}\left(\mathrm{CDCl}_{3}\right)$, $\delta: 2.40(\mathrm{~s}, 3 \mathrm{H}), 3.79$ (s, 3H), 5.08 (s, 1H), 5.92 (br s, 2H), 6.94-6.96 (m, 2H), 7.03 (d, J=8.1 Hz, $1 \mathrm{H}), 7.28(\mathrm{~d}, J=8.1 \mathrm{~Hz}, 3 \mathrm{H}), 7.81(\mathrm{~d}, J=8.1 \mathrm{~Hz}, 2 \mathrm{H}) .{ }^{13} \mathrm{C} \mathrm{NMR},\left(\mathrm{CDCl}_{3}\right), \delta: 21.4,55.4,92.2$, $111.9,116.2,118.5,126.0,129.5,130.0,138.4,141.6,143.0,155.9,159.8$. HRMS (ESI) m/z $\left(\mathrm{M}+\mathrm{H}^{+}\right)$calculated for $\left[\mathrm{C}_{16} \mathrm{H}_{18} \mathrm{NO}_{3} \mathrm{~S}\right]^{+}: 304.1002$. Found: 304.1003 .

(Z)-1-(4-(azidomethyl)phenyl)-2-tosylethenamine (3h)<smiles>[3H]/C=C(\N)c1ccc(CC#N)cc1</smiles>

Yellow solid. $141 \mathrm{mg}$ (yield 43\%). $\mathrm{R}_{\mathrm{f}}=0.34$ (PE:EA 2:1), $\mathrm{mp}=58.5-60.0^{\circ} \mathrm{C} .{ }^{1} \mathrm{H} \mathrm{NMR}\left(\mathrm{CDCl}_{3}\right)$, $\delta: 2.41(\mathrm{~s}, 3 \mathrm{H}), 4.35(\mathrm{~s}, 2 \mathrm{H}), 5.09(\mathrm{~s}, 1 \mathrm{H}), 5.92(\mathrm{br} \mathrm{s}, 2 \mathrm{H}), 7.29(\mathrm{~d}, J=8.3 \mathrm{~Hz}, 2 \mathrm{H}), 7.32(\mathrm{~d}, J=$ $7.7 \mathrm{~Hz}, 2 \mathrm{H}), 7.47$ (d, $J=7.7 \mathrm{~Hz}, 2 \mathrm{H}), 7.82(\mathrm{~d}, J=8.3 \mathrm{~Hz}, 2 \mathrm{H}) .{ }^{13} \mathrm{C} \mathrm{NMR},\left(\mathrm{CDCl}_{3}\right), \delta: 21.5,54.1$, 92.7, 126.0, 126.8, 128.6, 129.6, 136.9, 138.2, 141.4, 143.1, 155.3. HRMS (ESI) m/z (M+H $\left.{ }^{+}\right)$ calculated for $\left[\mathrm{C}_{16} \mathrm{H}_{17} \mathrm{~N}_{4} \mathrm{O}_{2} \mathrm{~S}\right]^{+}:$329.1067. Found: 329.1066 .

\section{(Z)-1-phenyl-2-tosylprop-1-en-1-amine (3i)}<smiles>CC([18F])=C(N)c1ccccc1</smiles>

Yellow solid. $198 \mathrm{mg}$ (yield 69\%). $\mathrm{R}_{\mathrm{f}}=0.54$ (PE:EA 1.5:1), $\mathrm{mp}=147.5-149.5^{\circ} \mathrm{C} .{ }^{1} \mathrm{H}$ NMR $\left(\mathrm{CDCl}_{3}\right), \delta: 1.59$ (s, 3H), $2.43(\mathrm{~s}, 3 \mathrm{H}), 5.74$ (br s, 2H), 7.30-7.38 (m, 7H), 7.83 (d, J = 8.1 Hz, $2 \mathrm{H}) .{ }^{13} \mathrm{C} \mathrm{NMR},\left(\mathrm{CDCl}_{3}\right), \delta: 14.5,21.5,96.8,126.6,127.6,128.6,129.2,129.5,138.1,139.4$, 143.2, 153.3. HRMS (ESI) $\mathrm{m} / \mathrm{z}\left(\mathrm{M}+\mathrm{H}^{+}\right)$calculated for $\left[\mathrm{C}_{16} \mathrm{H}_{18} \mathrm{NO}_{2} \mathrm{~S}\right]^{+}$: 288.1053. Found: 288.1041 .

(Z)-2-(4-chlorophenylsulfonyl)-1-phenylethenamine (3j) 
<smiles>N/C(=C\S(=O)(=O)c1ccc(Cl)cc1)c1ccccc1</smiles>

Yellow solid. $170 \mathrm{mg}$ (yield 58\%). $\mathrm{R}_{\mathrm{f}}=0.43$ (PE:EA 1.5:1), $\mathrm{mp}=127.0-129.0^{\circ} \mathrm{C} .{ }^{1} \mathrm{H}$ NMR $\left(\mathrm{CDCl}_{3}\right), \delta: 5.04(\mathrm{~s}, 1 \mathrm{H}), 6.05$ (br s, 2H), 7.34-7.46 (m, 7H), $7.85(\mathrm{~d}, J=8.8 \mathrm{~Hz}, 2 \mathrm{H}) .{ }^{13} \mathrm{C} \mathrm{NMR}$, $\left(\mathrm{CDCl}_{3}\right), \delta: 91.1,126.2,127.4,129.0,129.2,130.9,136.6,138.6,143.0,156.9$. HRMS (ESI) $\mathrm{m} / \mathrm{z}$ $\left(\mathrm{M}+\mathrm{H}^{+}\right)$calculated for $\left[\mathrm{C}_{14} \mathrm{H}_{13} \mathrm{ClNO}_{2} \mathrm{~S}\right]^{+}: 294.0350$. Found: 294.0348 .

\section{(Z)-2-(4-bromophenylsulfonyl)-1-phenylethenamine (3k)}<smiles>N/C(=C\c1ccccc1)S(=O)(=O)c1ccc(Br)cc1</smiles>

White solid. $213 \mathrm{mg}$ (yield 63\%). $\mathrm{R}_{\mathrm{f}}=0.40$ (PE:EA 2:1), $\mathrm{mp}=149.5-150.5^{\circ} \mathrm{C} .{ }^{1} \mathrm{H} \mathrm{NMR}$ $\left(\mathrm{CDCl}_{3}\right), \delta: 5.04(\mathrm{~s}, 1 \mathrm{H}), 6.02(\mathrm{br} \mathrm{s}, 2 \mathrm{H}), 7.35-7.46(\mathrm{~m}, 5 \mathrm{H}), 7.61(\mathrm{~d}, J=8.5 \mathrm{~Hz}, 2 \mathrm{H}), 7.79(\mathrm{~d}, J=$ $8.5 \mathrm{~Hz}, 2 \mathrm{H}) .{ }^{13} \mathrm{C} \mathrm{NMR},\left(\mathrm{CDCl}_{3}\right), \delta: 91.1,126.2,127.1,127.5,129.0,131.0,132.2,136.6,143.5$, 156.9. HRMS (ESI) m/z $\left(\mathrm{M}+\mathrm{H}^{+}\right)$calculated for $\left[\mathrm{C}_{14} \mathrm{H}_{13} \mathrm{BrNO}_{2} \mathrm{~S}\right]^{+}: 337.9845$. Found: 337.9848.

\section{(Z)-2-(4-fluorophenylsulfonyl)-1-phenylethenamine (3I)}<smiles>N/C(=C\S(=O)(=O)c1ccc(F)cc1)c1ccccc1</smiles>

Orange solid. $148 \mathrm{mg}$ (yield 65\%). $\mathrm{R}_{\mathrm{f}}=0.39$ (PE:EA 2:1), $\mathrm{mp}=62.0-63.0^{\circ} \mathrm{C} .{ }^{1} \mathrm{H} \mathrm{NMR}\left(\mathrm{CDCl}_{3}\right)$, $\delta: 5.06(\mathrm{~s}, 1 \mathrm{H}), 5.98$ (br s, 2H), $7.16(\mathrm{t}, J=8.6 \mathrm{~Hz}, 2 \mathrm{H}), 7.35-7.47$ (m, 5H), 7.94 (dd, $J=5.1,8.8$ $\mathrm{Hz}, 2 \mathrm{H}) .{ }^{13} \mathrm{C} \mathrm{NMR},\left(\mathrm{CDCl}_{3}\right), \delta: 91.6,116.1(\mathrm{~d}, J=23.2 \mathrm{~Hz}), 126.2,128.6(\mathrm{~d}, J=8.6 \mathrm{~Hz}), 129.0$, 130.9, 136.8, $140.6(\mathrm{~d}, J=3.2 \mathrm{~Hz}), 156.6,165.1(\mathrm{~d}, J=232.2 \mathrm{~Hz}) . \mathrm{HRMS}(\mathrm{ESI}) \mathrm{m} / \mathrm{z}\left(\mathrm{M}+\mathrm{H}^{+}\right)$ calculated for $\left[\mathrm{C}_{14} \mathrm{H}_{13} \mathrm{FNO}_{2} \mathrm{~S}\right]^{+}: 278.0646$. Found: 278.0650 .

\section{(Z)-2-(4-iodophenylsulfonyl)-1-phenylethenamine (3m)}<smiles>N/C(=C\S(=O)(=O)c1ccc(I)cc1)c1ccccc1</smiles>

Yellow solid. $166 \mathrm{mg}$ (yield 43\%). $\mathrm{R}_{\mathrm{f}}=0.46$ (PE:EA 2:1), $\mathrm{mp}=163.0-164.5^{\circ} \mathrm{C} .{ }^{1} \mathrm{H} \mathrm{NMR}$ (DMSO-d ${ }_{6}$ ), $\delta: 5.12$ (s, 1H), 7.15 (br s, 2H), 7.38-7.54 (m, 5H), $7.69(\mathrm{~d}, J=8.4 \mathrm{~Hz}, 2 \mathrm{H}), 7.94$ (d, $J=8.4 \mathrm{~Hz}, 2 \mathrm{H}) .{ }^{13} \mathrm{C} \mathrm{NMR}$, (DMSO-d ${ }_{6}$ ), $\delta: 88.2,100.0,126.8,127.3,128.6,130.7,135.8,138.0$, 144.5, 157.3. HRMS (ESI) $\mathrm{m} / \mathrm{z}\left(\mathrm{M}+\mathrm{H}^{+}\right)$calculated for $\left[\mathrm{C}_{14} \mathrm{H}_{13} \mathrm{INO}_{2} \mathrm{~S}\right]^{+}$: 385.9706. Found: 385.9704 .

(Z)-2-(4-methoxyphenylsulfonyl)-1-phenylethenamine (3n)<smiles>COc1ccc(S(=O)(=O)/C=C(\N)c2ccccc2)cc1</smiles> 
White solid. $179 \mathrm{mg}$ (yield 62\%). $\mathrm{R}_{\mathrm{f}}=0.40$ (PE:EA 2:1), $\mathrm{mp}=121.0-122.5^{\circ} \mathrm{C} .{ }^{1} \mathrm{H}$ NMR $\left(\mathrm{CDCl}_{3}\right), \delta: 3.84(\mathrm{~s}, 3 \mathrm{H}), 5.07(\mathrm{~s}, 1 \mathrm{H}), 5.93(\mathrm{br} \mathrm{s}, 2 \mathrm{H}), 6.95(\mathrm{~d}, J=8.9 \mathrm{~Hz}, 2 \mathrm{H})$, 7.34-7.46 (m, $5 \mathrm{H}), 7.86(\mathrm{~d}, J=8.9 \mathrm{~Hz}, 2 \mathrm{H}) .{ }^{13} \mathrm{C} \mathrm{NMR},\left(\mathrm{CDCl}_{3}\right), \delta: 55.5,92.8,114.1,126.3,128.1,128.9$, 130.7, 136.3, 137.0, 155.6, 162.7. HRMS (ESI) $\mathrm{m} / \mathrm{z}\left(\mathrm{M}+\mathrm{H}^{+}\right)$calculated for $\left[\mathrm{C}_{15} \mathrm{H}_{16} \mathrm{NO}_{3} \mathrm{~S}\right]^{+}$: 290.0845. Found: 290.0848.

(Z)-N-(4-(2-amino-2-phenylvinylsulfonyl)phenyl)acetamide (3o) ${ }^{6}$<smiles>NC(=O)Nc1ccc(S(=O)(=O)/C=C(\N)c2ccccc2)cc1</smiles>

White solid. $275 \mathrm{mg}$ (yield 87\%). $\mathrm{R}_{\mathrm{f}}=0.38$ (PE:EA 2:1), $\mathrm{mp}=195.5-197.0^{\circ} \mathrm{C} .{ }^{1} \mathrm{H} \mathrm{NMR}$ (DMSO-d $), \delta: 2.07$ (s, 3H), 5.09 (s, 1H), 7.02 (br s, 2H), 7.38-7.53 (m, 5H), 7.73 (d, J=8.8 Hz, 2H), 7.83 (d, $J=8.8 \mathrm{~Hz}, 2 \mathrm{H}), 10.27$ (s, 1H). ${ }^{13} \mathrm{C}$ NMR, (DMSO-d 6 ), $\delta: 24.1,89.6,118.6,126.6$, 126.7, 128.6, 130.6, 136.0, 138.7, 142.6, 156.2, 168.9. HRMS (ESI) m/z (M+Na+) calculated for $\left[\mathrm{C}_{16} \mathrm{H}_{16} \mathrm{~N}_{2} \mathrm{NaO}_{3} \mathrm{~S}\right]^{+}:$339.0774. Found: 339.0783.

\section{(Z)-2-(4-nitrophenylsulfonyl)-1-phenylethenamine (3p)<smiles>N/C(=C\S(=O)(=O)c1ccc([N+](=O)[O-])cc1)c1ccccc1</smiles>

Light-yellow solid. $58 \mathrm{mg}$ (yield 19\%). $\mathrm{R}_{\mathrm{f}}=0.46$ (PE:EA 1.5:1), $\mathrm{mp}=98.5-100.5^{\circ} \mathrm{C} .{ }^{1} \mathrm{H}$ NMR (DMSO-d 6 ), $\delta: 5.18$ (s, 1H), 7.33 (br s, 2H), 7.40-7.56 (m, 5H), 8.18 (d, J=8.8 Hz, 2H), 8.38 (d, $J=8.8 \mathrm{~Hz}, 2 \mathrm{H}) .{ }^{13} \mathrm{C} \mathrm{NMR}$, (DMSO-d 6 ), $\delta: 86.8,124.5,126.9,127.0,128.6,130.9,135.6,149.4$, 150.2, 158.5. HRMS (ESI) $\mathrm{m} / \mathrm{z}\left(\mathrm{M}+\mathrm{H}^{+}\right)$calculated for $\left[\mathrm{C}_{14} \mathrm{H}_{13} \mathrm{~N}_{2} \mathrm{O}_{4} \mathrm{~S}\right]^{+}$: 305.0591. Found: 305.0584 .

\section{(Z)-2-(3-nitrophenylsulfonyl)-1-phenylethenamine (3q)}<smiles>N/C(=C\c1ccccc1)S(=O)(=O)c1cccc([N+](=O)[O-])c1</smiles>

Brown solid. $31 \mathrm{mg}$ (yield 10\%). $\mathrm{R}_{\mathrm{f}}=0.46$ (PE:EA 1.5:1), $\mathrm{mp}=96.0-97.0^{\circ} \mathrm{C} .{ }^{1} \mathrm{H}$ NMR $\left(\mathrm{CDCl}_{3}\right)$, $\delta: 5.08(\mathrm{~s}, 1 \mathrm{H}), 6.10($ br s, 2H), 7.40-7.48 (m, 5H), $7.71(\mathrm{t}, J=7.7 \mathrm{~Hz}, 1 \mathrm{H}), 8.26(\mathrm{~d}, J=7.7 \mathrm{~Hz}$, $1 \mathrm{H}), 8.39(\mathrm{~d}, J=7.7 \mathrm{~Hz}, 1 \mathrm{H}), 8.77(\mathrm{~s}, 1 \mathrm{H}) .{ }^{13} \mathrm{C} \mathrm{NMR},\left(\mathrm{CDCl}_{3}\right), \delta: 89.7,121.2,126.3,126.7$, 129.1, 130.3, 131.2, 131.5, 136.3, 146.7, 148.3, 158.2. HRMS (ESI) $\mathrm{m} / \mathrm{z}\left(\mathrm{M}+\mathrm{H}^{+}\right)$calculated for $\left[\mathrm{C}_{14} \mathrm{H}_{13} \mathrm{~N}_{2} \mathrm{O}_{4} \mathrm{~S}\right]^{+}:$305.0591. Found: 305.0597 .

(Z)-2-(mesitylsulfonyl)-1-phenylethenamine (3r)<smiles>Cc1cc(C)c(S(=O)(=O)/C=C(\N)c2ccccc2)c(C)c1</smiles>

Light-brown solid. $138 \mathrm{mg}$ (yield 46\%). $\mathrm{R}_{\mathrm{f}}=0.64$ (PE:EA 2:1), $\mathrm{mp}=90.0-92.0^{\circ} \mathrm{C} .{ }^{1} \mathrm{H} \mathrm{NMR}$ $\left(\mathrm{CDCl}_{3}\right), \delta: 2.28(\mathrm{~s}, 3 \mathrm{H}), 2.68(\mathrm{~s}, 6 \mathrm{H}), 5.07$ (s, 1H), 5.90 (br s, 2H), 6.93 (s, 2H), 7.34-7.48 (m, $5 \mathrm{H}) .{ }^{13} \mathrm{C} \mathrm{NMR},\left(\mathrm{CDCl}_{3}\right), \delta: 20.8,22.6,93.8,126.3,128.8,130.5,131.9,137.4,137.6,139.1$, 
141.8, 154.8. HRMS (ESI) $\mathrm{m} / \mathrm{z}\left(\mathrm{M}+\mathrm{H}^{+}\right)$calculated for $\left[\mathrm{C}_{17} \mathrm{H}_{19} \mathrm{NNaO}_{2} \mathrm{~S}\right]^{+}$: 324.1029. Found: 324.1032 .

\section{(Z)-2-(naphthalen-2-ylsulfonyl)-1-phenylethenamine (3s)}<smiles>N/C(=C\c1ccccc1)S(=O)(=O)c1ccc2ccccc2c1</smiles>

Light-yellow solid. $133 \mathrm{mg}$ (yield 43\%). $\mathrm{R}_{\mathrm{f}}=0.32$ (PE:EA 2:1), $\mathrm{mp}=122.0-124.0^{\circ} \mathrm{C} .{ }^{1} \mathrm{H}$ NMR $\left(\mathrm{CDCl}_{3}\right), \delta: 5.16(\mathrm{~s}, 1 \mathrm{H}), 6.05(\mathrm{br} \mathrm{s}, 2 \mathrm{H}), 7.33-7.47(\mathrm{~m}, 5 \mathrm{H}), 7.55-7.63(\mathrm{~m}, 2 \mathrm{H}), 7.87-7.97(\mathrm{~m}$, $4 \mathrm{H}), 8.49$ (s, $1 \mathrm{H}) .{ }^{13} \mathrm{C} \mathrm{NMR},\left(\mathrm{CDCl}_{3}\right), \delta: 91.8,121.9,126.3,126.7,127.3,127.8,128.4,128.9$, 129.3, 129.3, 130.8, 132.2, 134.8, 136.9, 141.2, 156.5. HRMS (ESI) m/z (M+H') calculated for $\left[\mathrm{C}_{18} \mathrm{H}_{16} \mathrm{NO}_{2} \mathrm{~S}\right]^{+}:$310.0896. Found: 310.0899 .

\section{(Z)-1-phenyl-2-(phenylsulfonyl)ethenamine $(3 t)^{5}$}<smiles>N/C(=C\c1ccccc1)S(=O)(=O)c1ccccc1</smiles>

White solid. $104 \mathrm{mg}$ (yield 40\%). $\mathrm{R}_{\mathrm{f}}=0.42$ (PE:EA 2:1), $\mathrm{mp}=117.0-119.0^{\circ} \mathrm{C} .{ }^{1} \mathrm{H}$ NMR $\left(\mathrm{CDCl}_{3}\right), \delta: 5.07(\mathrm{~s}, 1 \mathrm{H}), 6.02(\mathrm{br} \mathrm{s}, 2 \mathrm{H}), 7.33-7.56(\mathrm{~m}, 8 \mathrm{H}), 7.93(\mathrm{~d}, J=8.1 \mathrm{~Hz}, 2 \mathrm{H}) .{ }^{13} \mathrm{C} \mathrm{NMR}$, $\left(\mathrm{CDCl}_{3}\right), \delta: 91.5,125.8,126.2,128.9,128.9,130.7,132.2,136.8,144.4,156.5$.

\section{(Z)-2-(methylsulfonyl)-1-phenylethenamine (3u)}<smiles>CS(=O)(=O)C=C(N)c1ccccc1</smiles>

Brown oil. $63 \mathrm{mg}$ (yield 32\%). $\mathrm{R}_{\mathrm{f}}=0.30$ (PE:EA 1.5:1). ${ }^{1} \mathrm{H} \mathrm{NMR}\left(\mathrm{CDCl}_{3}\right), \delta: 3.00(\mathrm{~s}, 3 \mathrm{H}), 5.02$ $(\mathrm{s}, 1 \mathrm{H}), 5.86$ (br s, 2H), 7.37-7.50 (m, 5H). ${ }^{13} \mathrm{C} \mathrm{NMR,}\left(\mathrm{CDCl}_{3}\right), \delta: 44.6,91.0,126.2,129.0$, 130.8, 136.7, 156.9. HRMS (ESI) $\mathrm{m} / \mathrm{z}\left(\mathrm{M}+\mathrm{H}^{+}\right)$calculated for $\left[\mathrm{C}_{19} \mathrm{H}_{12} \mathrm{NO}_{2} \mathrm{~S}\right]^{+}$: 198.0583. Found: 198.0589.

(Z)-2-(2,5-dimethylthiophen-3-ylsulfonyl)-1-phenylethenamine (3v)<smiles>Cc1cc(S(=O)(=O)/C=C(\N)c2ccccc2)c(C)s1</smiles>

Yellow solid. $105 \mathrm{mg}$ (yield 36\%). $\mathrm{R}_{\mathrm{f}}=0.58$ (PE:EA 2:1), $\mathrm{mp}=119.5-120.5^{\circ} \mathrm{C} .{ }^{1} \mathrm{H} \mathrm{NMR}$ $\left(\mathrm{CDCl}_{3}\right), \delta: 2.37(\mathrm{~s}, 3 \mathrm{H}), 2.63(\mathrm{~s}, 3 \mathrm{H}), 5.08(\mathrm{~s}, 1 \mathrm{H}), 5.91$ (br s, 2H), $6.96(\mathrm{~s}, 1 \mathrm{H}), 7.36-7.49$ (m, $5 \mathrm{H}) .{ }^{13} \mathrm{C} \mathrm{NMR},\left(\mathrm{CDCl}_{3}\right), \delta: 14.0,14.9,92.7,124.8,126.3,128.9,130.7,136.0,137.1,138.6$, 141.9, 155.6. HRMS (ESI) $\mathrm{m} / \mathrm{z}\left(\mathrm{M}+\mathrm{H}^{+}\right)$calculated for $\left[\mathrm{C}_{14} \mathrm{H}_{16} \mathrm{NO}_{2} \mathrm{~S}_{2}\right]^{+}:$294.0617. Found: 294.0614.

(Z)-2-(isothiazol-5-ylsulfonyl)-1-phenylethenamine (3w)<smiles>N/C(=C\S(=O)(=O)c1ccns1)c1ccccc1</smiles> 
Light-brown solid. $101 \mathrm{mg}$ (yield 38\%). $\mathrm{R}_{\mathrm{f}}=0.55$ (PE:EA 1.5:1), $\mathrm{mp}=131.0-133.0^{\circ} \mathrm{C} .{ }^{1} \mathrm{H}$ NMR $\left(\mathrm{CDCl}_{3}\right), \delta: 5.22(\mathrm{~s}, 1 \mathrm{H}), 6.18(\mathrm{br} \mathrm{s}, 2 \mathrm{H}), 7.39-7.49(\mathrm{~m}, 5 \mathrm{H}), 7.65(\mathrm{~d}, J=1.5 \mathrm{~Hz}, 1 \mathrm{H}), 8.45(\mathrm{~d}, J=$ $1.5 \mathrm{~Hz}, 1 \mathrm{H}) .{ }^{13} \mathrm{C} \mathrm{NMR},\left(\mathrm{CDCl}_{3}\right), \delta: 90.6,124.5,126.3,129.1,131.4,136.0,157.3,158.6,170.1$. HRMS (ESI) $\mathrm{m} / \mathrm{z}\left(\mathrm{M}+\mathrm{H}^{+}\right)$calculated for $\left[\mathrm{C}_{11} \mathrm{H}_{11} \mathrm{~N}_{2} \mathrm{O}_{2} \mathrm{~S}_{2}\right]^{+}:$267.0256. Found: 267.0268.

\section{1-Phenyl-2-tosylethanone $(\mathrm{A})^{7}$<smiles>O=C(C[As])c1ccccc1</smiles>

White solid. $\mathrm{R}_{\mathrm{f}}=0.73$ (PE:EA, 2:1), $\mathrm{mp}=102.5-104.5{ }^{\circ} \mathrm{C} .{ }^{1} \mathrm{H} \mathrm{NMR}\left(\mathrm{CDCl}_{3}\right), \delta: 2.43(\mathrm{~s}, 3 \mathrm{H})$, $4.73(\mathrm{~s}, 2 \mathrm{H}), 7.32(\mathrm{~d}, J=8.2 \mathrm{~Hz}, 2 \mathrm{H}), 7.46(\mathrm{dd}, J=7.5,7.3 \mathrm{~Hz}, 2 \mathrm{H}), 7.61(\mathrm{t}, J=7.5 \mathrm{~Hz}, 1 \mathrm{H})$, $7.77(\mathrm{~d}, J=8.2 \mathrm{~Hz}, 2 \mathrm{H}), 7.94(\mathrm{~d}, J=7.3 \mathrm{~Hz}, 2 \mathrm{H}) .{ }^{13} \mathrm{C} \mathrm{NMR}\left(\mathrm{CDCl}_{3}\right), \delta: 21.6,63.5,128.5$, $128.7,129.2,129.7,134.2,135.7,135.8,145.2,188.1$.

\section{Control experiments}

Procedure for $I_{2}$-mediated reaction of vinyl azide 1a and sulfonyl hydrazide 2a (Scheme 5, eq. a).To the solution of vinyl azide $\mathbf{1 a}(1 \mathrm{mmol}, 145 \mathrm{mg})$ and sulfonyl hydrazide $\mathbf{2 a}(1.5 \mathrm{mmol}$, $279 \mathrm{mg}$ ) in $10 \mathrm{~mL}$ of DMSO-THF (1:1) the solution of $\mathrm{I}_{2}(1 \mathrm{mmol}, 254 \mathrm{mg})$ in $10 \mathrm{~mL}$ of DMSOTHF (1:1) was added under magnetic stirring. The reaction mixture was stirred for 90 min at room temperature. After that the reaction mixture was diluted with $0.3 \mathrm{M}$ solution of $\mathrm{Na}_{2} \mathrm{~S}_{2} \mathrm{O}_{3}$ $(50 \mathrm{~mL})$ and washed with EA $(5 \times 10 \mathrm{~mL})$. Combined organic layer was washed with $1 \mathrm{M}$ solution of $\mathrm{Na}_{2} \mathrm{~S}_{2} \mathrm{O}_{3}(10 \mathrm{~mL})$, water $(10 \mathrm{~mL})$, and brine $(10 \mathrm{~mL})$, dried over $\mathrm{Na}_{2} \mathrm{SO}_{4}$ and concentrated under reduced pressure. According to ${ }^{1} \mathrm{H}$ NMR spectroscopy (1,4-dinitrobenzene as internal standard) the target product 3aa was formed only in trace amounts.

Procedure for the electrosynthesis of 3aa in divided electrochemical cell (Scheme 5, eq. b). A divided cell was equipped with a carbon plate anode $\left(5 \mathrm{~cm}^{2}\right)$ and a stainless steel plate cathode $\left(5 \mathrm{~cm}^{2}\right)$ and connected to a DC regulated power supply. The solution of vinyl azide 1a $(1 \mathrm{mmol}, 145 \mathrm{mg})$, sulfonyl hydrazide $2 \mathbf{a}(1.5 \mathrm{mmol}, 279 \mathrm{mg})$ and supporting electrolyte $\mathrm{NH}_{4} \mathrm{I}(4 \mathrm{mmol}, 580 \mathrm{mg}$ ) in $20 \mathrm{~mL}$ of DMSO-THF (1:1) was added into the anode chamber. The solution of supporting electrolyte $\mathrm{NH}_{4} \mathrm{I}(4 \mathrm{mmol}, 580 \mathrm{mg}$ ) in $20 \mathrm{~mL}$ of DMSO-THF (1:1) was added into the cathode chamber. This system was electrolyzed using constant current conditions ( $\mathrm{I}=60 \mathrm{~mA}, \mathrm{j}=20 \mathrm{~mA} / \mathrm{cm}^{2}$ at room temperature, $\tau=1.5 \mathrm{~h}$ ) under magnetic stirring. After that the reaction mixture was diluted with $0.3 \mathrm{M}$ solution of $\mathrm{Na}_{2} \mathrm{~S}_{2} \mathrm{O}_{3}(50 \mathrm{~mL})$ and washed with EA $(5 \times 10 \mathrm{~mL})$, which was used for the washing of electrodes after the reaction. Combined organic layer was washed with $1 \mathrm{M}$ solution of $\mathrm{Na}_{2} \mathrm{~S}_{2} \mathrm{O}_{3}(10 \mathrm{~mL})$, water $(10 \mathrm{~mL})$, and brine $(10 \mathrm{~mL})$, dried over $\mathrm{Na}_{2} \mathrm{SO}_{4}$ and concentrated under reduced pressure. The yield of $\mathbf{3 a}$ was $73 \%$ according to ${ }^{1} \mathrm{H}$ NMR spectroscopy (1,4-dinitrobenzene as internal standard).

\section{References and notes}

1. Terent'ev, A. O.; Mulina, O. M.; Pirgach, D. A.; Demchuk, D. V.; Syroeshkin, M. A.; Nikishin, G. I., Copper(i)-mediated synthesis of $\beta$-hydroxysulfones from styrenes and sulfonylhydrazides: an electrochemical mechanistic study. RSC Adv. 2016, 6, 93476-93485. 
2. Dey, R.; Banerjee, P., Lewis Acid Catalyzed Diastereoselective Cycloaddition Reactions of Donor-Acceptor Cyclopropanes and Vinyl Azides: Synthesis of Functionalized Azidocyclopentane and Tetrahydropyridine Derivatives. Org. Lett. 2017, 19, 304-307.

3. Wang, Y.; Lei, X.; Tang, Y., Rh(II)-catalyzed cycloadditions of 1-tosyl 1,2,3-triazoles with 2H-azirines: switchable reactivity of Rh-azavinylcarbene as [2C]- or aza-[3C]-synthon. Chem. Commun. 2015,51, 4507-4510.

4. Ning, Y.; Ji, Q.; Liao, P.; Anderson, E. A.; Bi, X., Silver-Catalyzed Stereoselective Aminosulfonylation of Alkynes. Angew. Chem. Int. Ed. 2017,56, 13805-13808.

5. Tsui, G. C.; Glenadel, Q.; Lau, C.; Lautens, M., Rhodium(I)-catalyzed addition of arylboronic acids to (benzyl-/arylsulfonyl)acetonitriles: efficient synthesis of (Z)-beta-sulfonylvinylamines and beta-keto sulfones. Org. Lett. 2011, 13, 208-211.

6 . For the isolation of this compound during column chromatography $2 \%$ of $\mathrm{MeOH}$ was also added in all eluents due to its very low solubility.

7. Tang, Y.; Zhang, Y.; Wang, K.; Li, X.; Xu, X.; Du, X., Tetrabutylammonium iodide-catalyzed oxidative coupling of enamides with sulfonylhydrazides: synthesis of $\beta$-keto-sulfones. Org. Biomol. Chem., 2015, 13, 7084-7090. 


\section{NMR spectra of synthesized compounds}

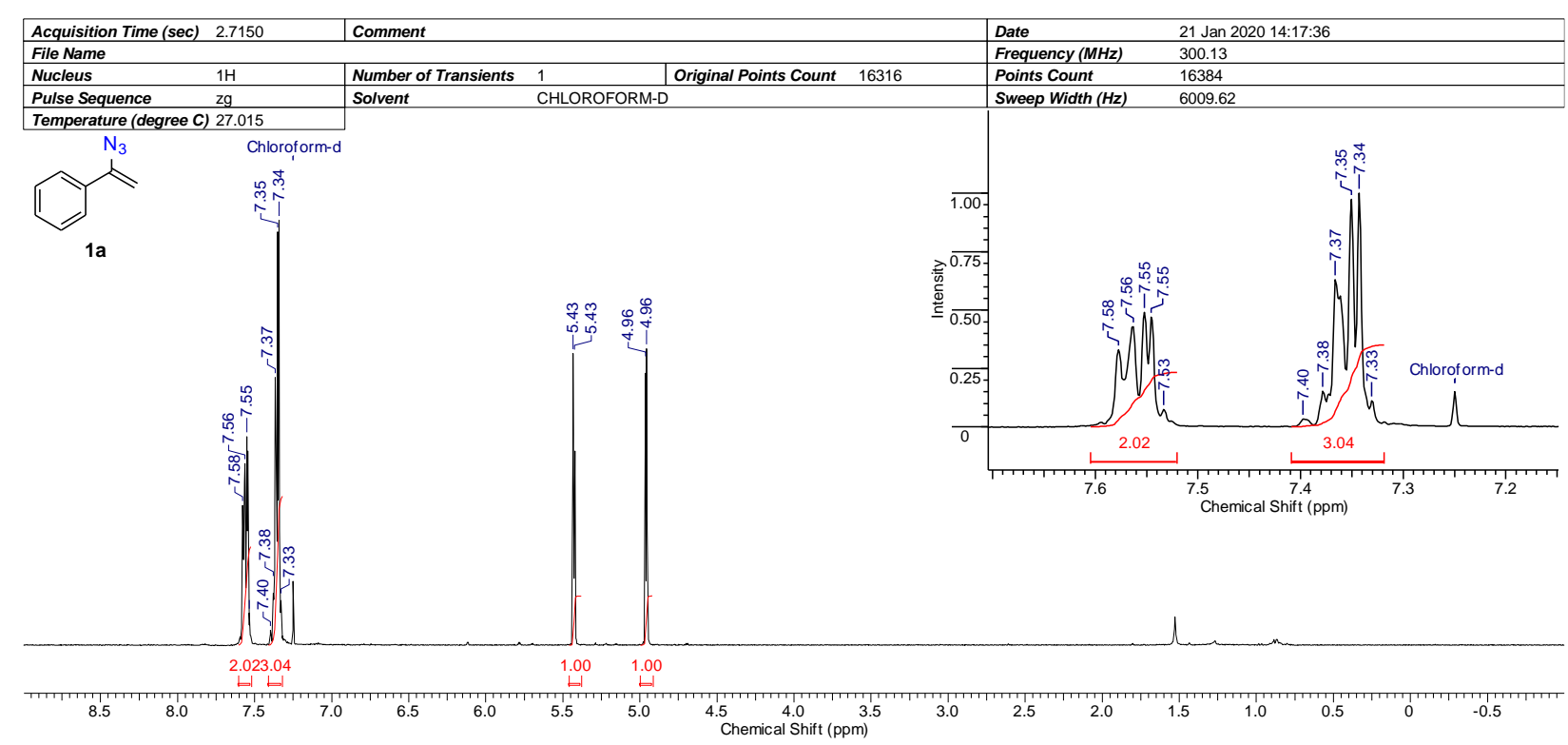

${ }^{1} \mathrm{H}$ NMR $\left(\mathrm{CDCl}_{3}\right), \delta: 4.96(\mathrm{~d}, J=2.2 \mathrm{~Hz}, 1 \mathrm{H}), 5.43(\mathrm{~d}, J=2.2 \mathrm{~Hz}, 1 \mathrm{H}), 7.33-7.40(\mathrm{~m}, 3 \mathrm{H}), 7.53-$ 7.58 (m, 2H). 


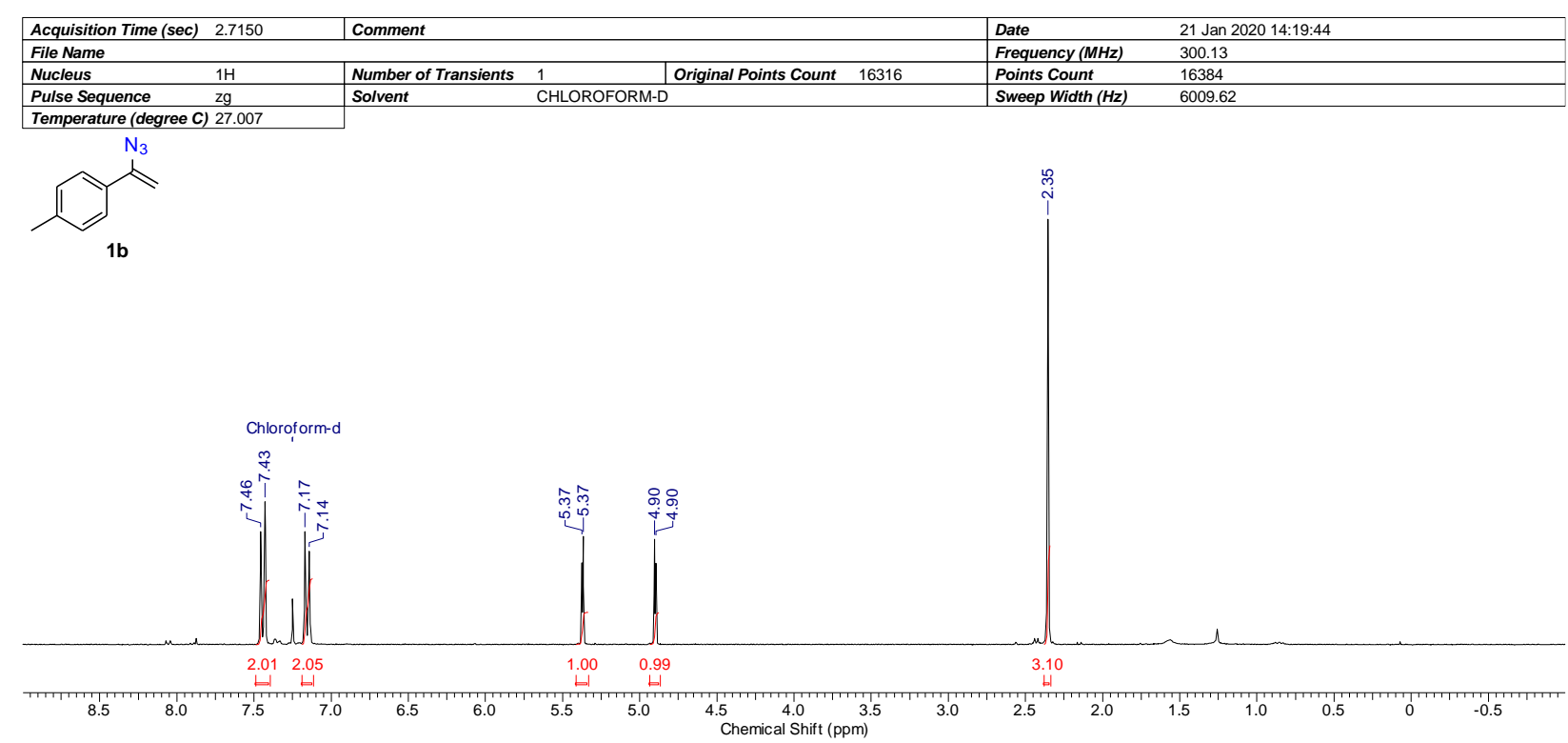

${ }^{1} \mathrm{H} \mathrm{NMR}\left(\mathrm{CDCl}_{3}\right), \delta: 2.35(\mathrm{~s}, 3 \mathrm{H}), 4.90(\mathrm{~d}, J=2.2 \mathrm{~Hz}, 1 \mathrm{H}), 5.37(\mathrm{~d}, J=2.2 \mathrm{~Hz}, 1 \mathrm{H}), 7.15(\mathrm{~d}, J=$ $8.1 \mathrm{~Hz}, 2 \mathrm{H}), 7.44(\mathrm{~d}, J=8.1 \mathrm{~Hz}, 2 \mathrm{H})$. 


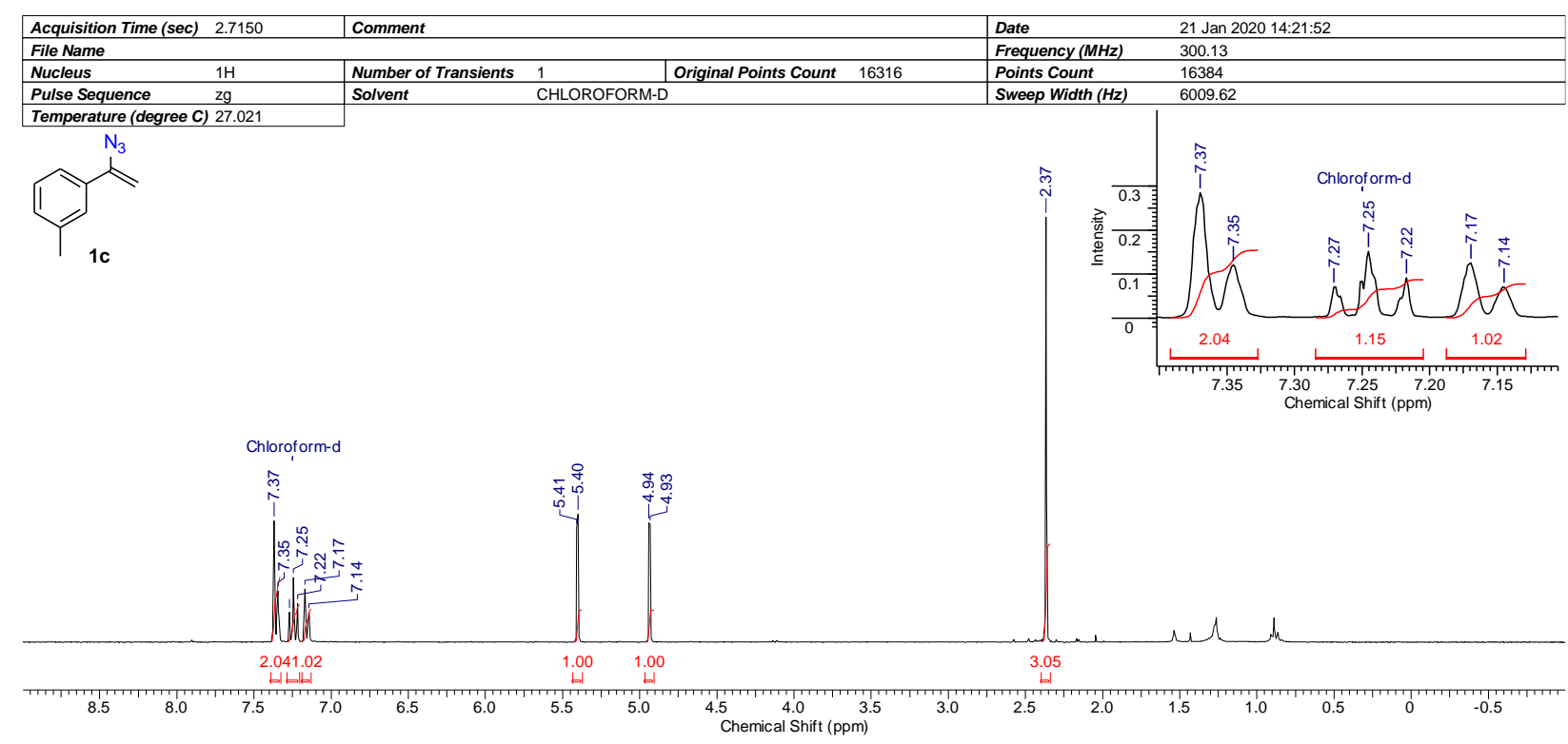

${ }^{1} \mathrm{H} \mathrm{NMR}\left(\mathrm{CDCl}_{3}\right), \delta: 2.37(\mathrm{~s}, 3 \mathrm{H}), 4.93(\mathrm{~d}, J=2.6 \mathrm{~Hz}, 1 \mathrm{H}), 5.40(\mathrm{~d}, J=2.6 \mathrm{~Hz}, 1 \mathrm{H}), 7.15(\mathrm{~d}, J=$ $7.7 \mathrm{~Hz}, 2 \mathrm{H}), 7.25$ (t, $J=7.7 \mathrm{~Hz}, 2 \mathrm{H}), 7.35-7.37$ (m, 2H). 


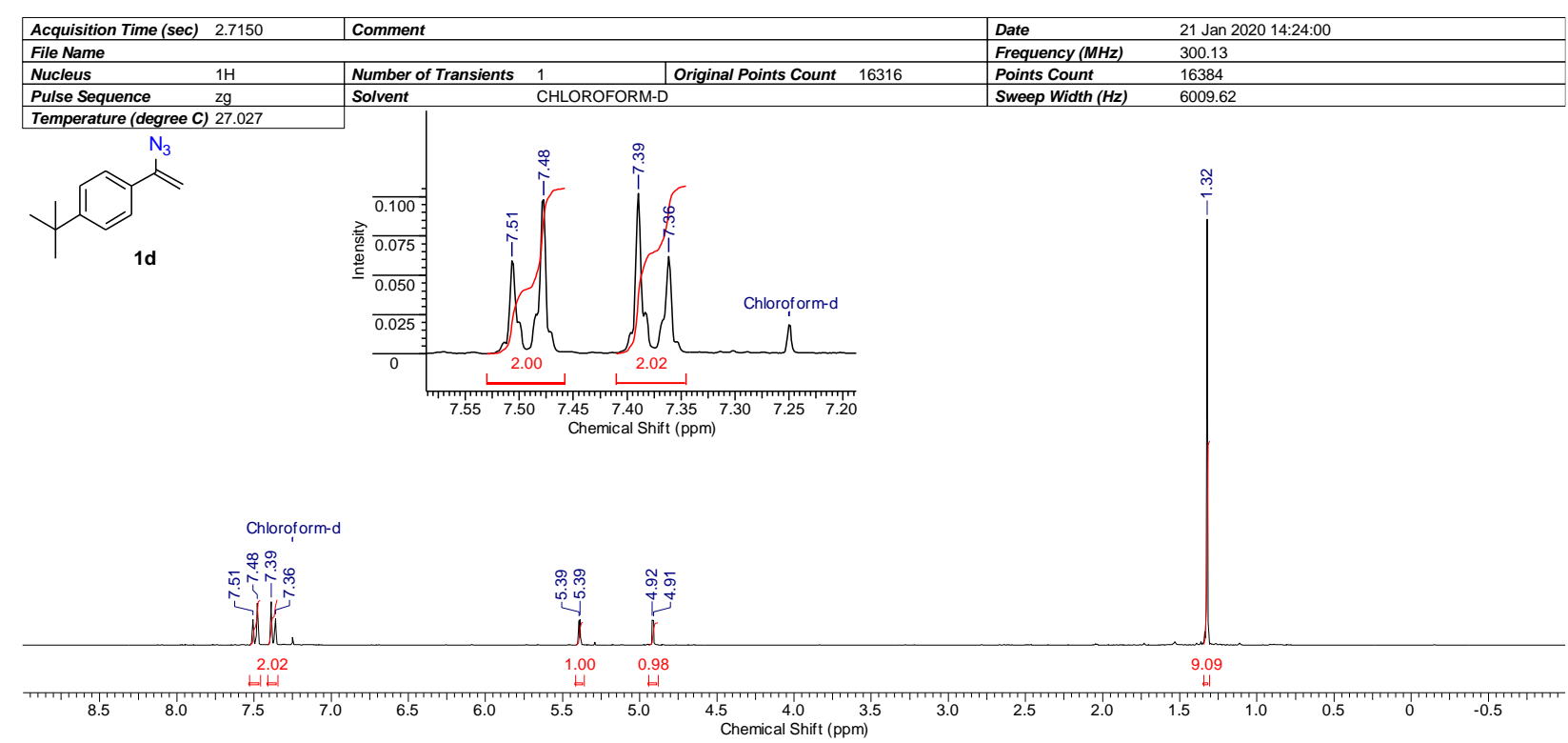

${ }^{1} \mathrm{H}$ NMR $\left(\mathrm{CDCl}_{3}\right), \delta: 1.32(\mathrm{~s}, 9 \mathrm{H}), 4.91(\mathrm{~d}, J=2.2 \mathrm{~Hz}, 1 \mathrm{H}), 5.39(\mathrm{~d}, J=2.2 \mathrm{~Hz}, 1 \mathrm{H}), 7.37(\mathrm{~d}, J=$ $8.5 \mathrm{~Hz}, 2 \mathrm{H}), 7.49(\mathrm{~d}, J=8.5 \mathrm{~Hz}, 2 \mathrm{H})$. 


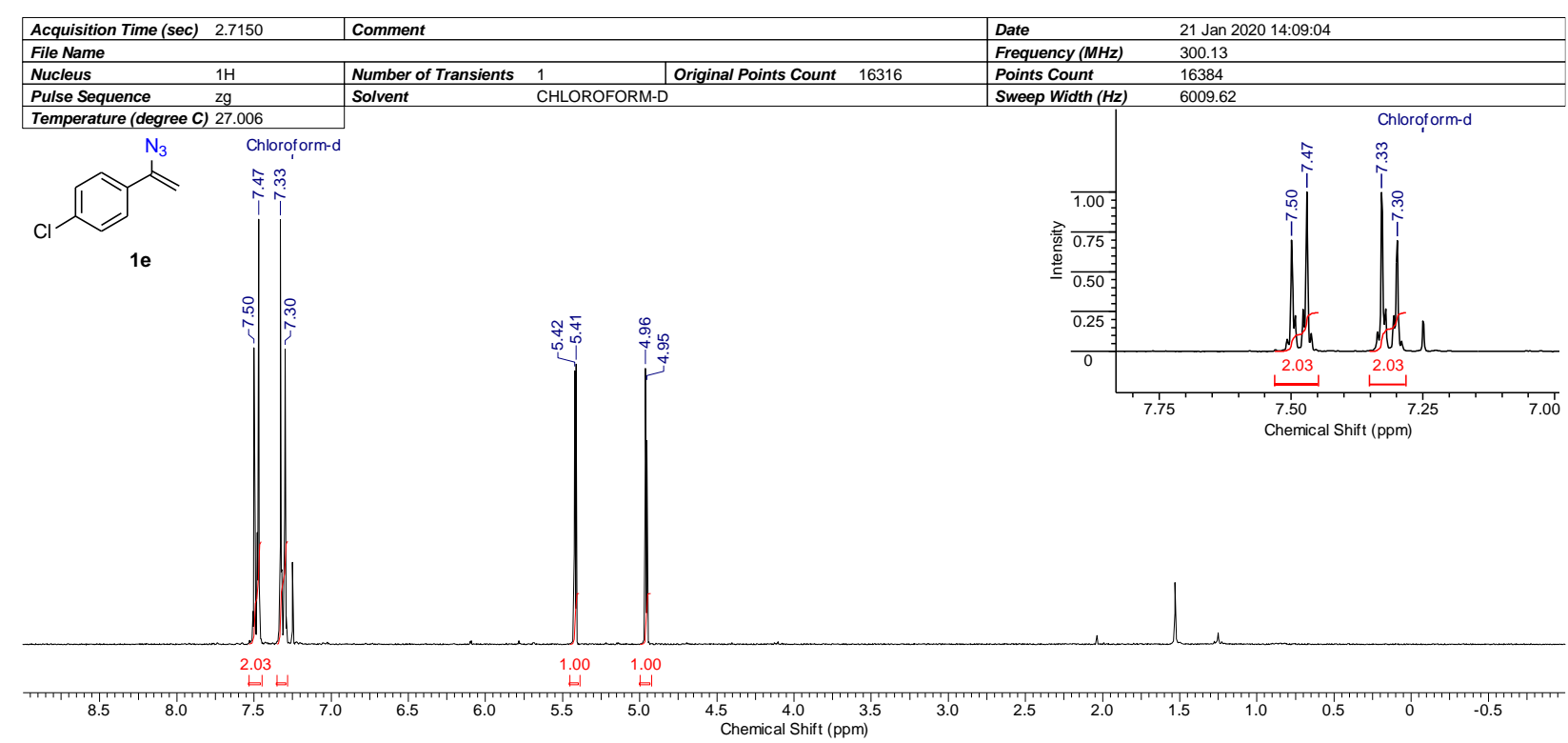

${ }^{1} \mathrm{H} \mathrm{NMR}\left(\mathrm{CDCl}_{3}\right), \delta: 4.95(\mathrm{~d}, J=2.6 \mathrm{~Hz}, 1 \mathrm{H}), 5.41(\mathrm{~d}, J=2.6 \mathrm{~Hz}, 1 \mathrm{H}), 7.31(\mathrm{~d}, J=8.8 \mathrm{~Hz}, 2 \mathrm{H})$, 7.48 (d, $J=8.8 \mathrm{~Hz}, 2 \mathrm{H})$. 


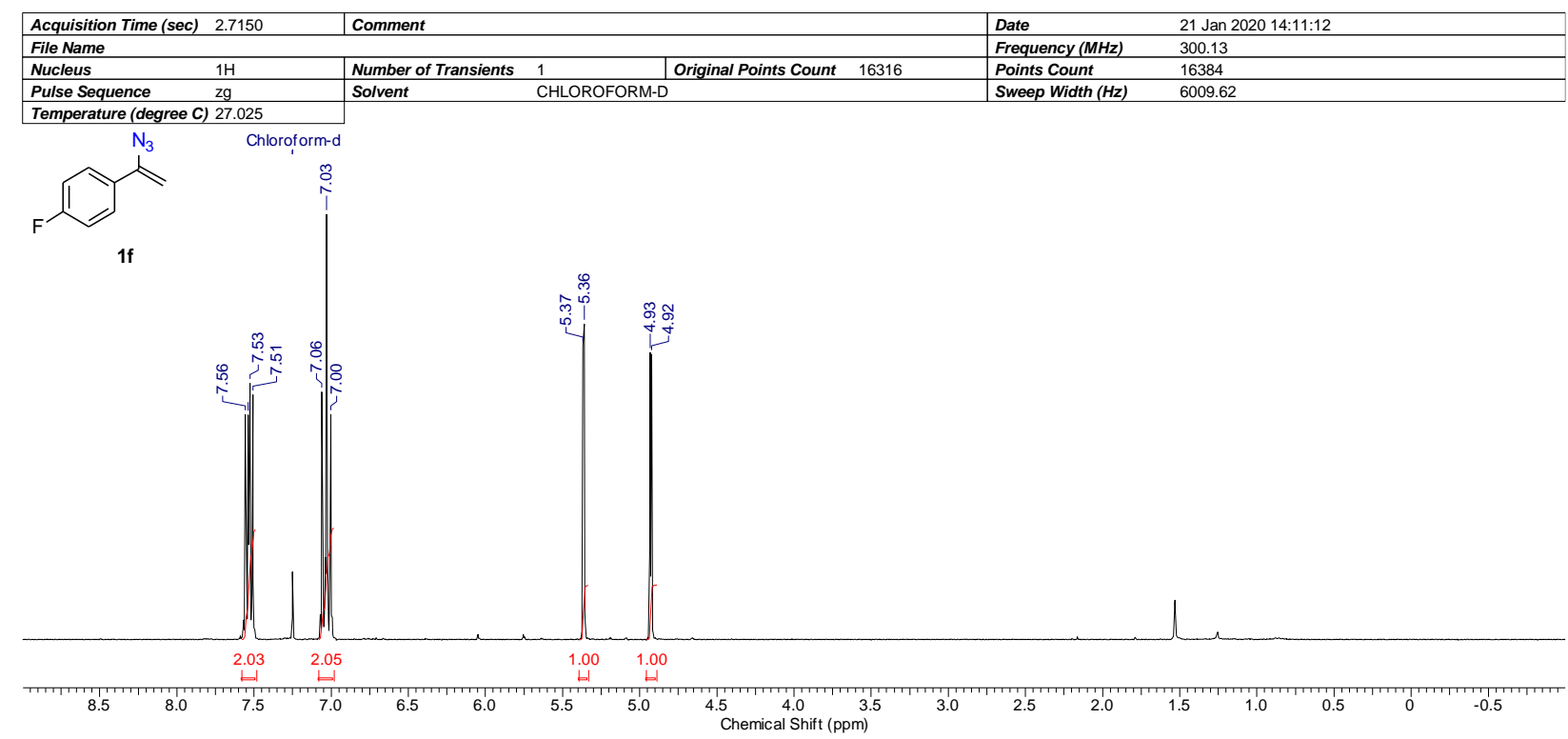

${ }^{1} \mathrm{H} \mathrm{NMR}\left(\mathrm{CDCl}_{3}\right), \delta: 4.92(\mathrm{~d}, J=2.6 \mathrm{~Hz}, 1 \mathrm{H}), 5.36(\mathrm{~d}, J=2.6 \mathrm{~Hz}, 1 \mathrm{H}), 7.03(\mathrm{t}, J=8.8 \mathrm{~Hz}, 2 \mathrm{H})$, $7.53(\mathrm{dd}, J=5.2,8.8 \mathrm{~Hz}, 2 \mathrm{H})$. 


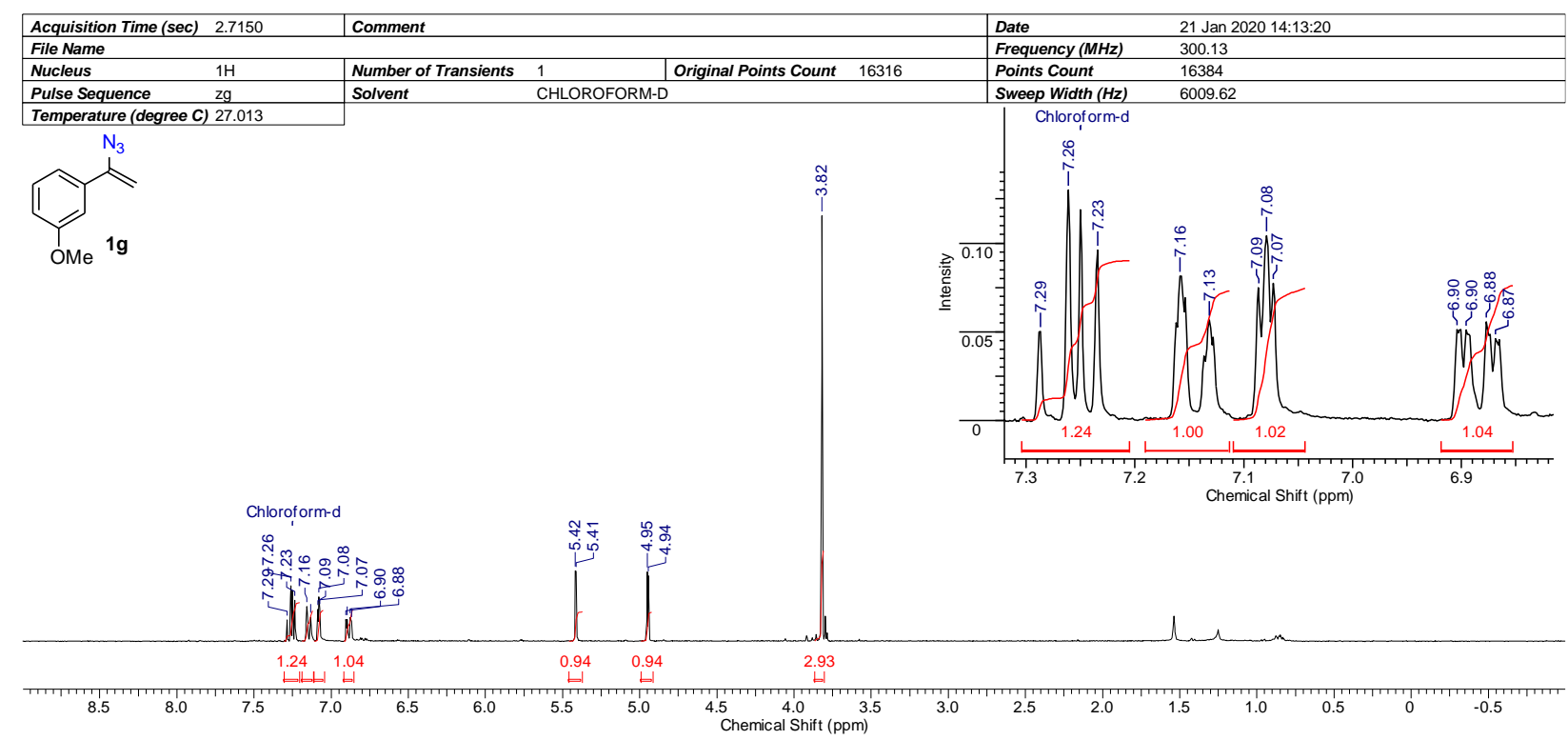

${ }^{1} \mathrm{H}$ NMR $\left(\mathrm{CDCl}_{3}\right), \delta: 4.92(\mathrm{~d}, J=2.3 \mathrm{~Hz}, 1 \mathrm{H}), 5.36(\mathrm{~d}, J=2.3 \mathrm{~Hz}, 1 \mathrm{H}), 6.89(\mathrm{dd}, J=2.6,8.1 \mathrm{~Hz}$, $1 \mathrm{H}), 7.08(\mathrm{t}, J=2.6 \mathrm{~Hz}, 1 \mathrm{H}), 7.14(\mathrm{dd}, J=2.6,8.1 \mathrm{~Hz}, 1 \mathrm{H}), 7.26(\mathrm{t}, J=8.1 \mathrm{~Hz}, 1 \mathrm{H})$. 


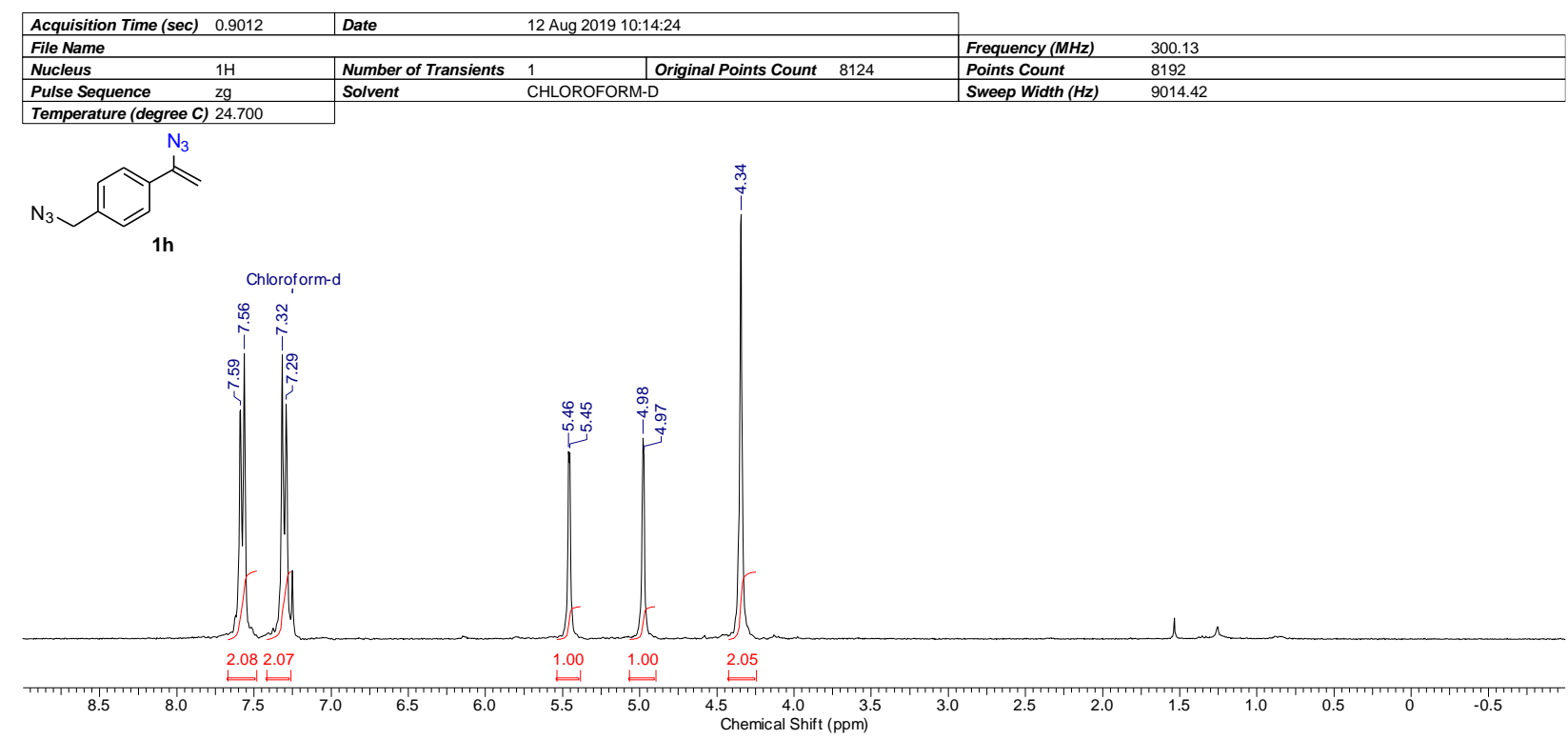

${ }^{1} \mathrm{H} \mathrm{NMR}\left(\mathrm{CDCl}_{3}\right), \delta: 4.34(\mathrm{~s}, 2 \mathrm{H}), 4.97(\mathrm{~d}, J=2.2 \mathrm{~Hz}, 1 \mathrm{H}), 5.45(\mathrm{~d}, J=2.2 \mathrm{~Hz}, 1 \mathrm{H}), 7.30(\mathrm{~d}, J=$ $7.7 \mathrm{~Hz}, 2 \mathrm{H}), 7.57$ (d, $J=7.7 \mathrm{~Hz}, 2 \mathrm{H})$. 


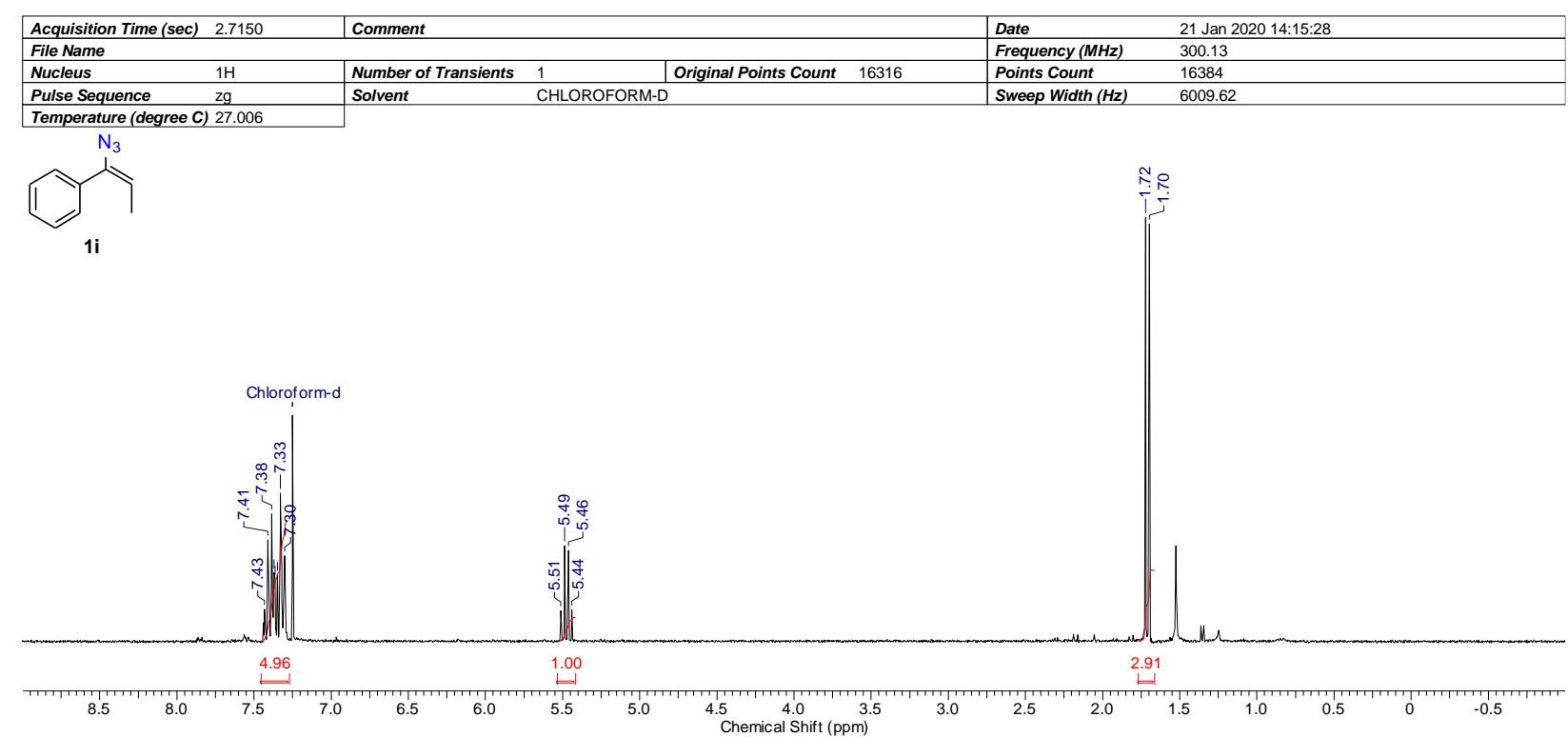

${ }^{1} \mathrm{H} \operatorname{NMR}\left(\mathrm{CDCl}_{3}\right), \delta: 1.71(\mathrm{~d}, J=7.3 \mathrm{~Hz}, 3 \mathrm{H}), 4.97(\mathrm{q}, J=7.3 \mathrm{~Hz}, 1 \mathrm{H}), 7.30-7.43(\mathrm{~m}, 5 \mathrm{H})$. 


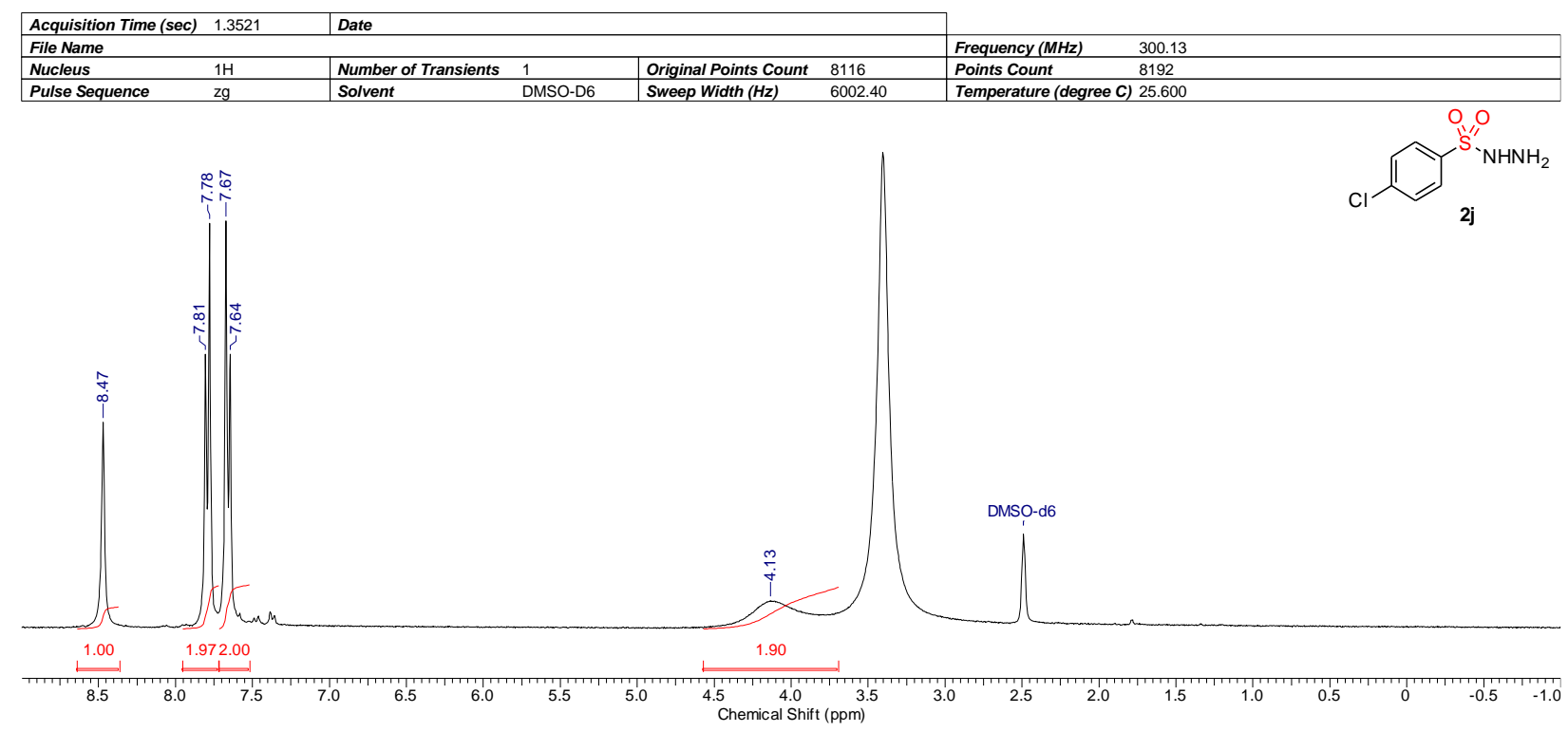

${ }^{1} \mathrm{H}$ NMR (DMSO-d $), \delta: 4.13$ (br s, 2H), $7.65(\mathrm{~d}, J=8.1 \mathrm{~Hz}, 2 \mathrm{H}), 7.79(\mathrm{~d}, J=8.1 \mathrm{~Hz}, 2 \mathrm{H}), 8.47$ (s, 1H). 


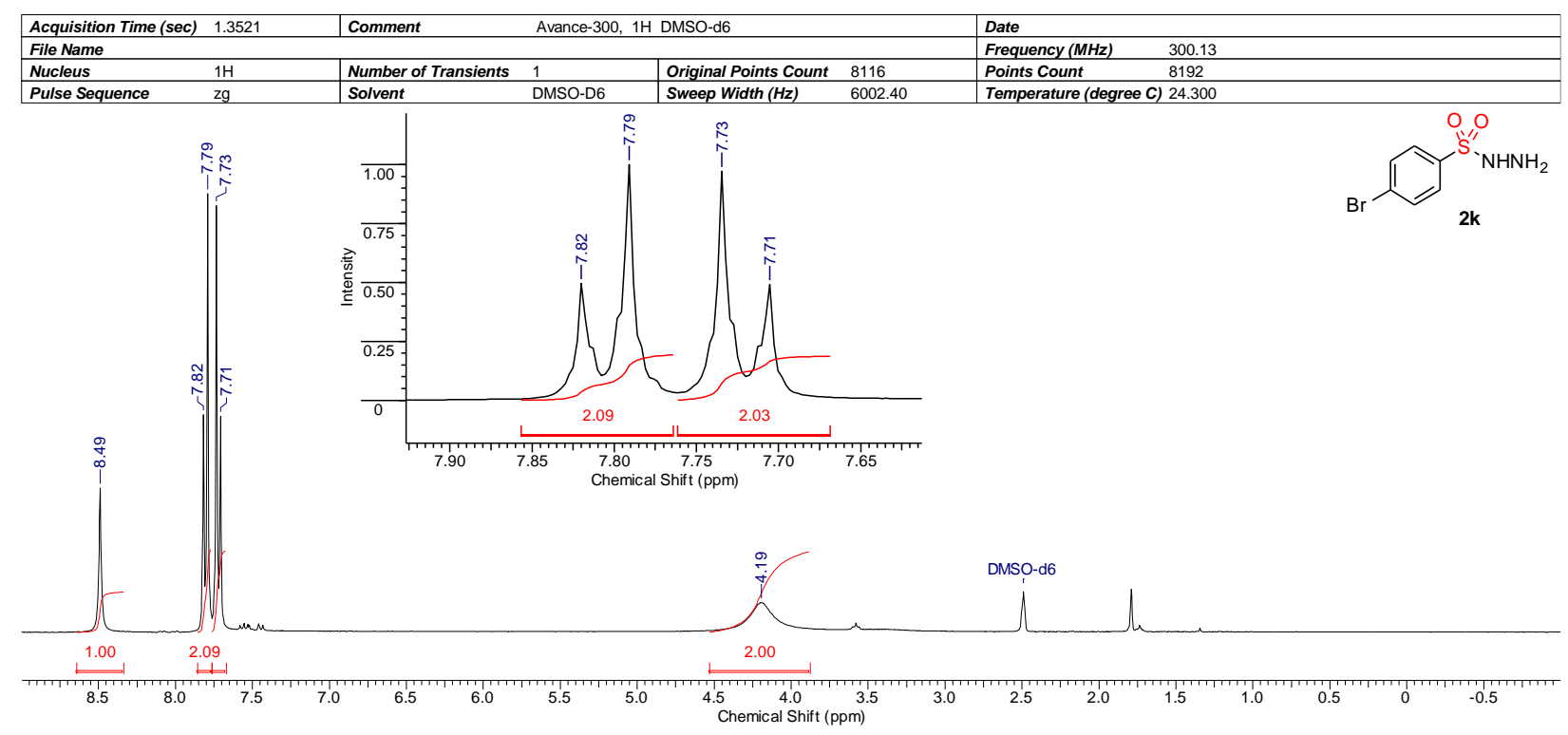

${ }^{1} \mathrm{H}$ NMR (DMSO-d $), \delta: 4.19$ (br s, 2H), $7.72(\mathrm{~d}, J=8.8 \mathrm{~Hz}, 2 \mathrm{H}), 7.80(\mathrm{~d}, J=8.8 \mathrm{~Hz}, 2 \mathrm{H}), 8.49$ (s, 1H). 


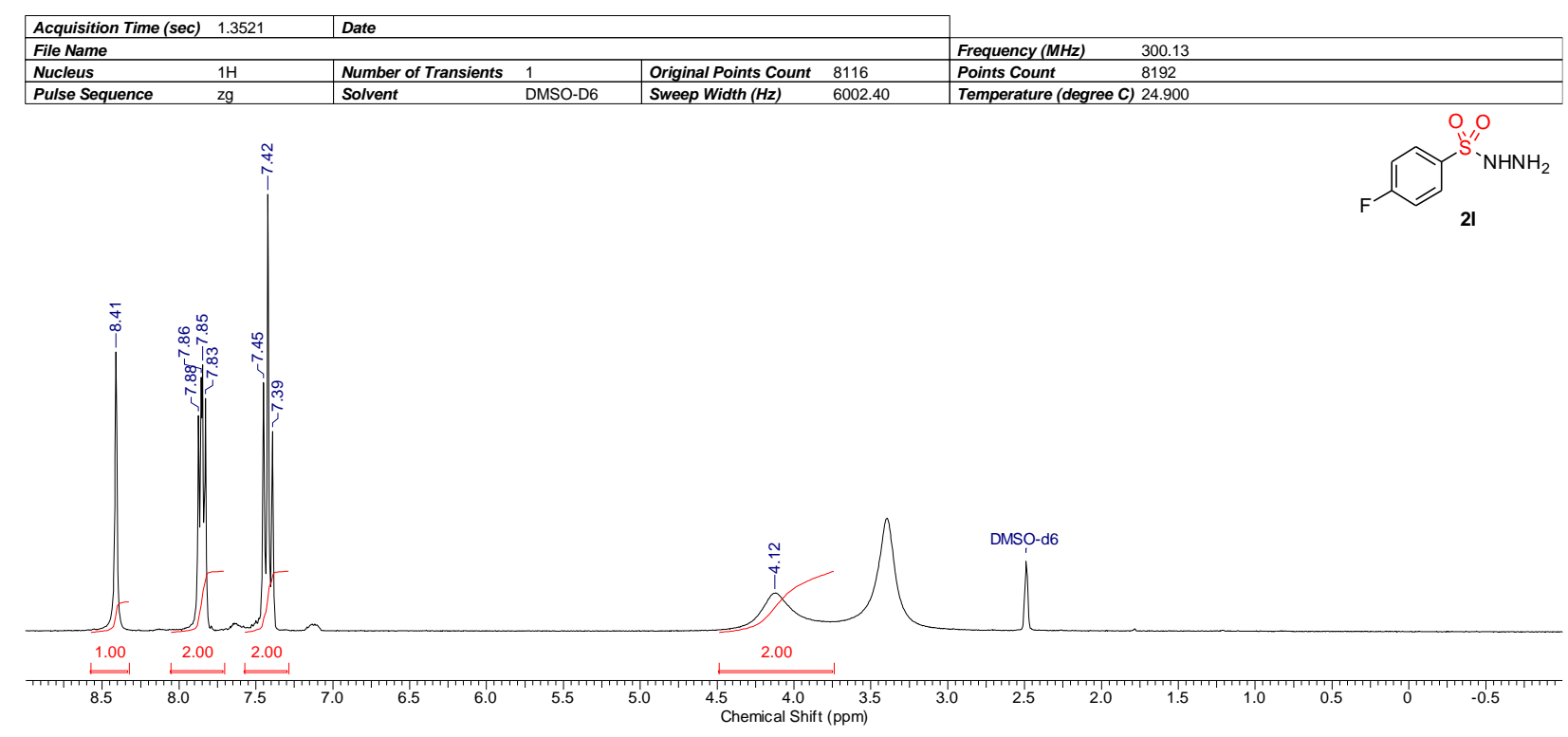

${ }^{1} \mathrm{H}$ NMR (DMSO-d $), \delta: 4.12($ br s, 2H), $7.42(\mathrm{t}, J=8.8 \mathrm{~Hz}, 2 \mathrm{H}), 7.85(\mathrm{dd}, J=5.9,8.8 \mathrm{~Hz}, 2 \mathrm{H})$, 8.41 (s, 1H). 


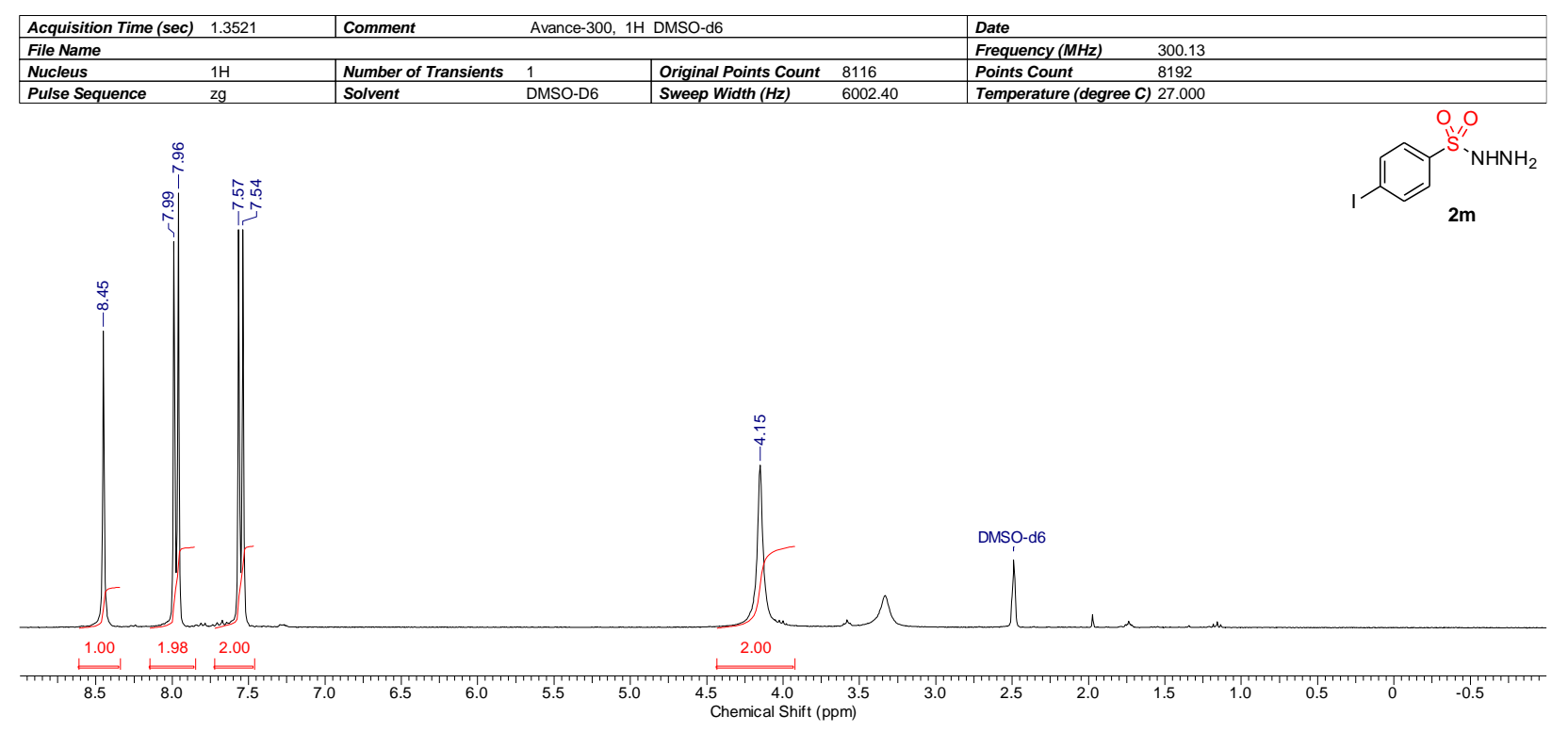

${ }^{1} \mathrm{H}$ NMR (DMSO-d $), \delta: 4.15$ (br s, 2H), 7.55 (d, $\left.J=8.8 \mathrm{~Hz}, 2 \mathrm{H}\right), 7.97$ (d, $\left.J=8.8 \mathrm{~Hz}, 2 \mathrm{H}\right), 8.45$ (s, 1H). 


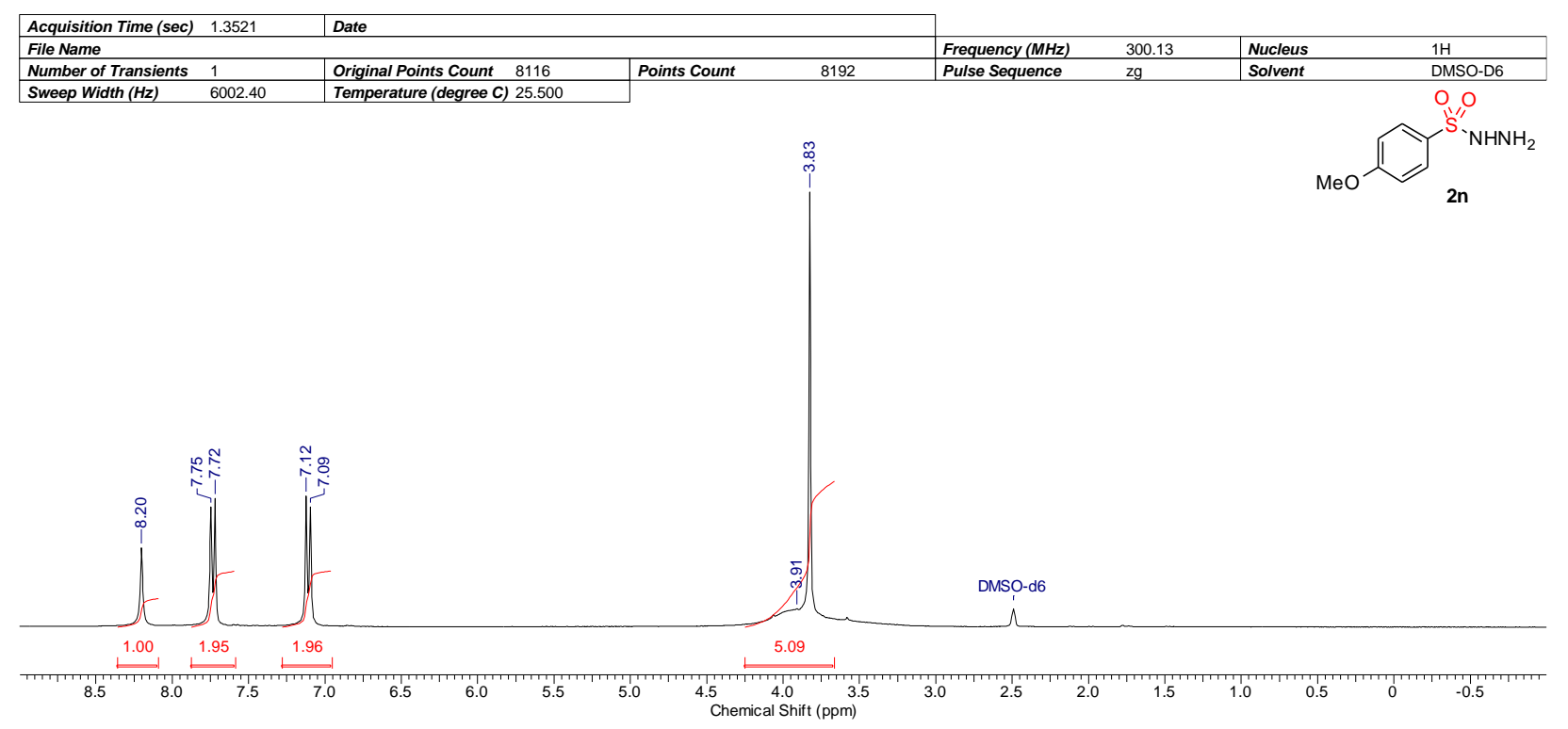

${ }^{1} \mathrm{H}$ NMR (DMSO-d $), \delta: 3.83$ (s, 3H), 3.91 (br s, 2H), 7.10 (d, $\left.J=8.1 \mathrm{~Hz}, 2 \mathrm{H}\right), 7.73$ (d, $J=8.1$ $\mathrm{Hz}, 2 \mathrm{H}), 8.20$ (s, 1H). 


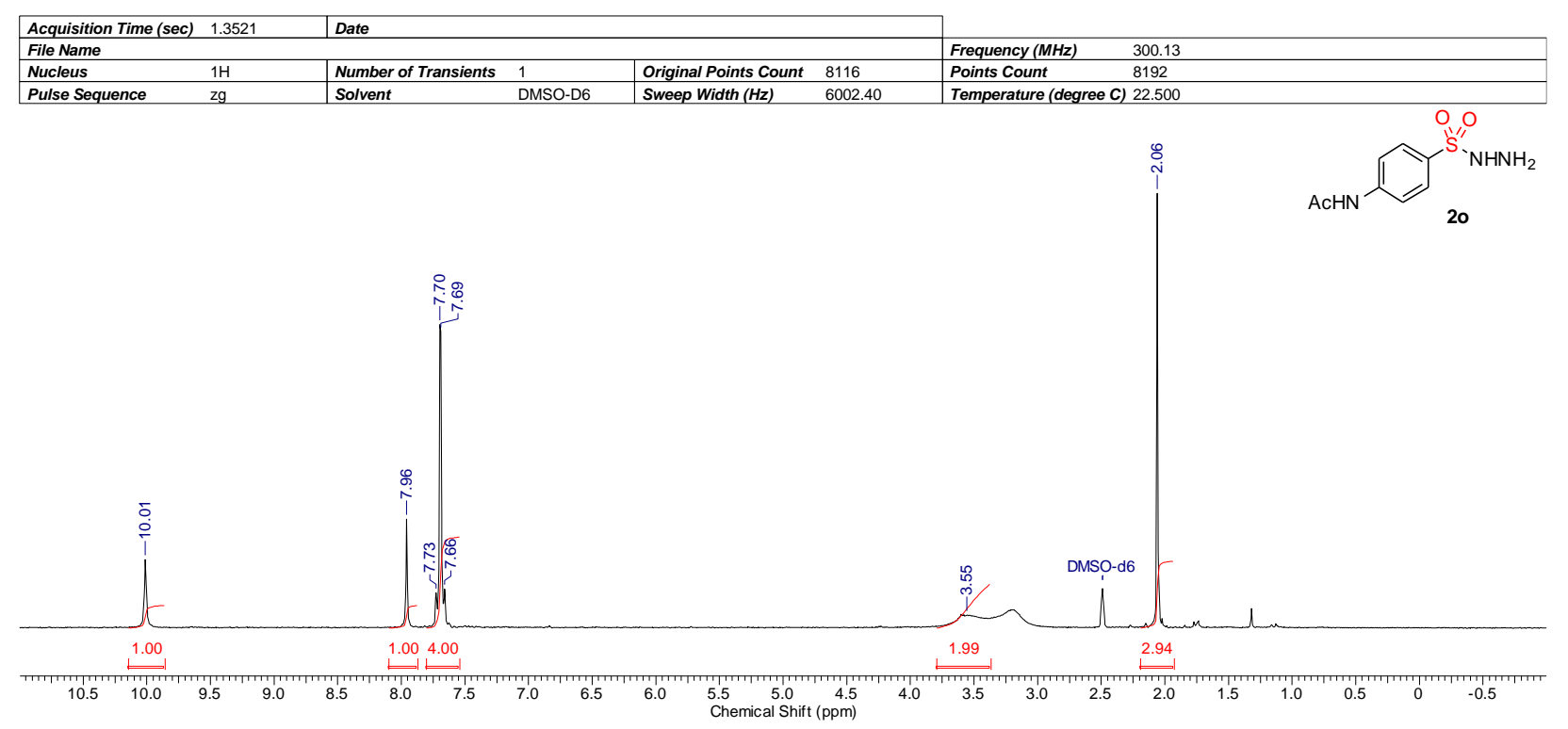

${ }^{1} \mathrm{H}$ NMR (DMSO-d $), \delta: 2.06$ (s, 3H), 3.55 (br s, 2H), 7.67 (d, $\left.J=8.8 \mathrm{~Hz}, 2 \mathrm{H}\right), 7.71$ (d, $J=8.8$ $\mathrm{Hz}, 2 \mathrm{H}), 7.96(\mathrm{~s}, 1 \mathrm{H}), 10.01(\mathrm{~s}, 1 \mathrm{H})$. 


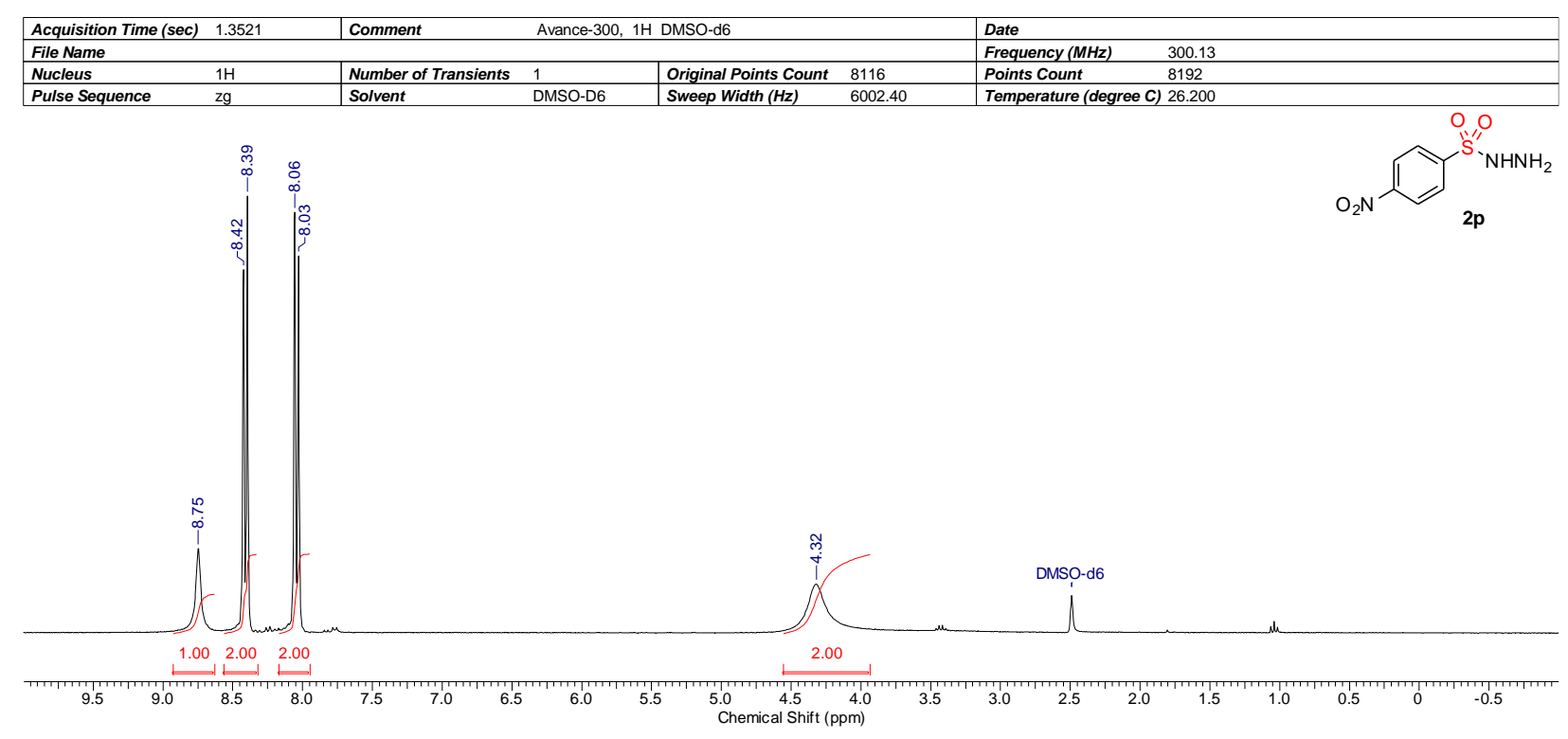

${ }^{1} \mathrm{H}$ NMR (DMSO-d $), \delta: 4.32$ (br s, 2H), $8.04(\mathrm{~d}, J=8.8 \mathrm{~Hz}, 2 \mathrm{H}), 8.40(\mathrm{~d}, J=8.8 \mathrm{~Hz}, 2 \mathrm{H}), 8.75$ (s, 1H). 


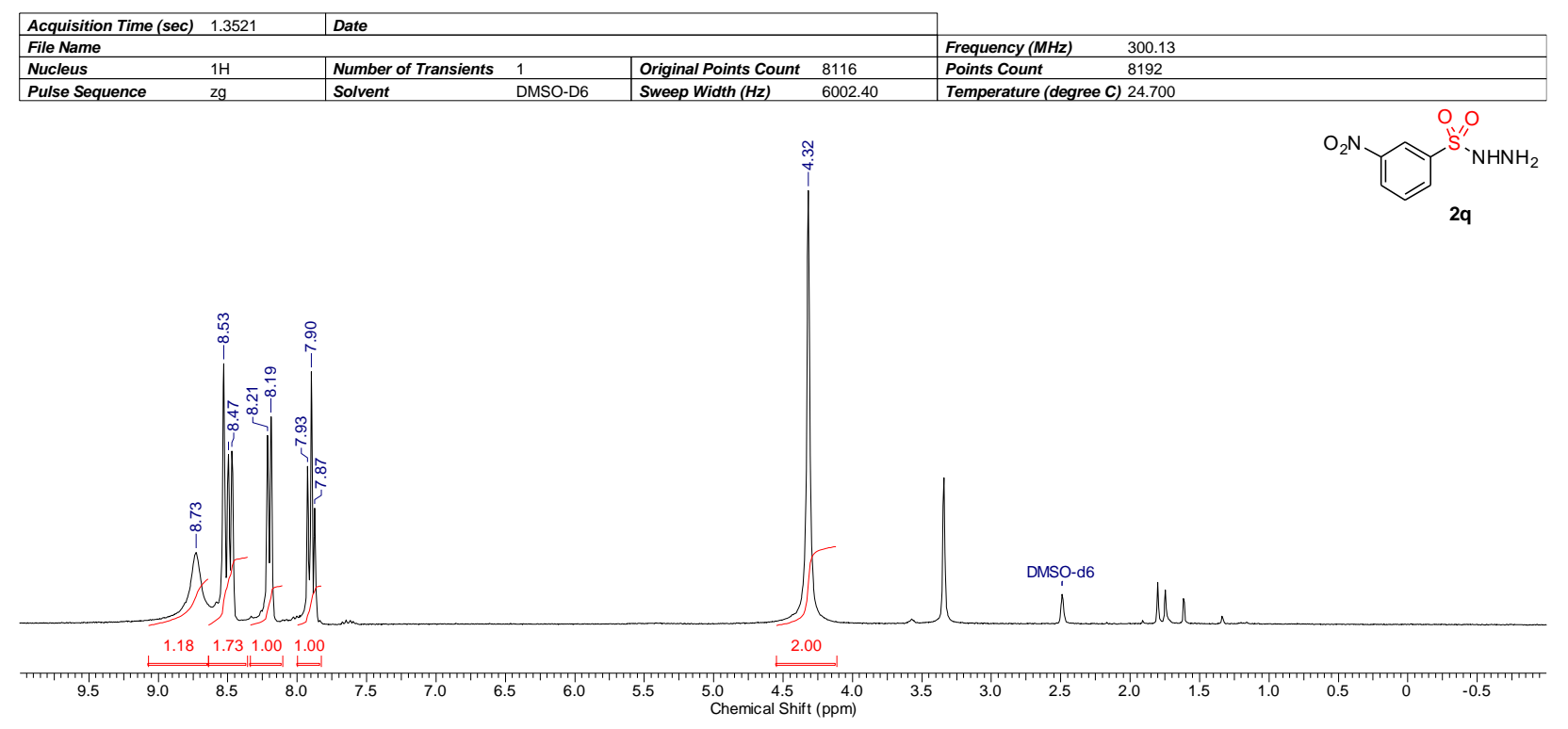

${ }^{1} \mathrm{H}$ NMR (DMSO-d $), \delta: 4.32(\mathrm{~s}, 2 \mathrm{H}), 7.90(\mathrm{t}, J=8.3 \mathrm{~Hz}, 1 \mathrm{H}), 8.20(\mathrm{~d}, J=8.3 \mathrm{~Hz}, 1 \mathrm{H}), 8.48(\mathrm{~d}$, $J=8.3 \mathrm{~Hz}, 1 \mathrm{H}), 8.53(\mathrm{~s}, 1 \mathrm{H}), 8.73$ (br s, $1 \mathrm{H})$. 


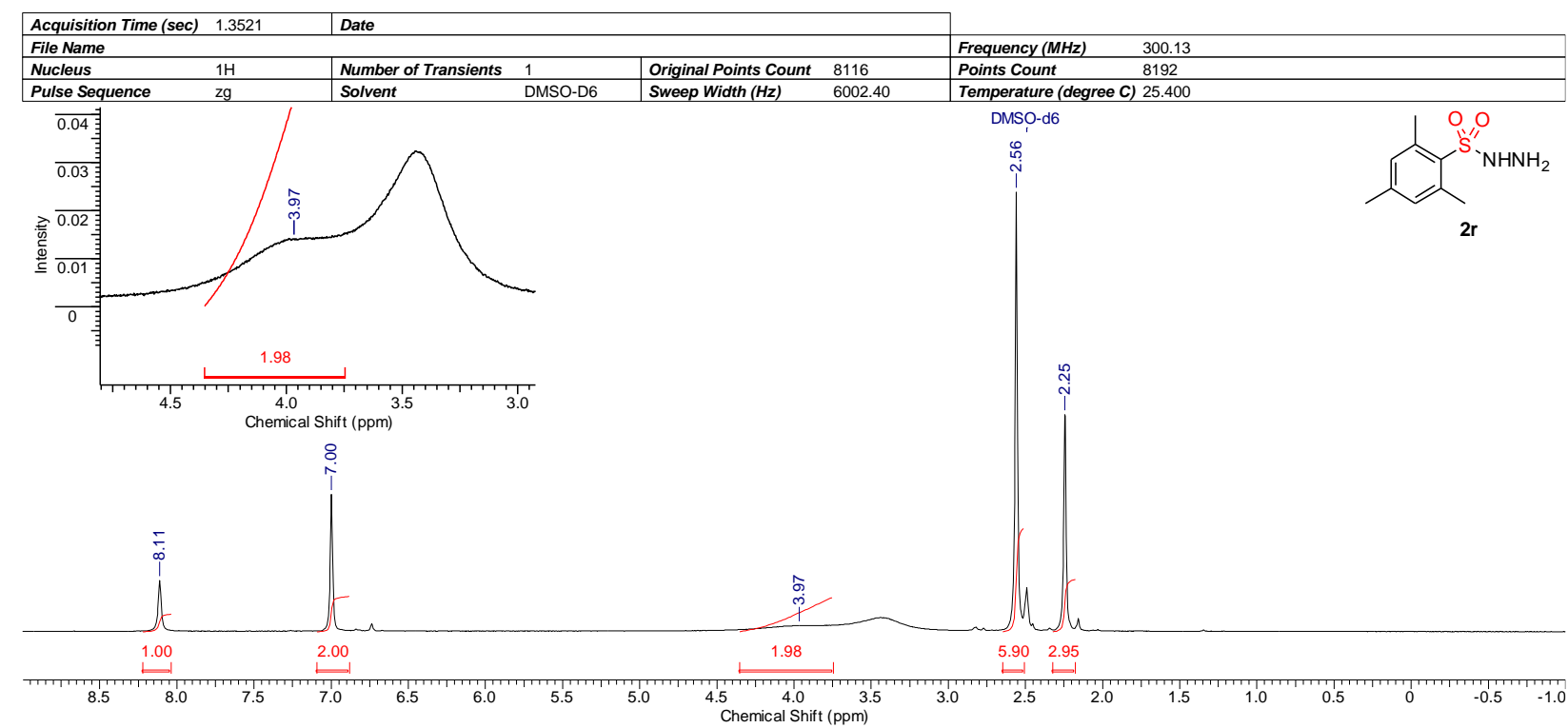

${ }^{1} \mathrm{H}$ NMR (DMSO-d $), \delta: 2.25$ (s, 3H), 2.56 (s, 6H), 3.97 (br s, 2H), 7.00 (s, 2H), 8.11 (s, 1H). 


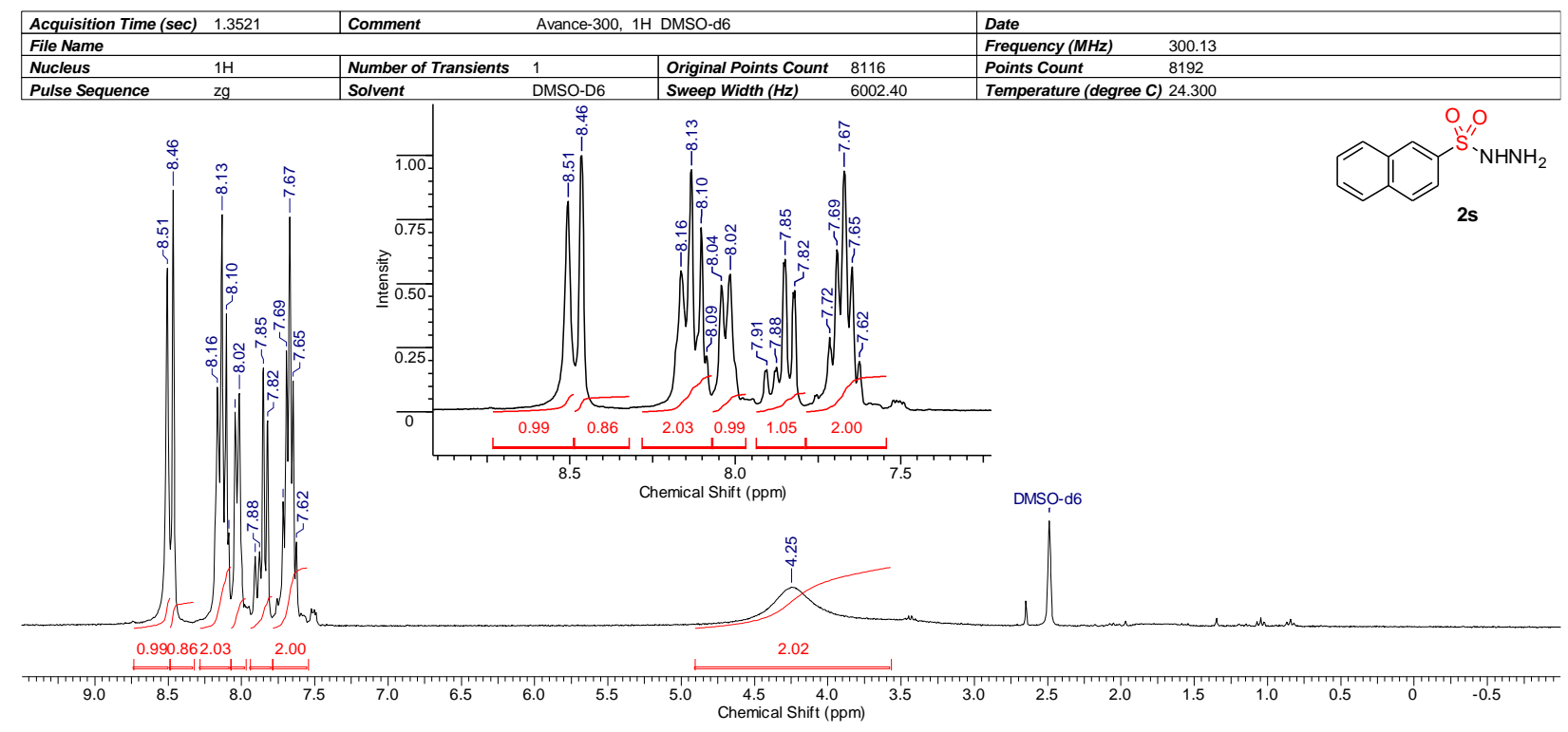

${ }^{1} \mathrm{H}$ NMR (DMSO-d $), \delta: 4.24$ (br s, 2H), 7.62-7.72 (m, 2H), 7.82-7.91 (m, 1H), 8.03 (d, $J=7.8$ $\mathrm{Hz}, 1 \mathrm{H}), 8.09-8.16(\mathrm{~m}, 2 \mathrm{H}), 8.46(\mathrm{~s}, 1 \mathrm{H}), 8.51$ (s, 1H). 


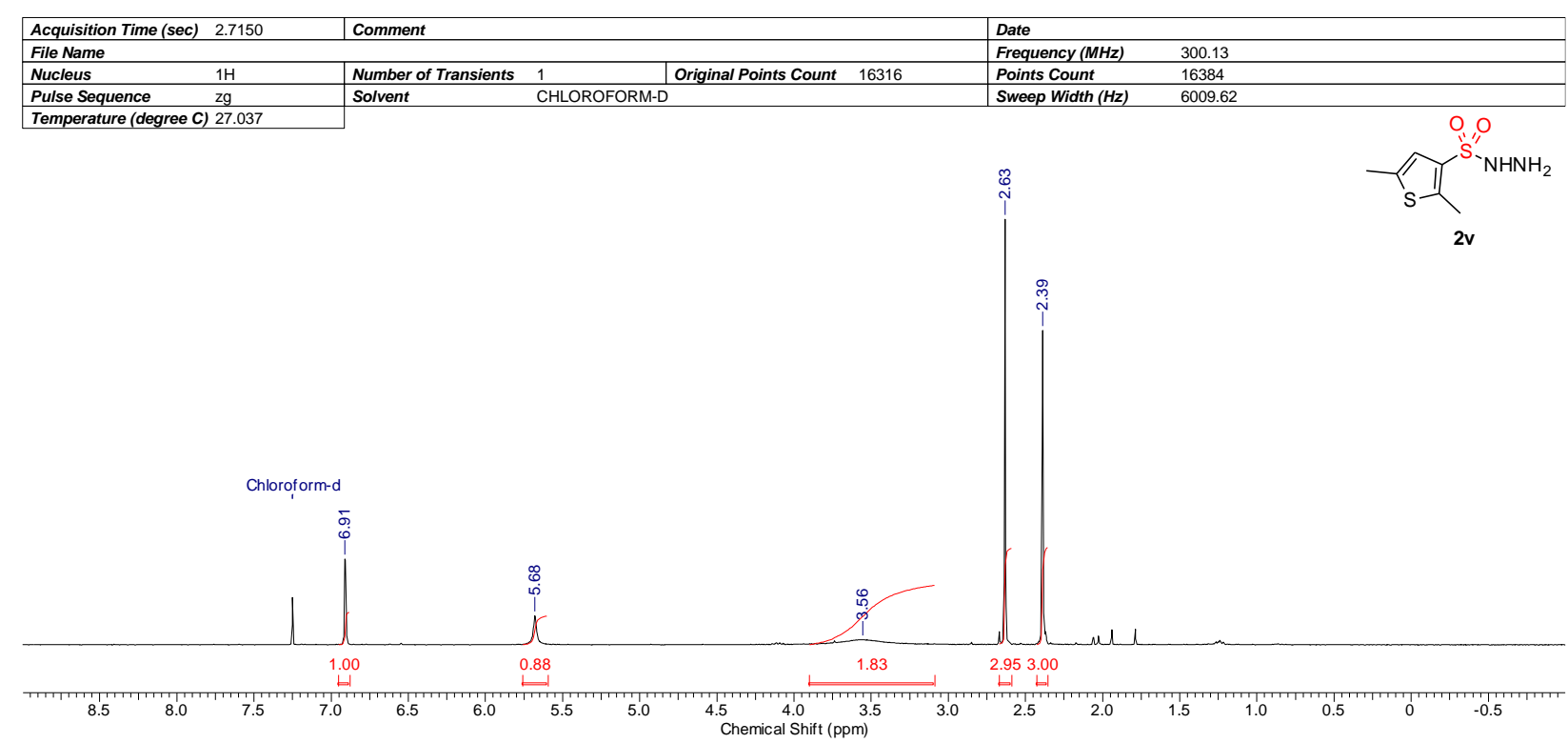

${ }^{1} \mathrm{H} \mathrm{NMR}\left(\mathrm{CDCl}_{3}\right), \delta: 2.39(\mathrm{~s}, 3 \mathrm{H}), 2.63(\mathrm{~s}, 3 \mathrm{H}), 3.56(\mathrm{br} \mathrm{s}, 2 \mathrm{H}), 5.68(\mathrm{~s}, 1 \mathrm{H}), 6.91(\mathrm{~s}, 1 \mathrm{H})$. 


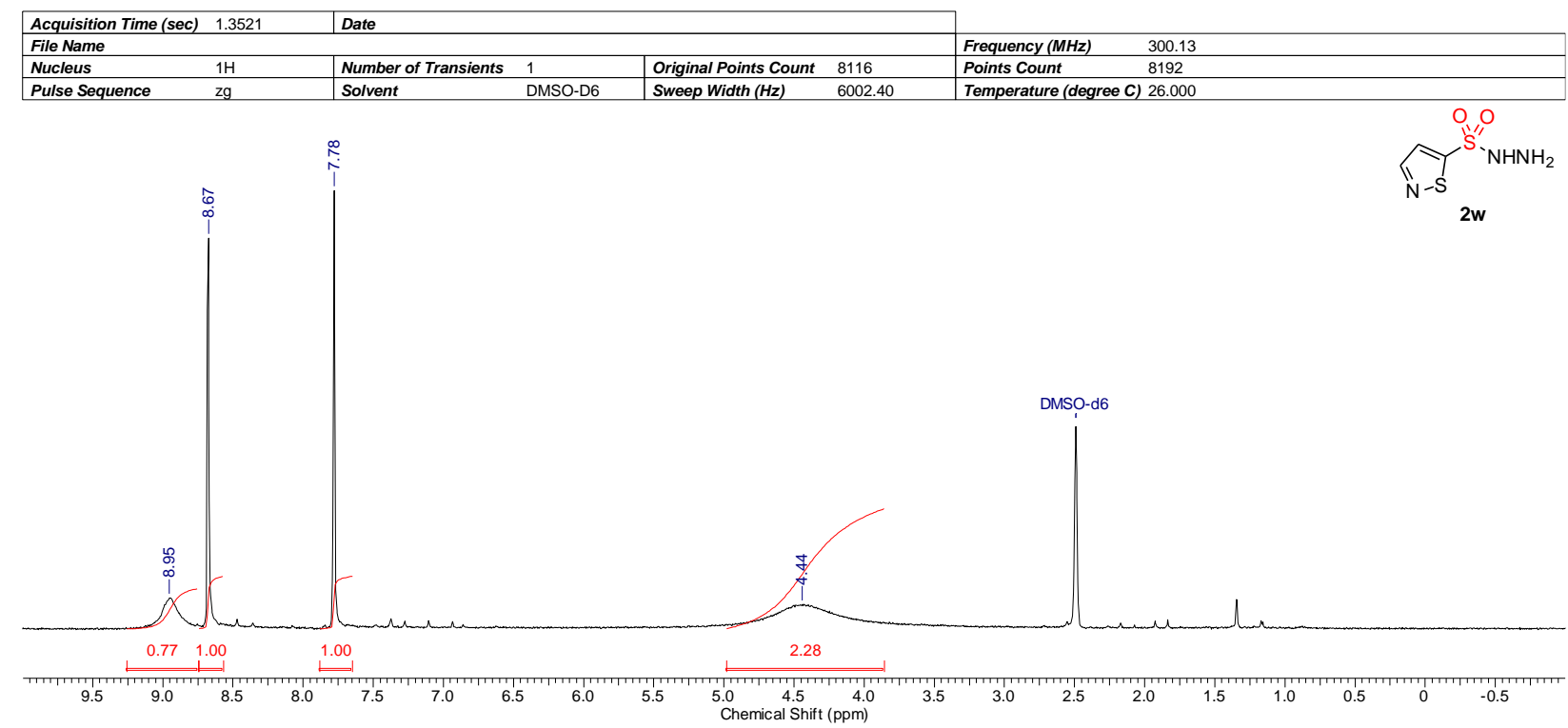

${ }^{1} \mathrm{H}$ NMR (DMSO-d $\mathrm{d}_{6}$ ), $\delta$ : 4.44 (br s, 2H), 7.78 (s, 1H), 8.67 (s, 1H), 8.95 (br s, 1H). 


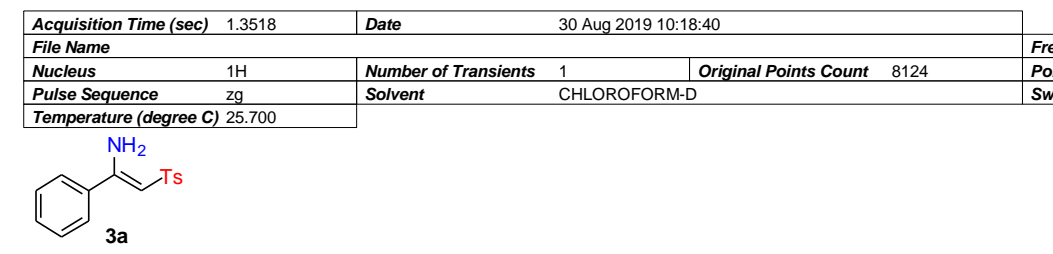

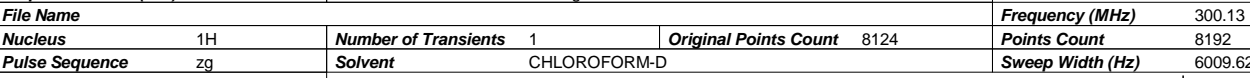

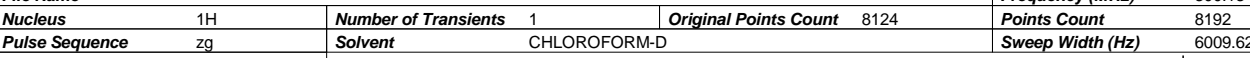

Temperature (degre
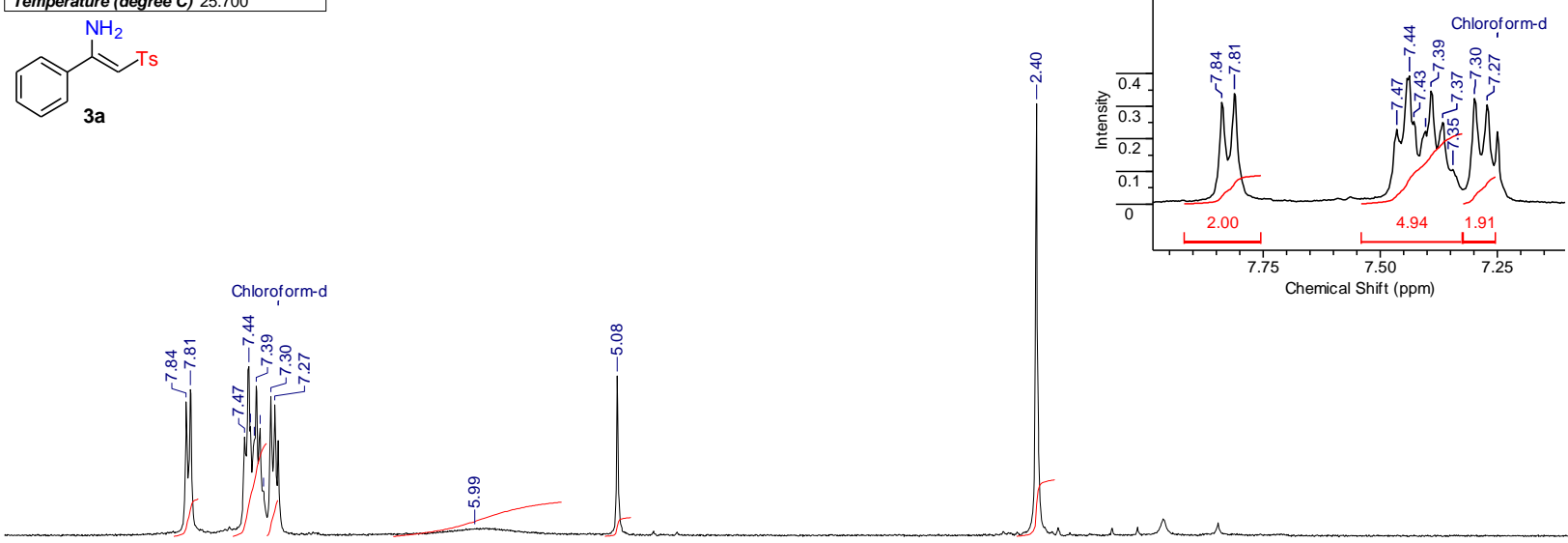

$200 \quad 4.94$

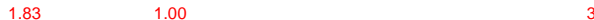

3.00

$8.5 \quad 8.0$

$7.5+1111011111$

Acquisition Time (sec) 0.9002 File Name

Pulse Sequence $13 \mathrm{C}$ 25.400 \begin{tabular}{|l} 
Number of \\
Solvent
\end{tabular}

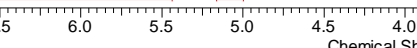
$5+111110$<smiles>[3H]C=C(N)c1ccccc1</smiles>

3a (degree C) 25.400 30 Aug 2019 12:01:04 Chemical Shift ( 3.5 


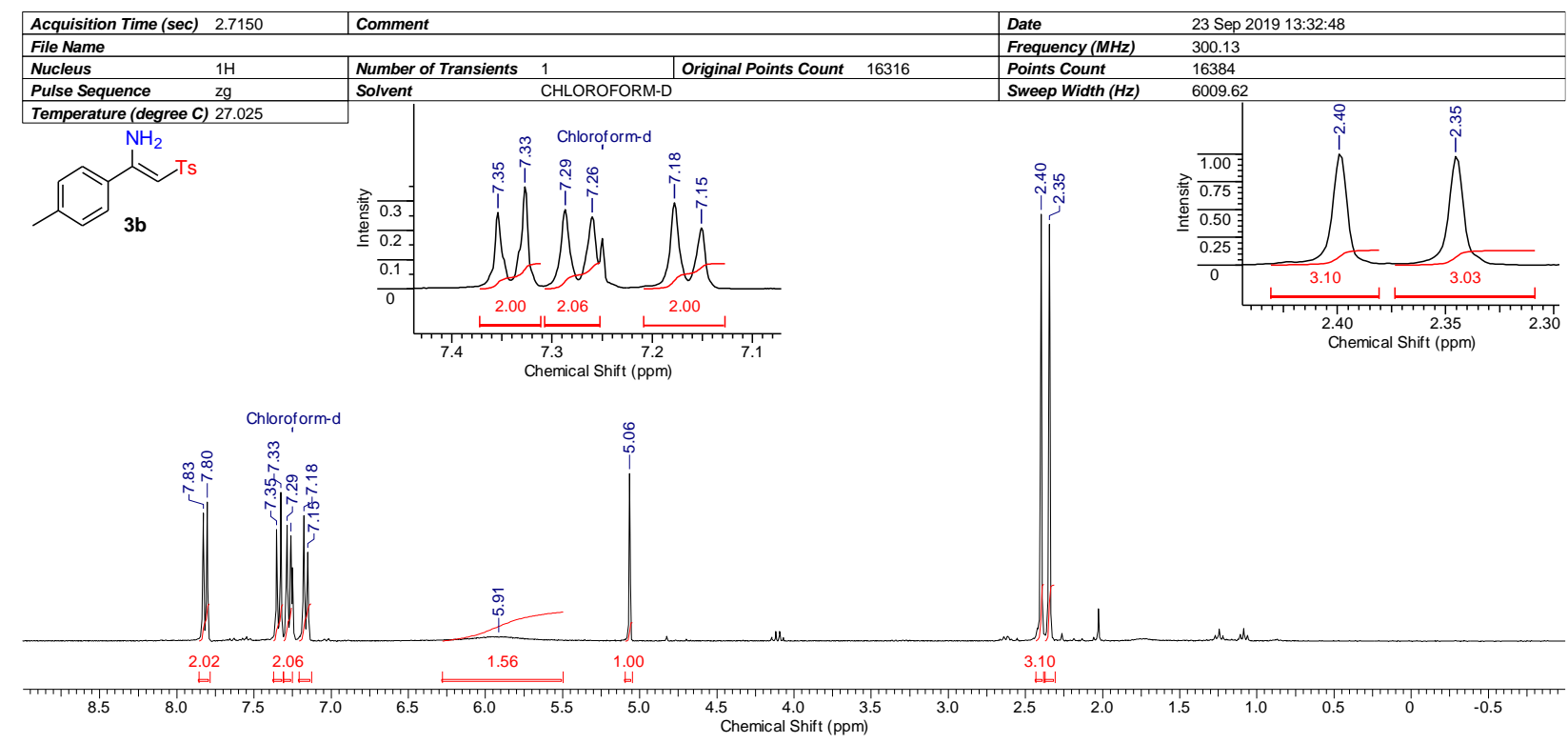

\begin{tabular}{|c|c|c|c|c|c|}
\hline \multirow{2}{*}{\multicolumn{6}{|c|}{ File Name }} \\
\hline & & & & & \\
\hline Nucleus & $13 \mathrm{C}$ & Number of Transients & 160 & Original Points Count & 16316 \\
\hline Pulse Sequence & zgpg30 & Solvent & $\mathrm{CHL}$ & & \\
\hline
\end{tabular}

Temperature (degree C) 27.029 Solvent CHLOROFORM-D<smiles>[3H]C=C(N)c1ccc(C)cc1</smiles>

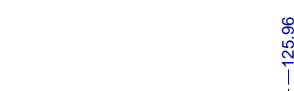

$3 b$

@̊.

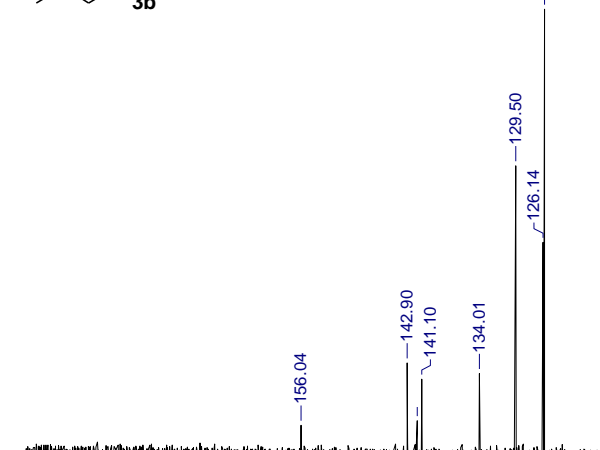

Date \begin{tabular}{|ll}
\hline Frequency $(\mathbf{M H z})$ & 75.48 \\
\hline Points Count & 16384
\end{tabular} $\begin{array}{ll}\text { Points Count } & 16384 \\ \text { Sweep Width }(\mathrm{Hz}) & 18028.85\end{array}$

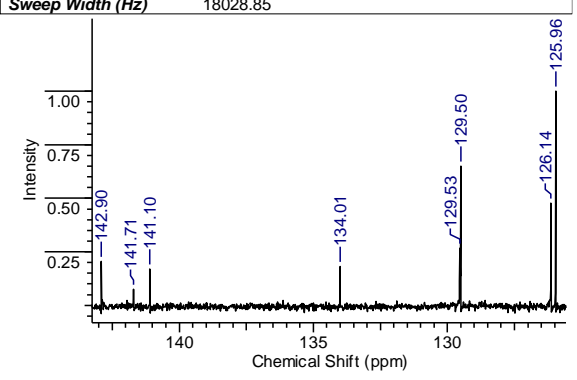

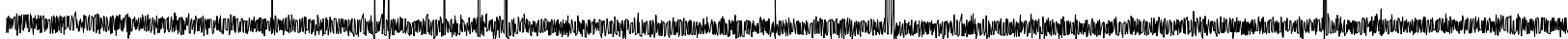

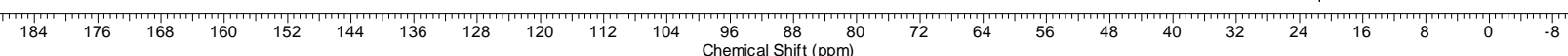



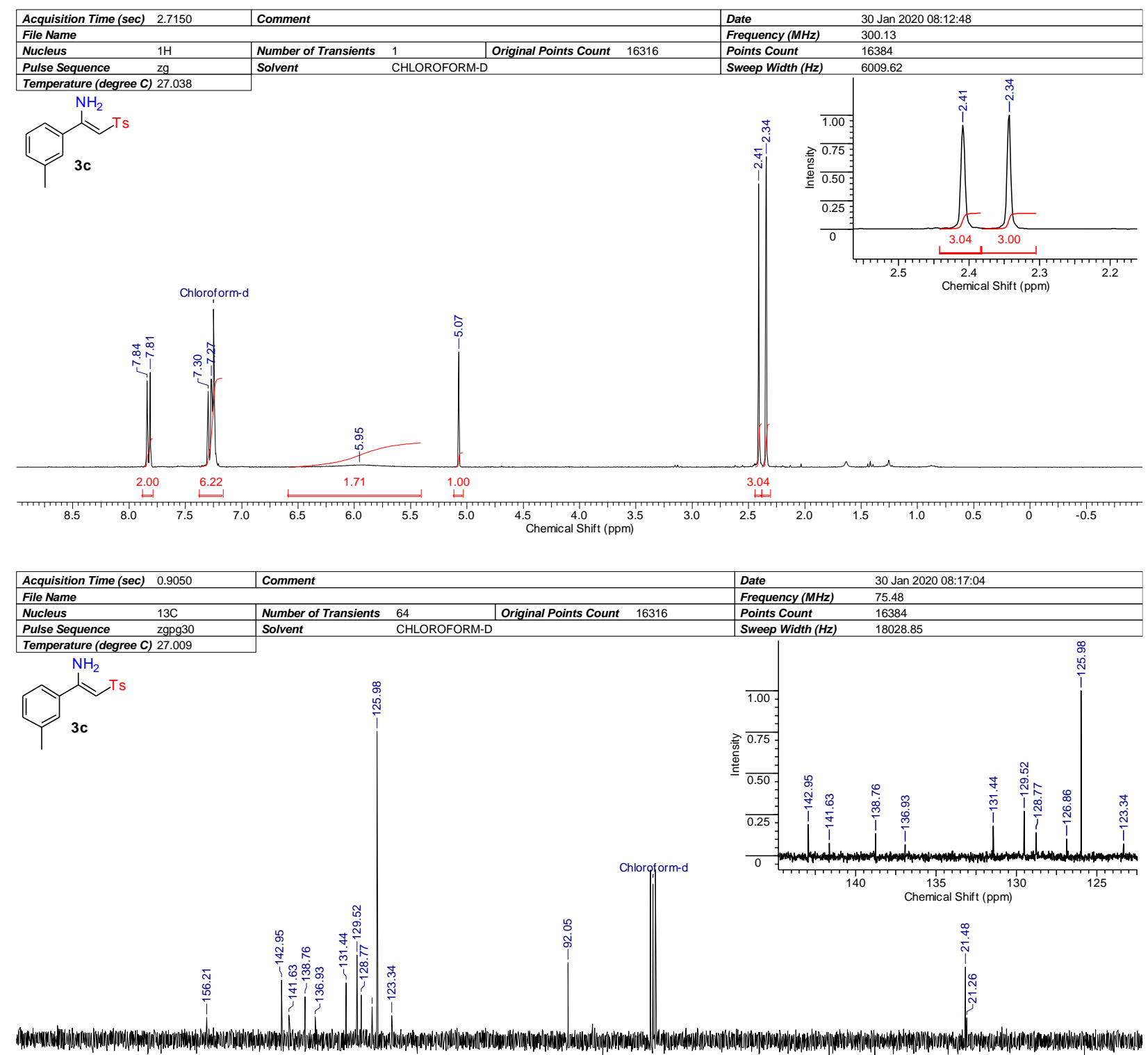

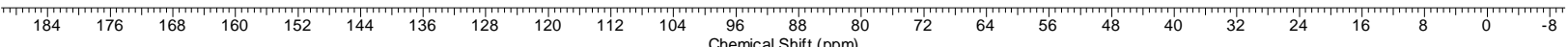



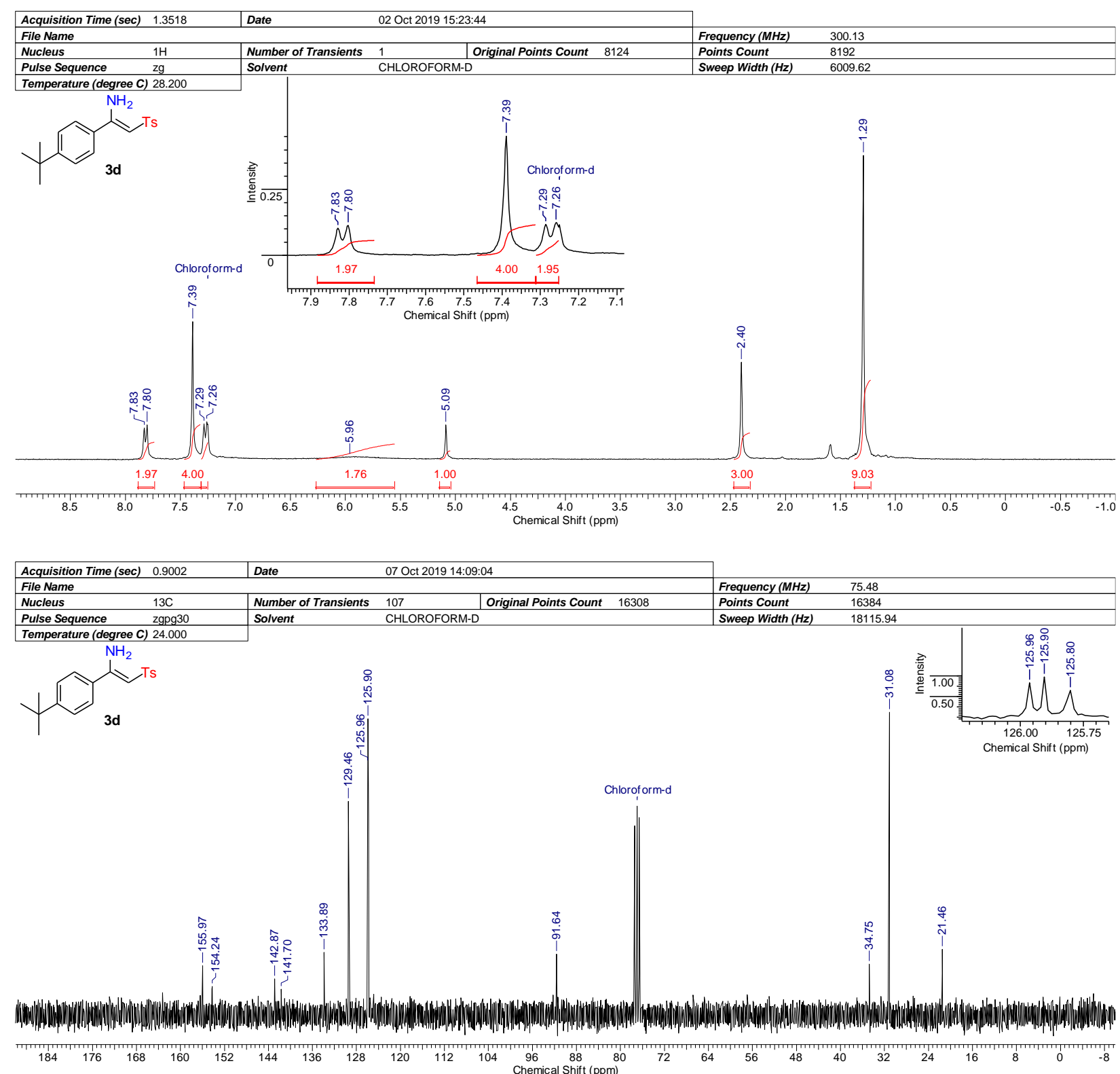


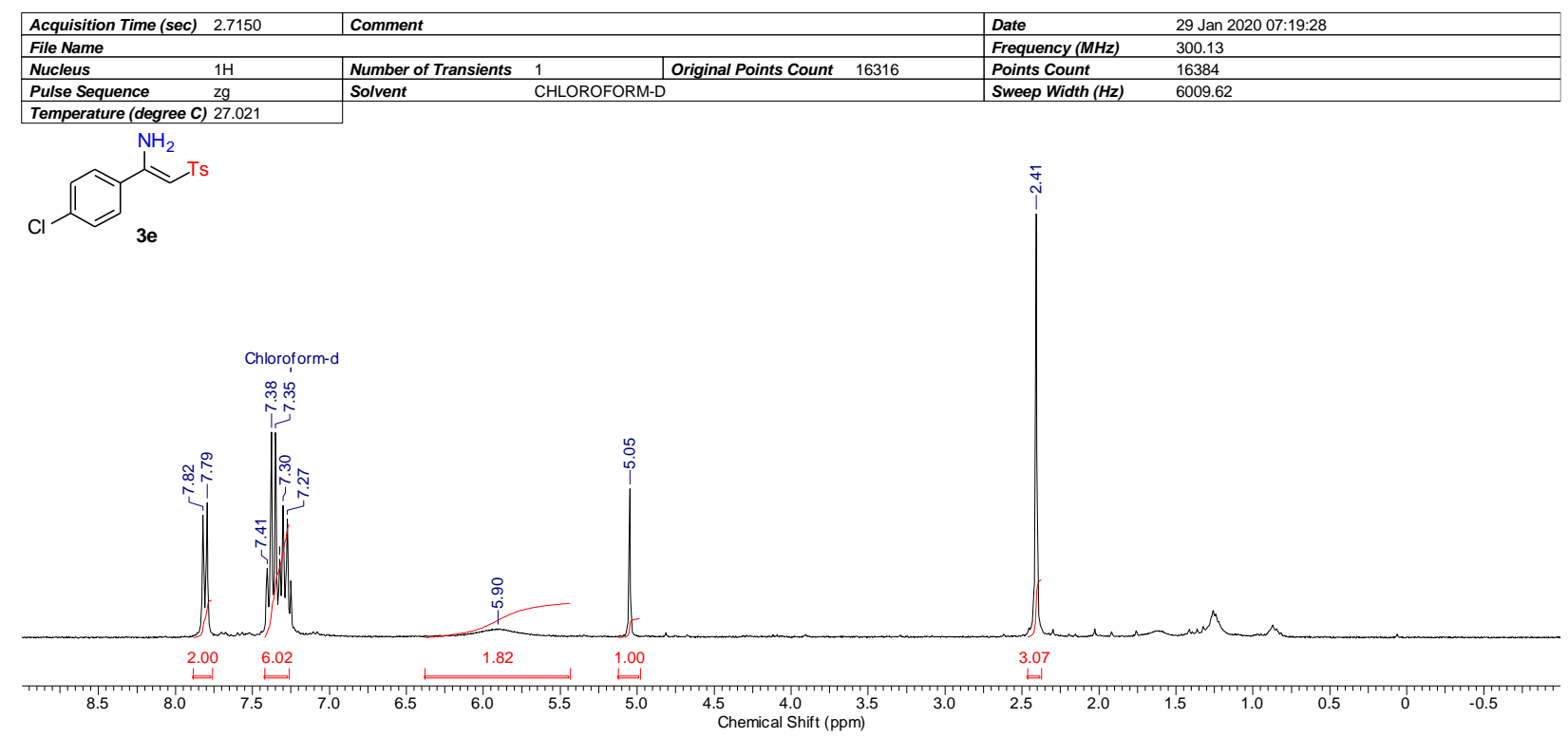

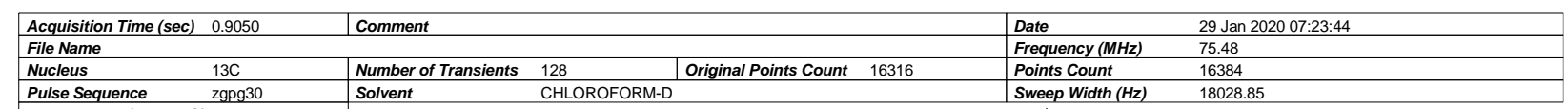
\begin{tabular}{|l|l|l}
\hline Pulse Sequence $\quad$ zgpg30 \\
\hline Temperature (degree $\mathrm{C}$ ) 26.997
\end{tabular} Solvent

Points Count $\quad 16384$

Temperature (degree
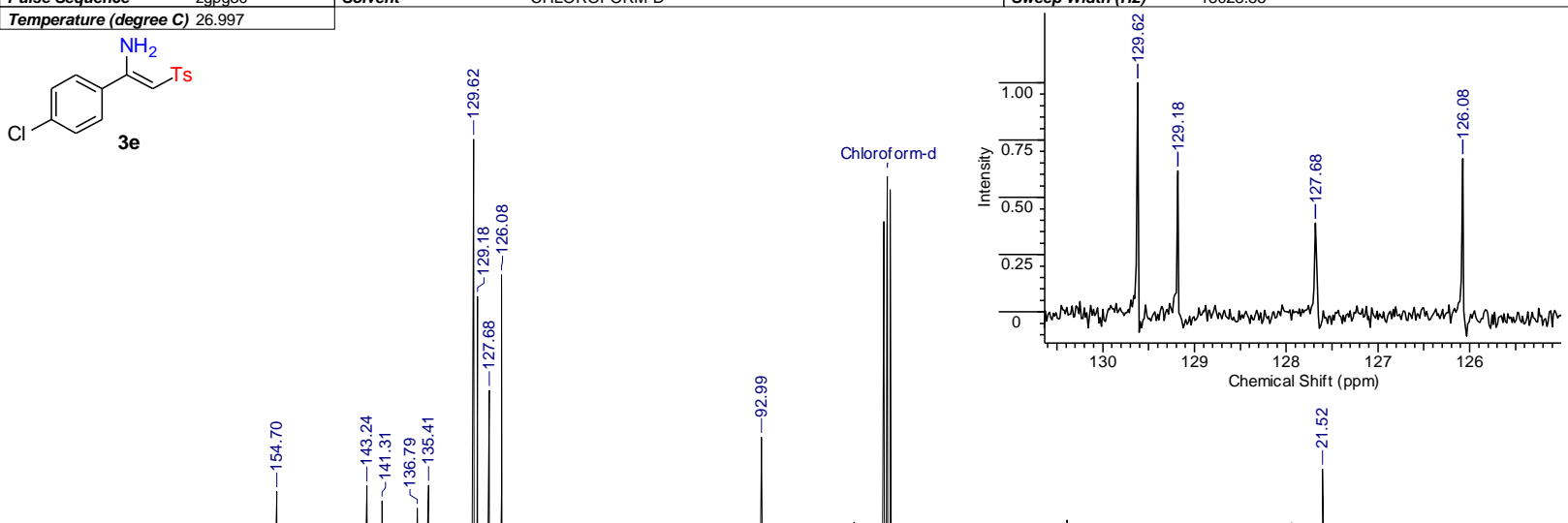

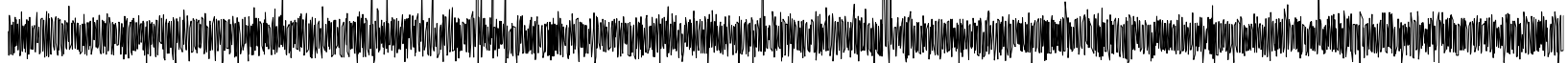

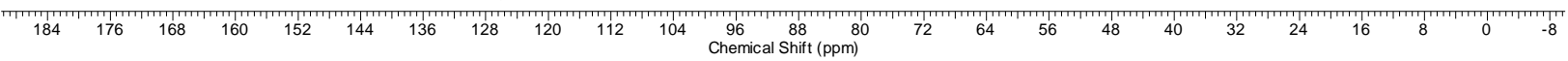



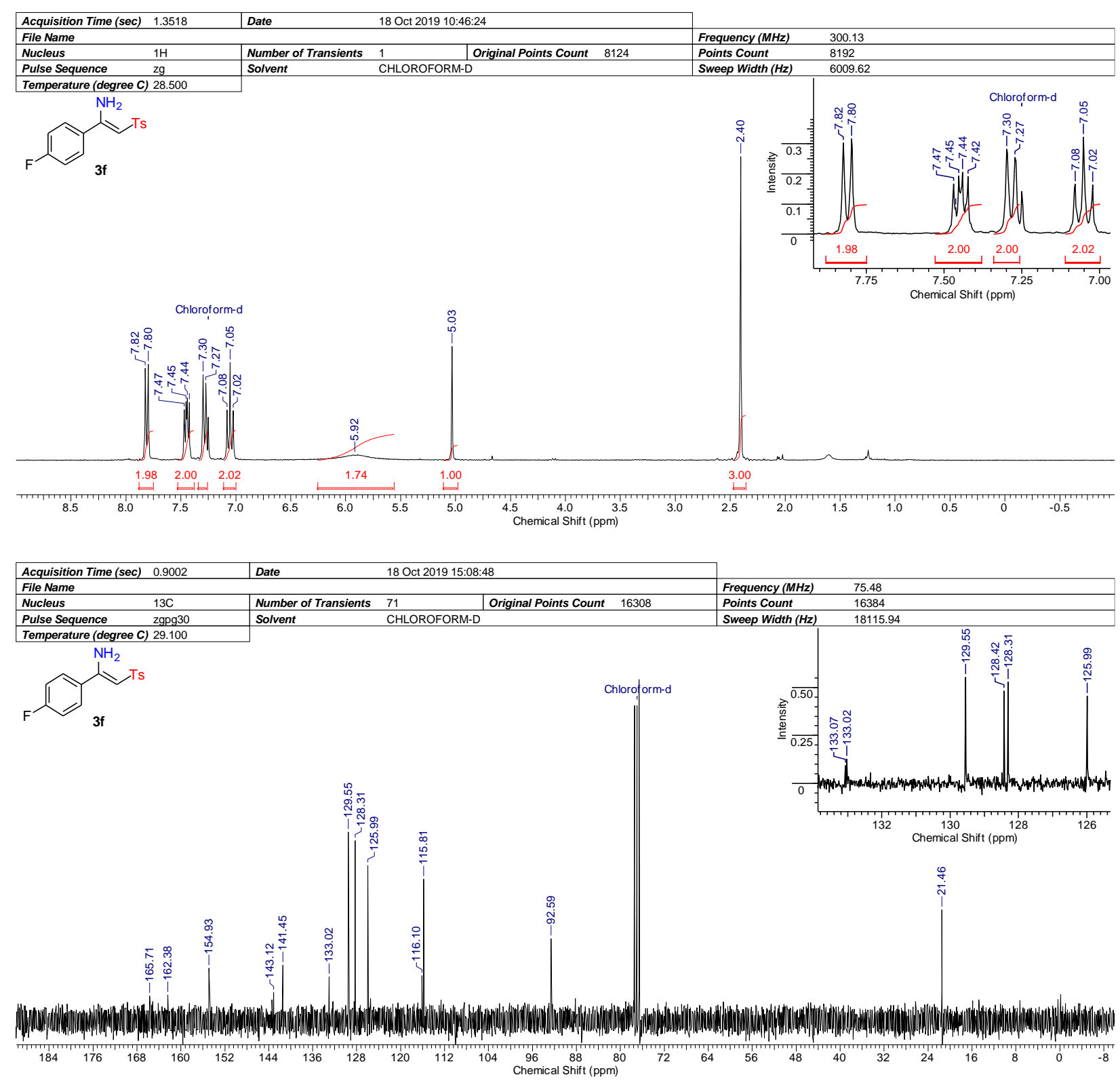

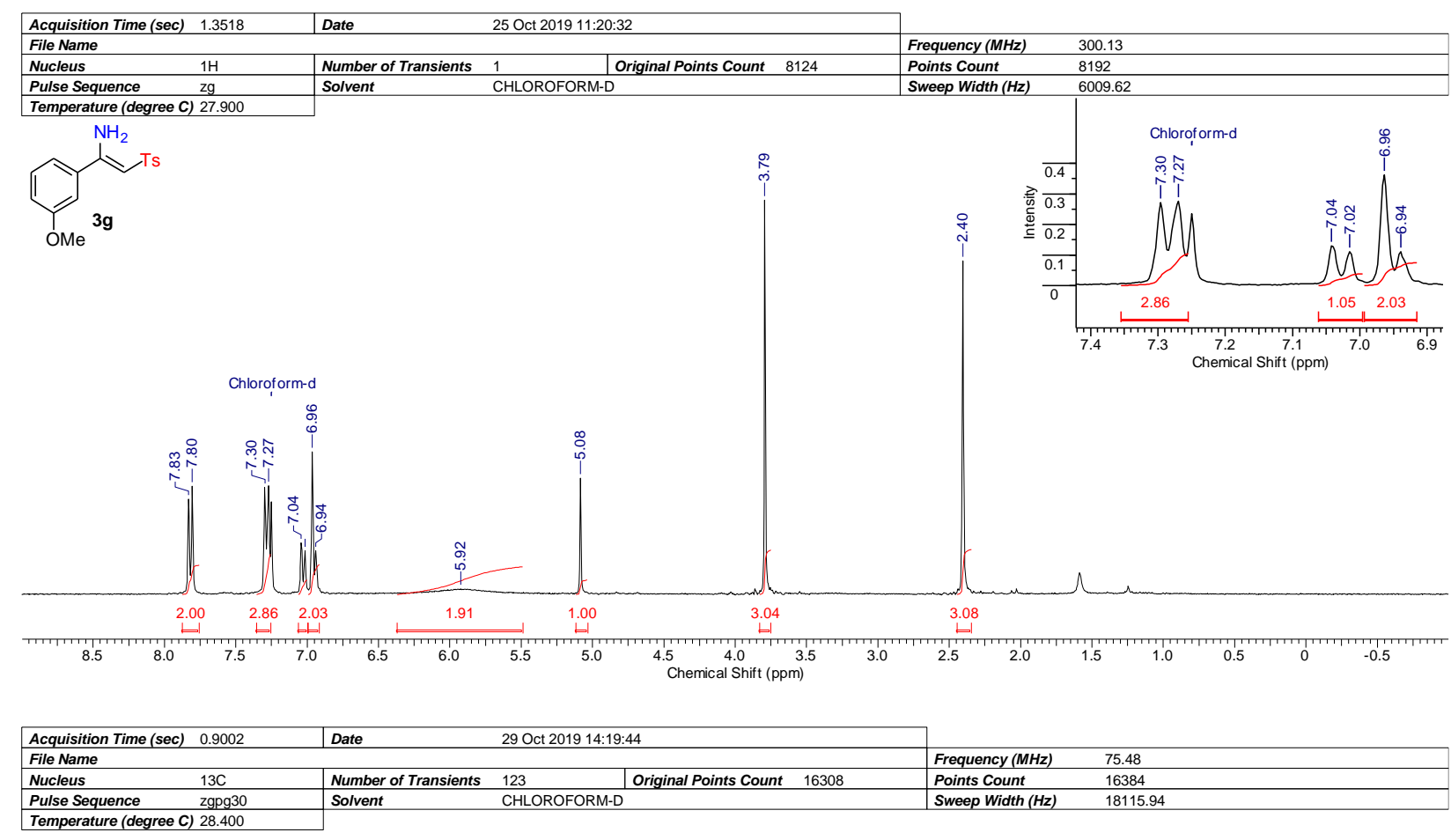<smiles>COc1cccc(/C(N)=C/[Hg])c1</smiles>

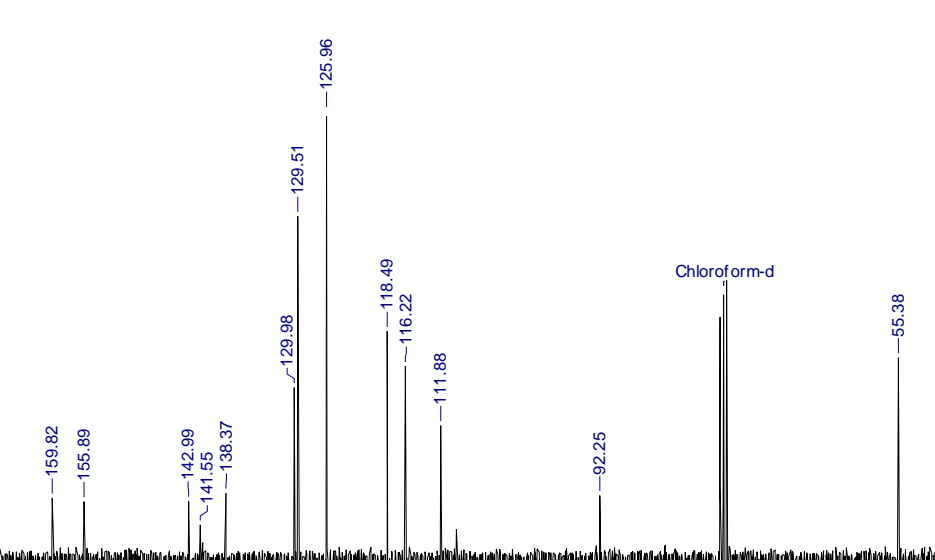

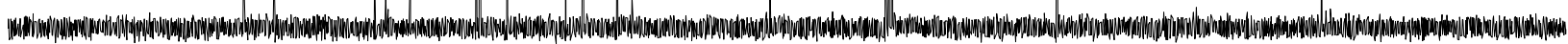

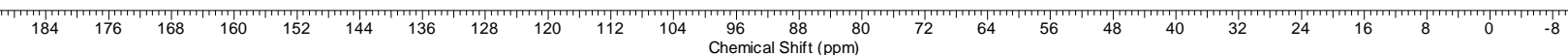



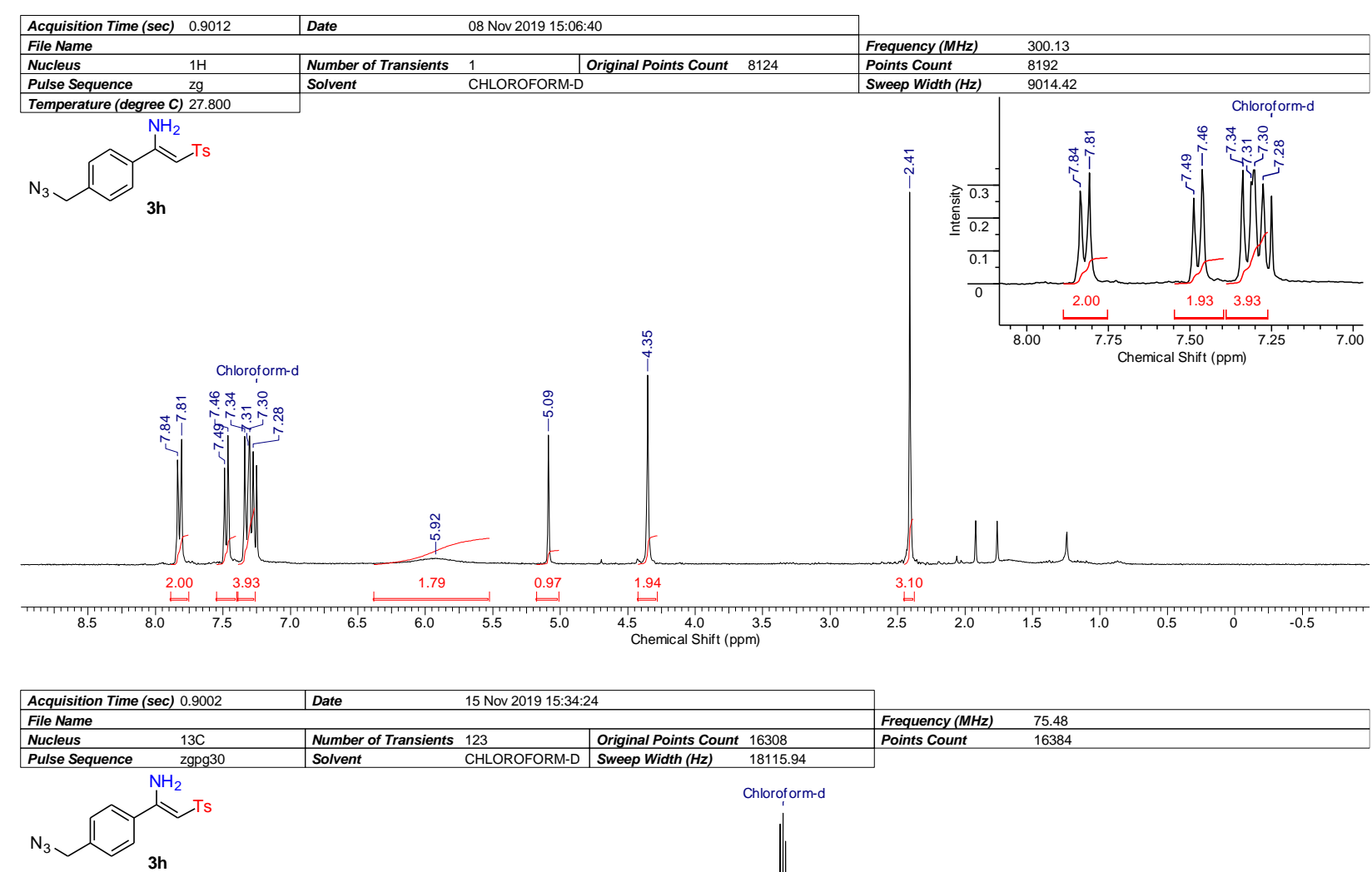

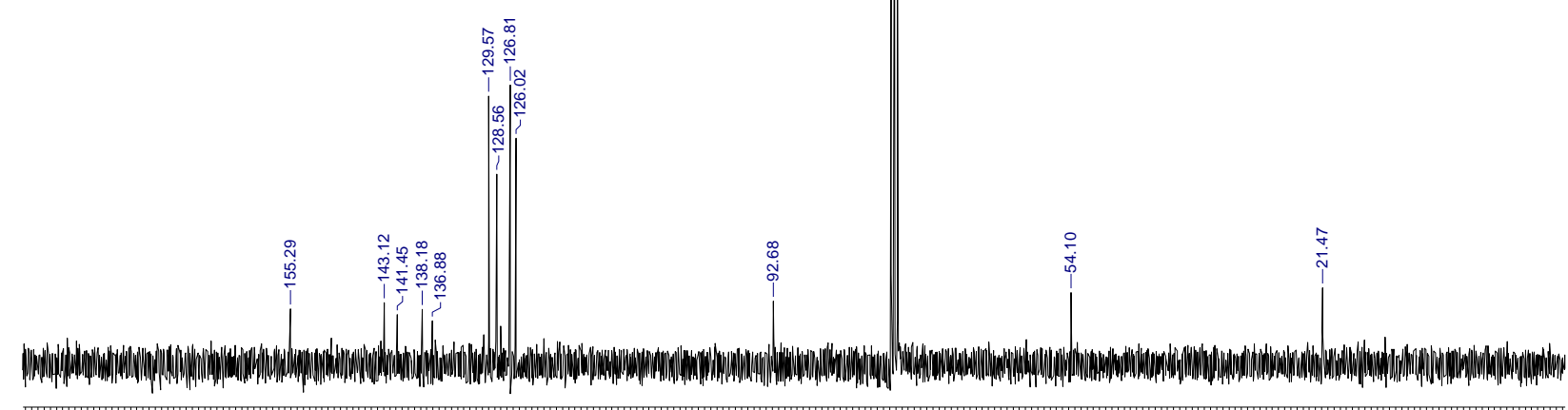

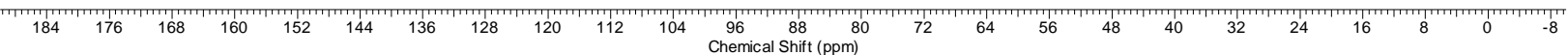



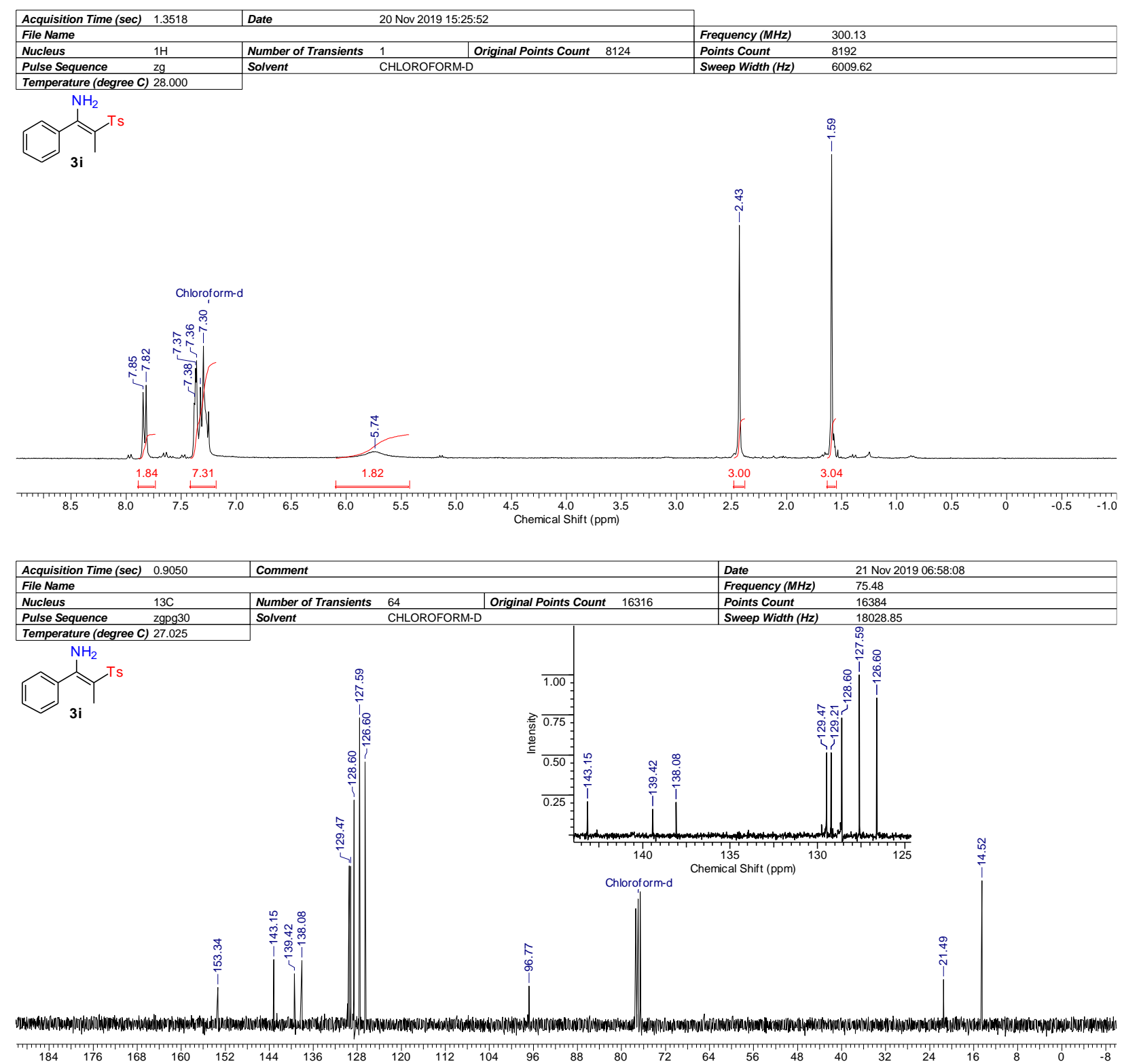

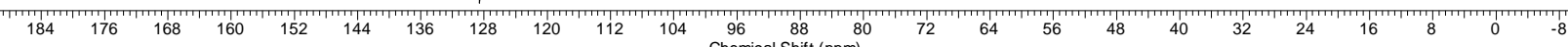



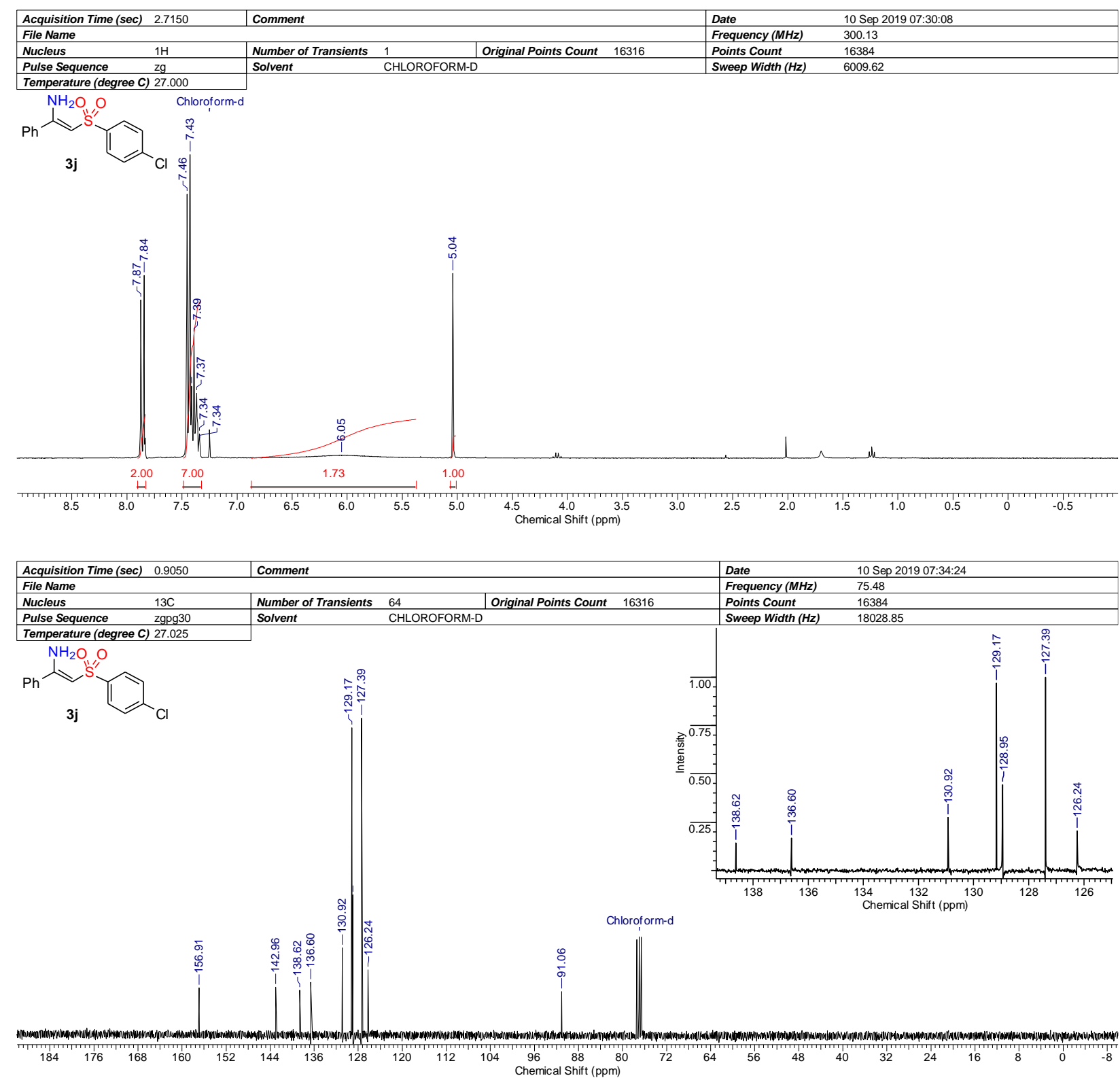

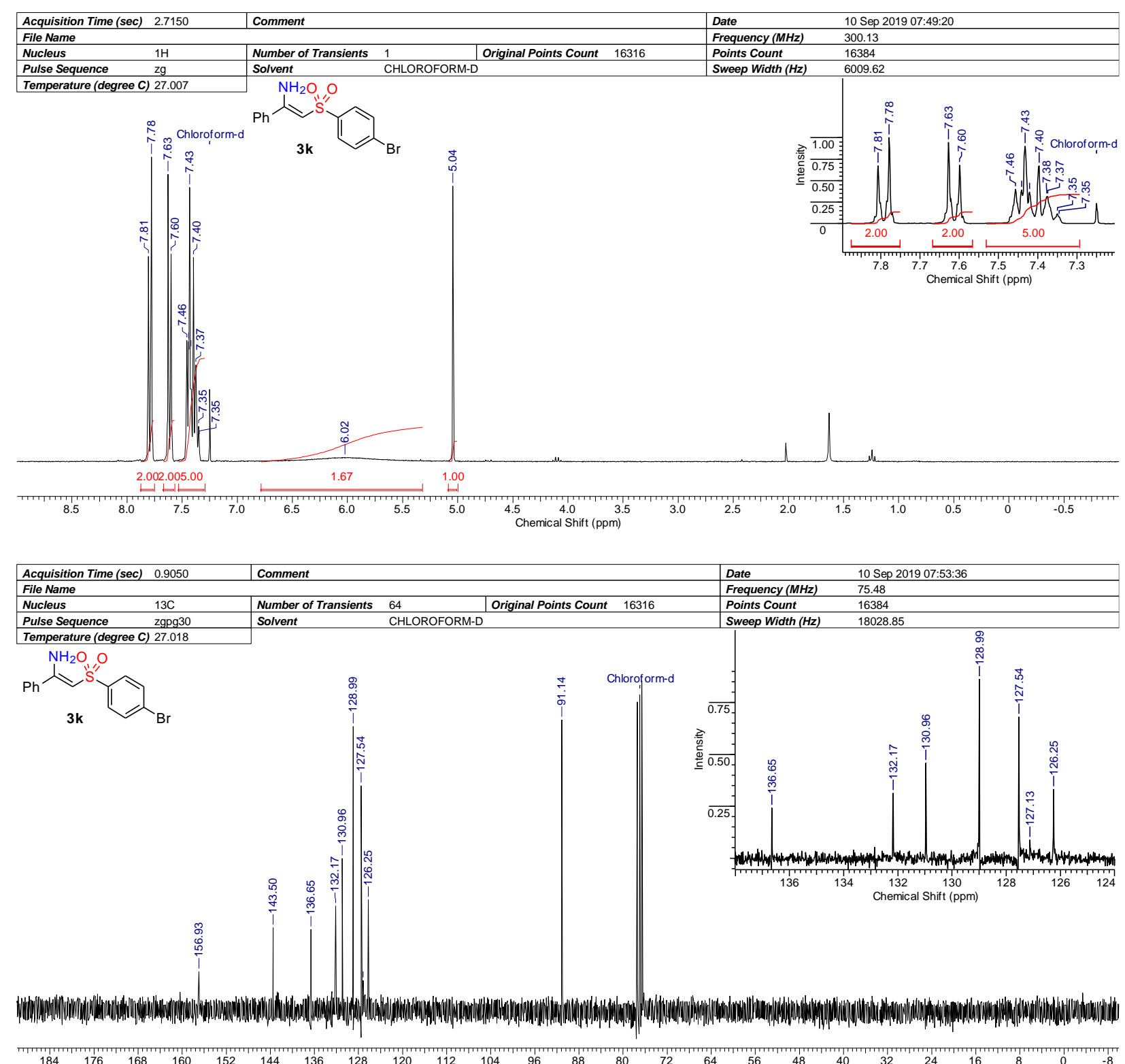

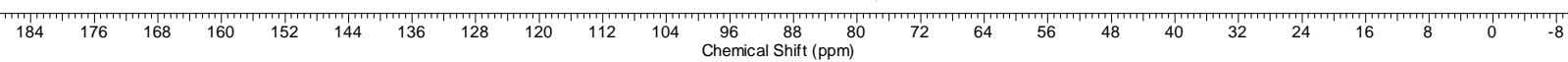



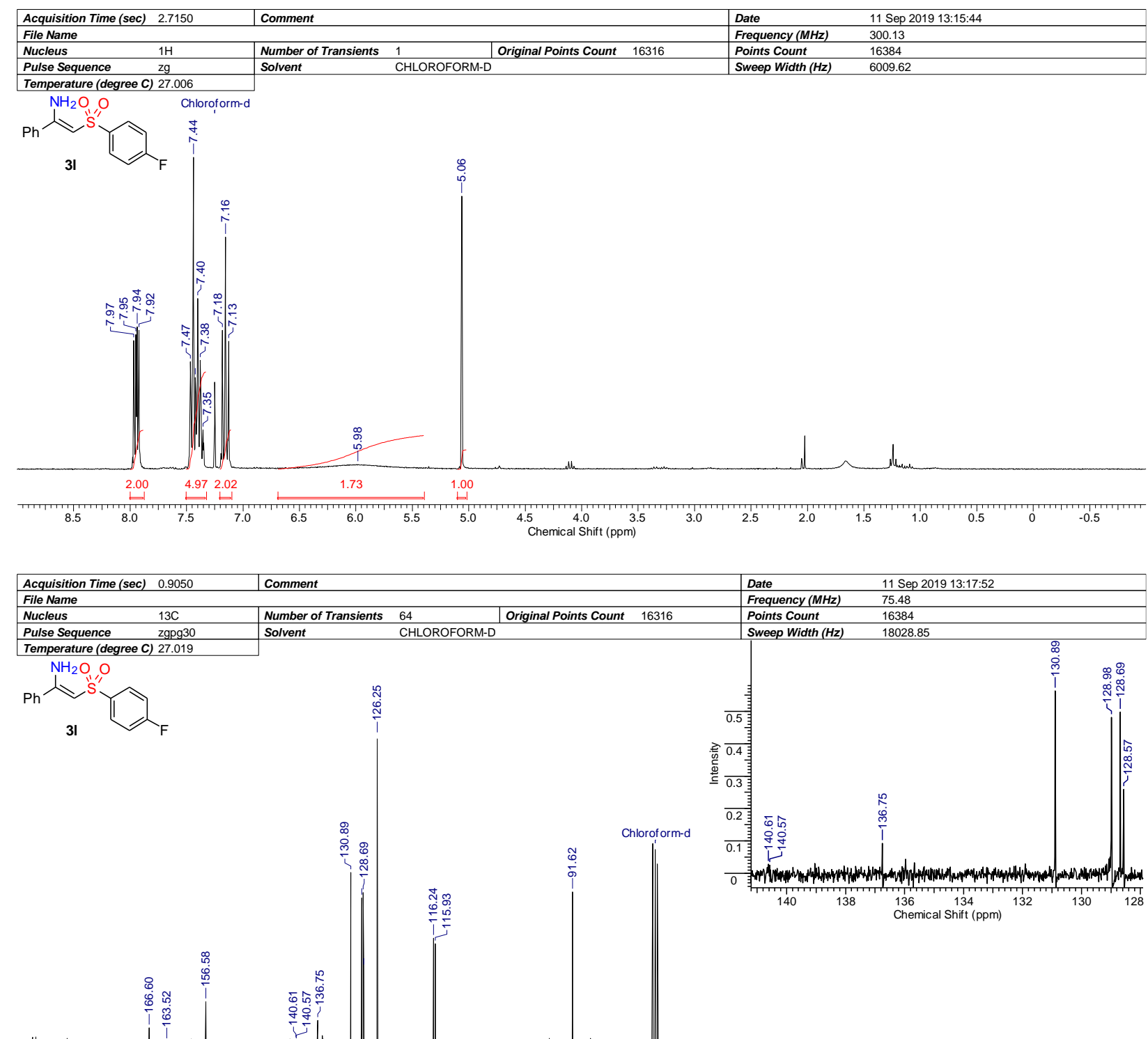

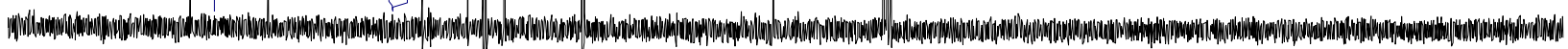

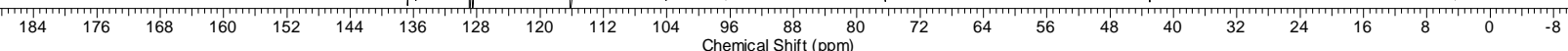



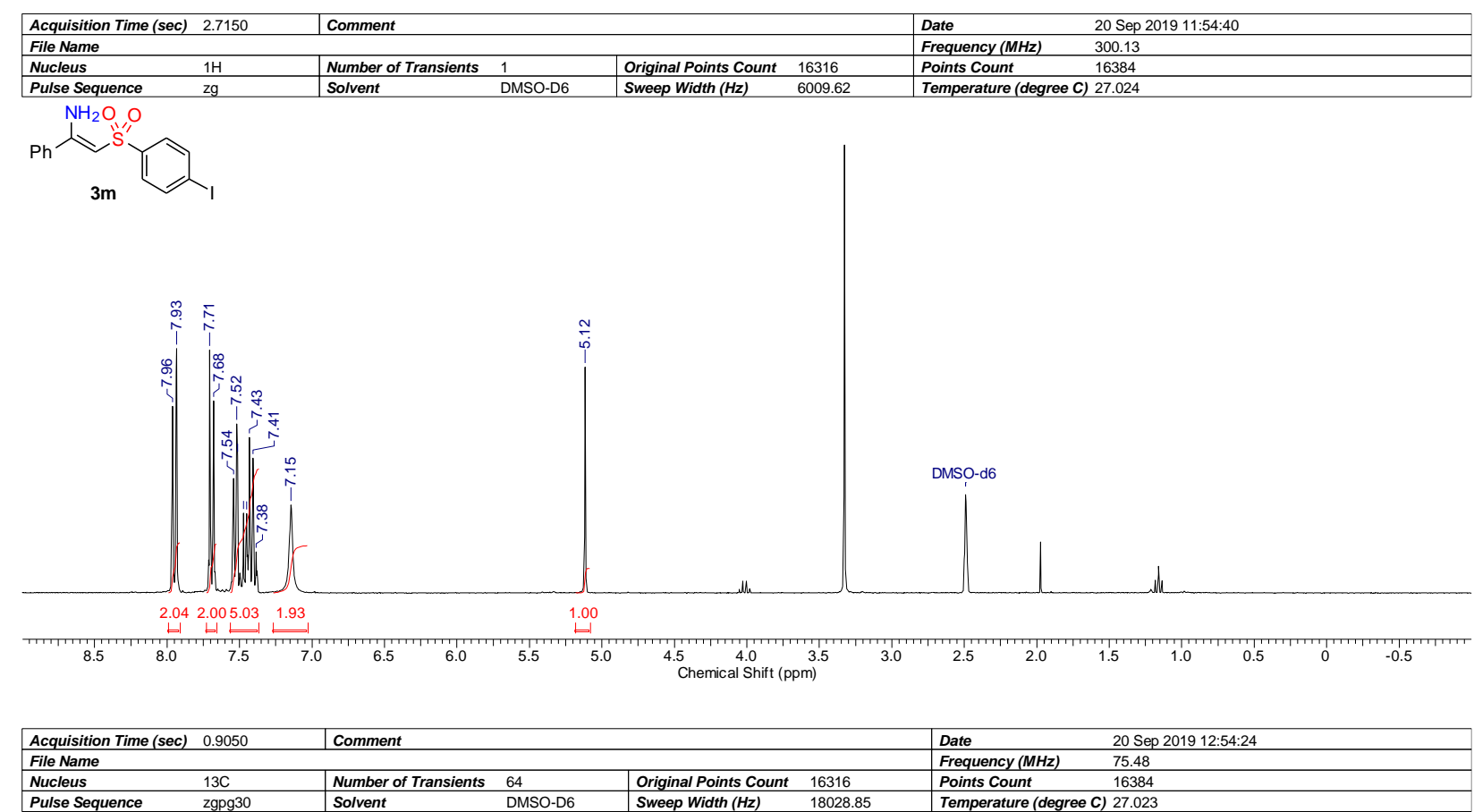

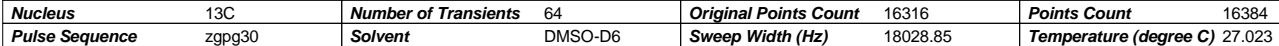

$\mathrm{NH}_{2}$

管

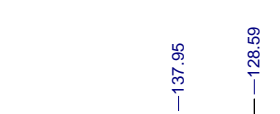

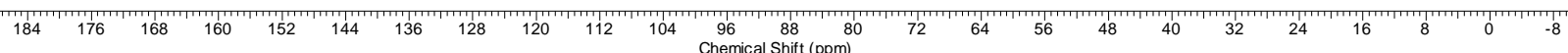




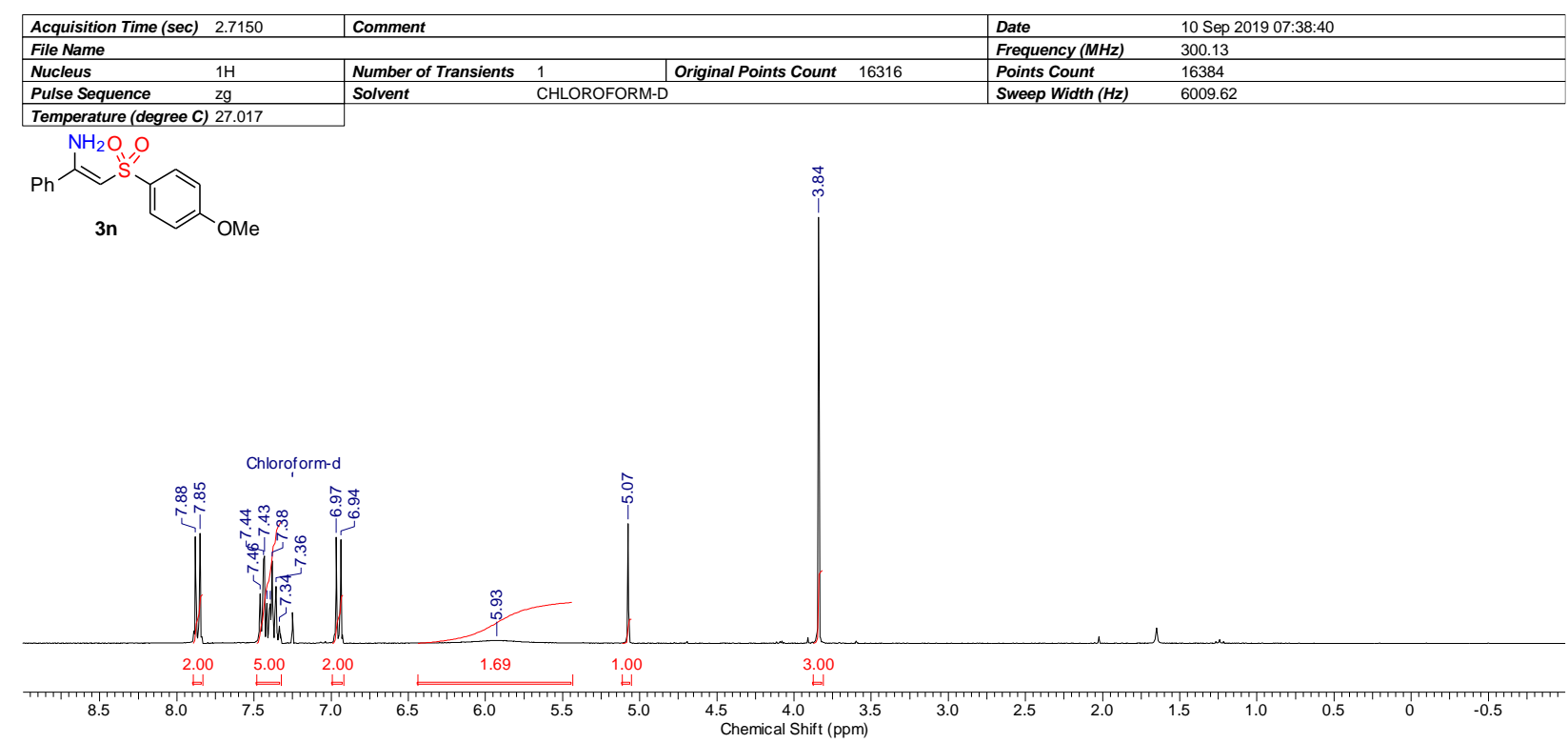

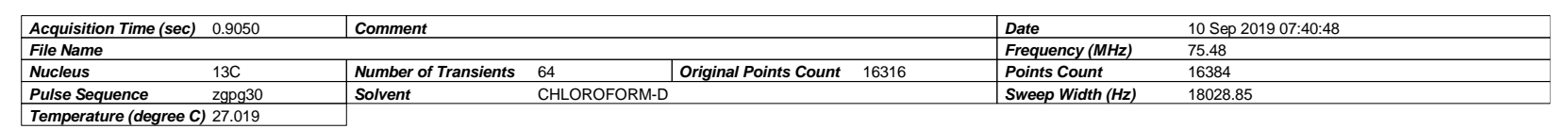
Temperature (degree $C) 27.019$<smiles>COc1ccc(S(=O)(=O)/C=C(\N)c2ccccc2)cc1</smiles>

$3 n$

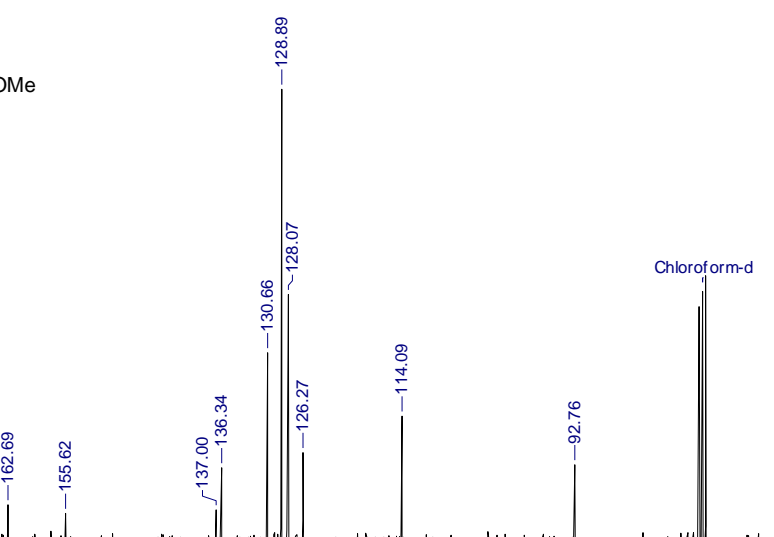

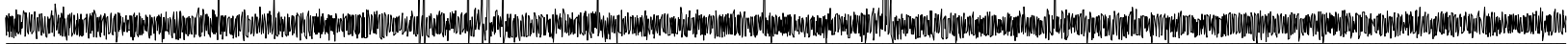

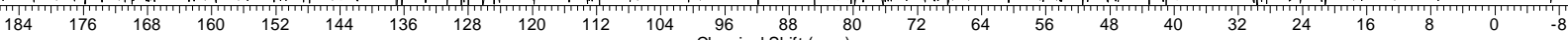



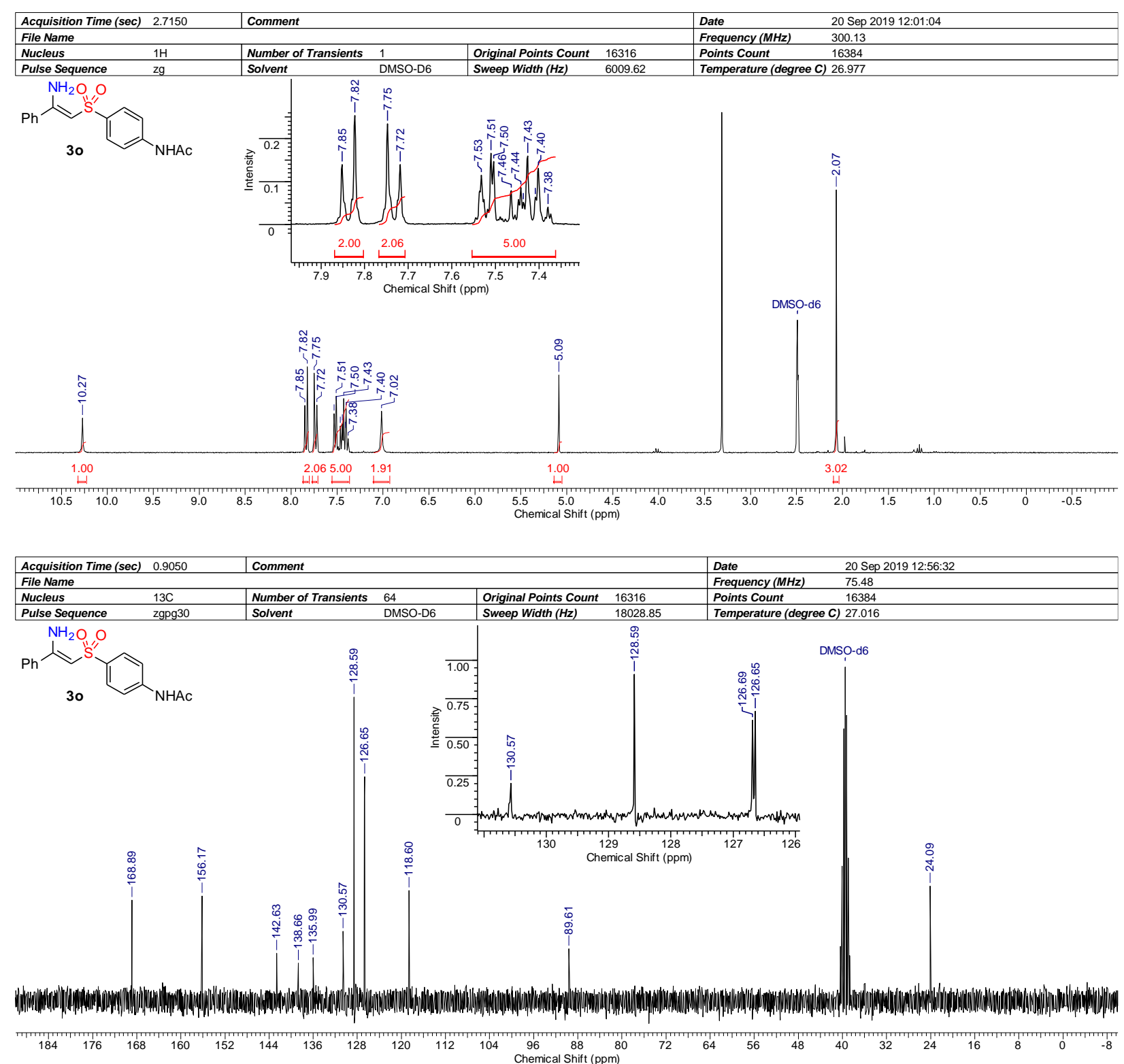

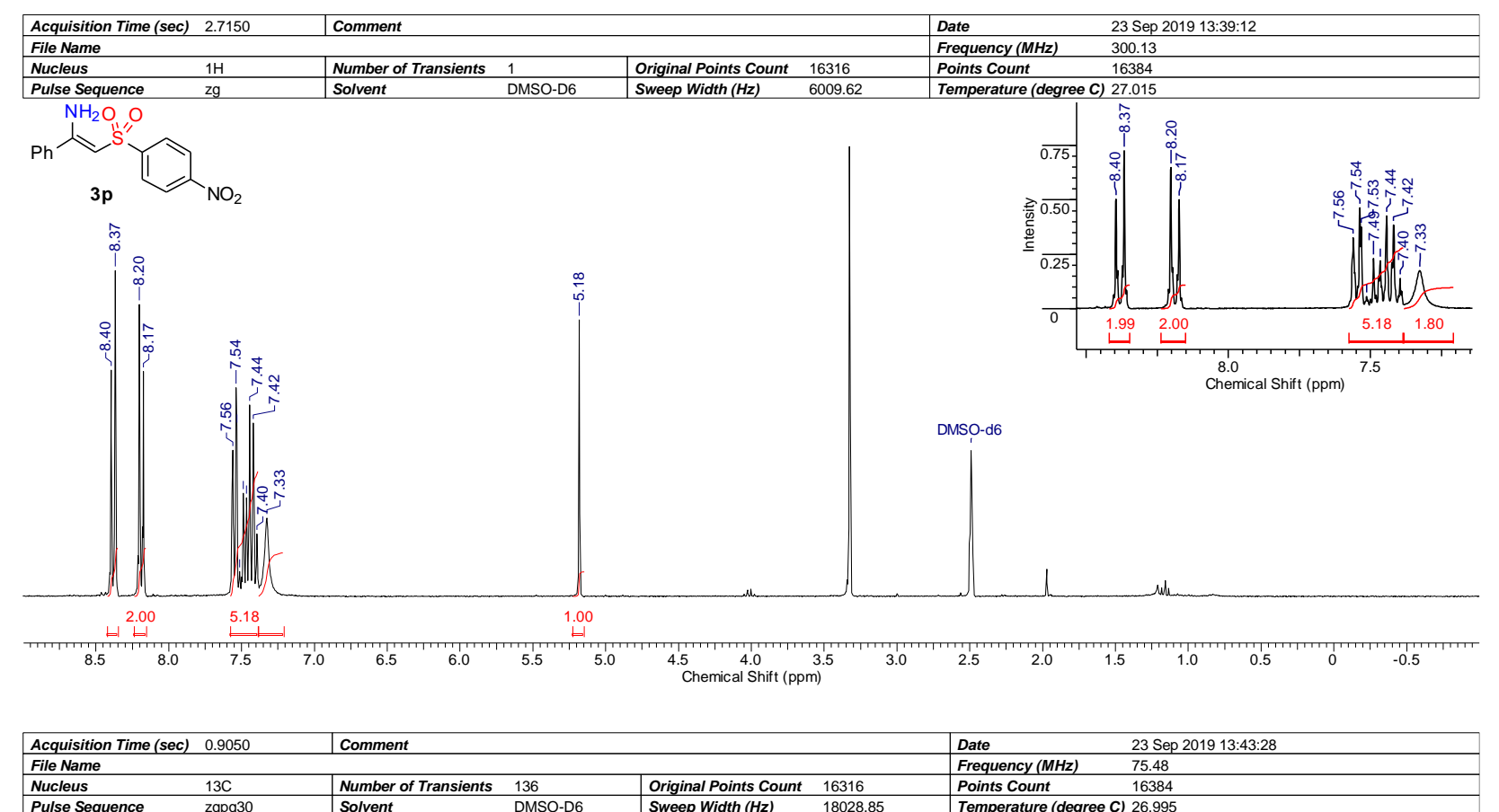

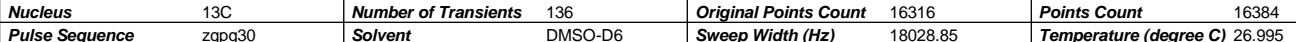

人" "s"

$3 p$
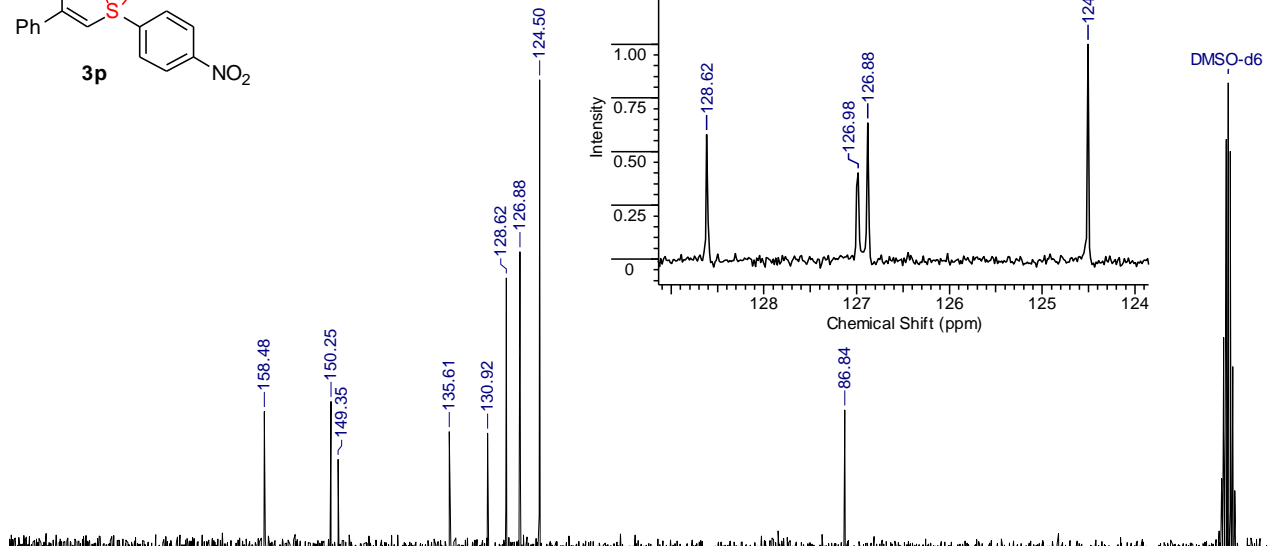

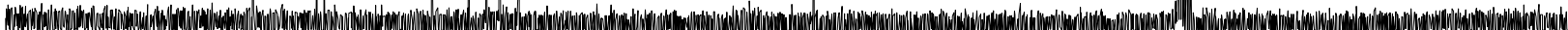

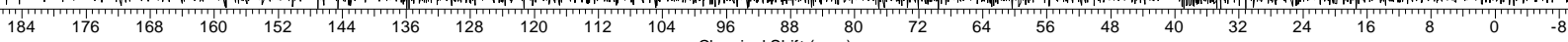



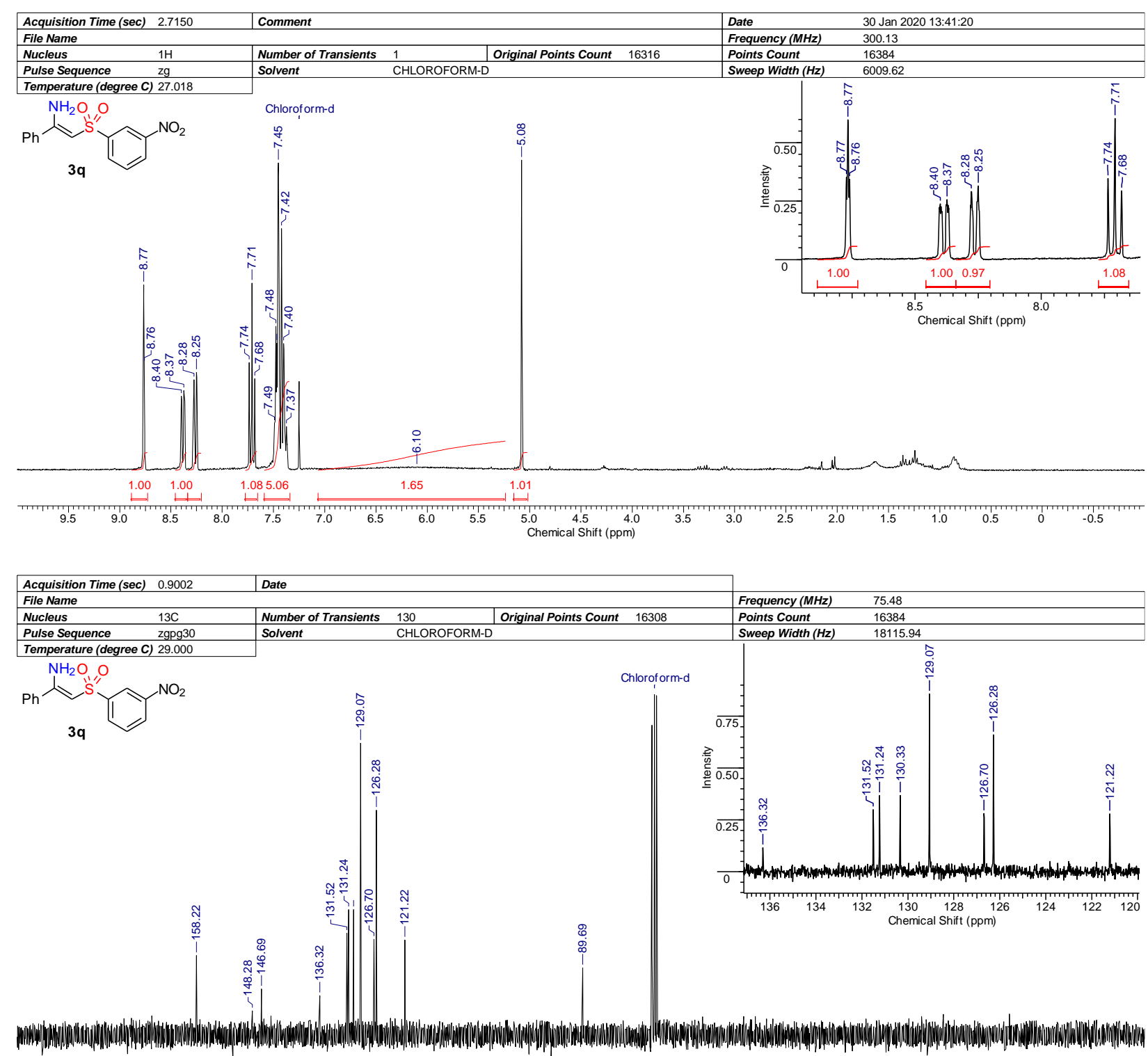

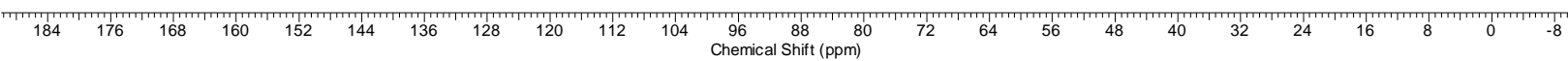



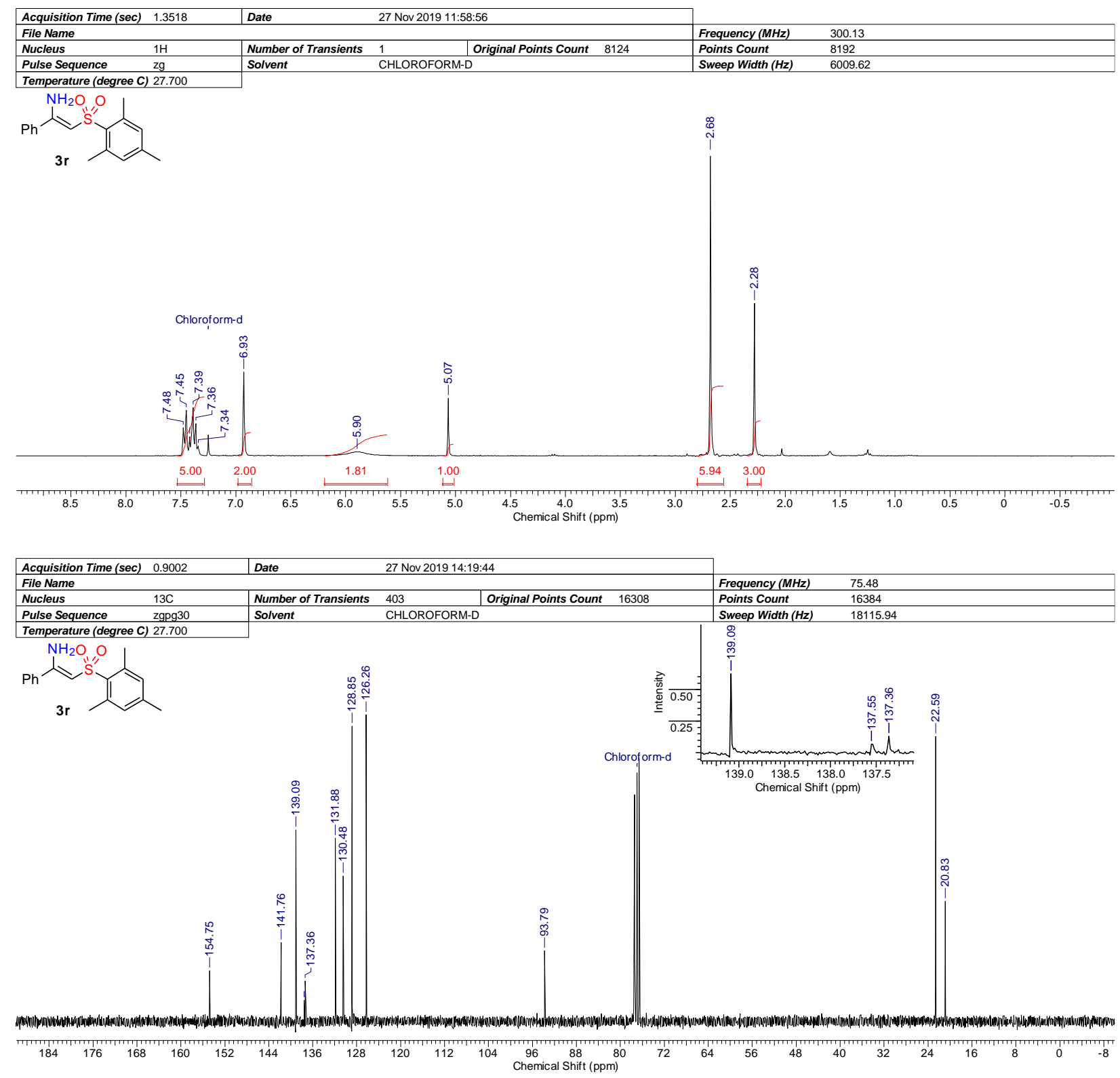

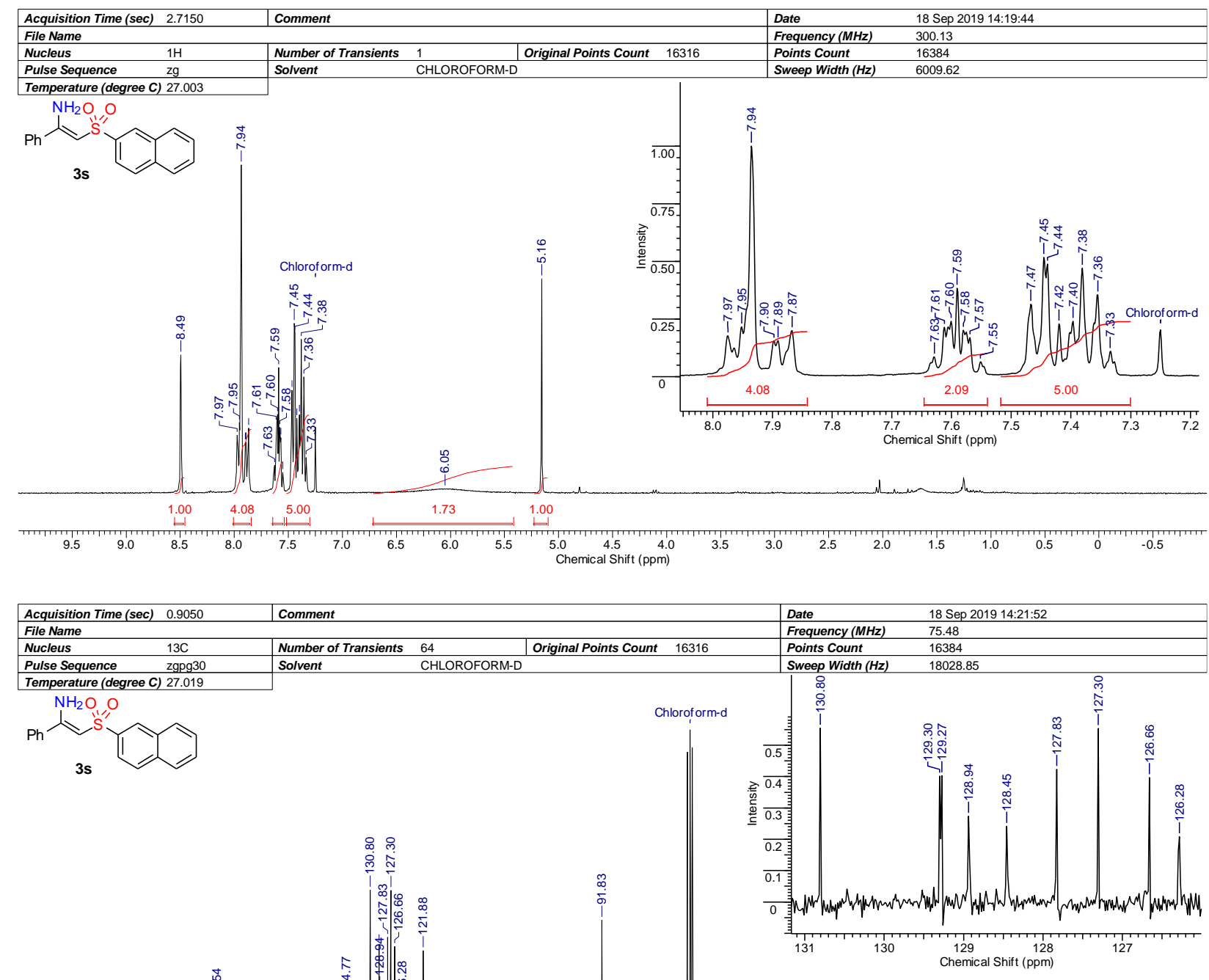

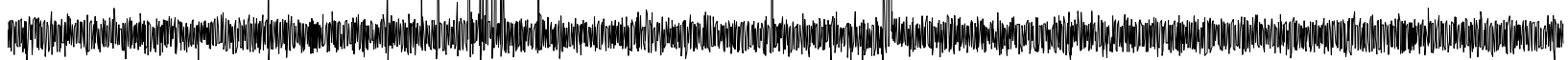

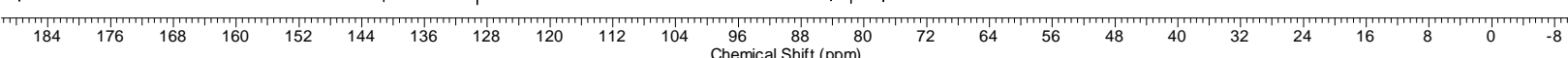



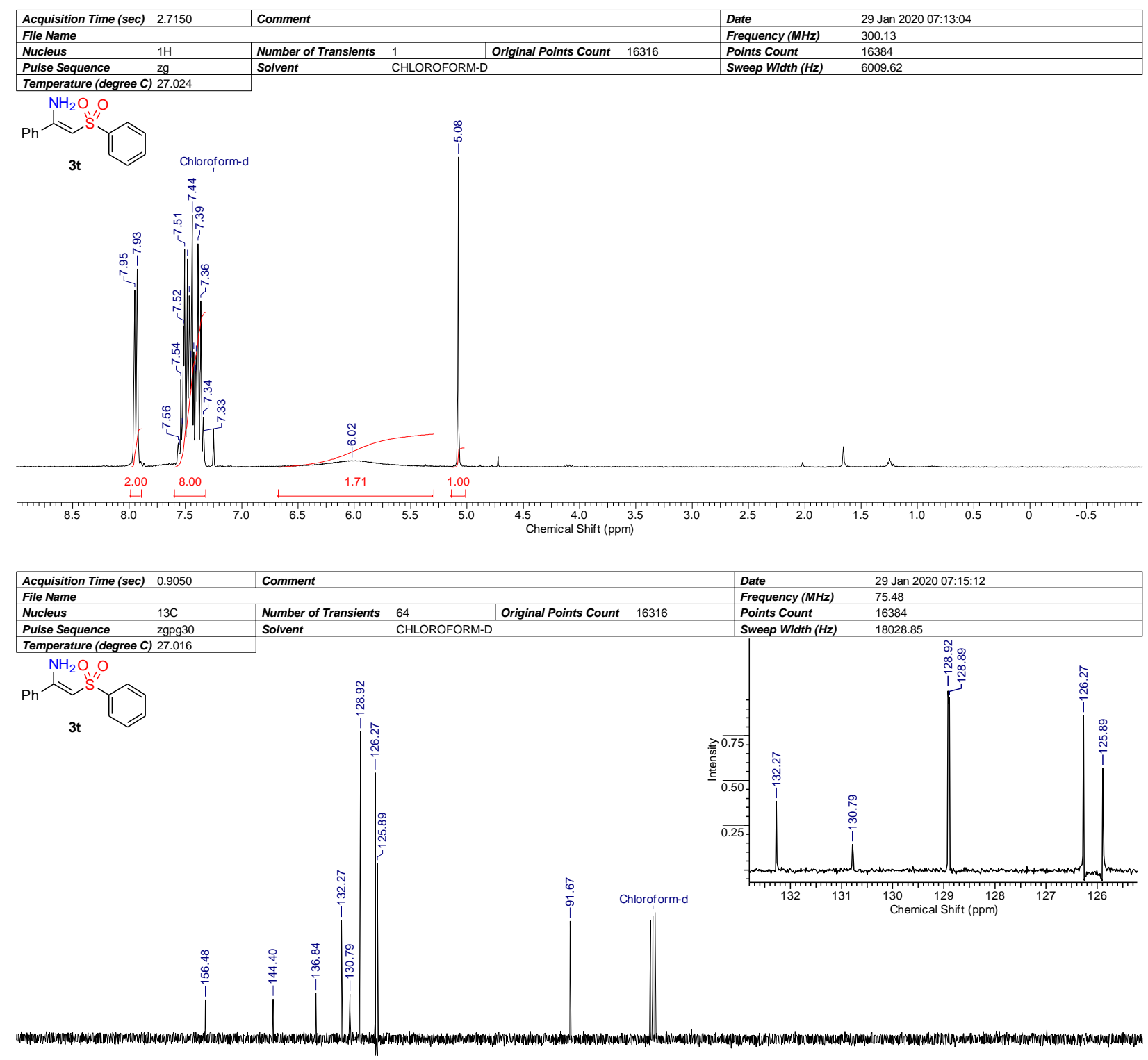

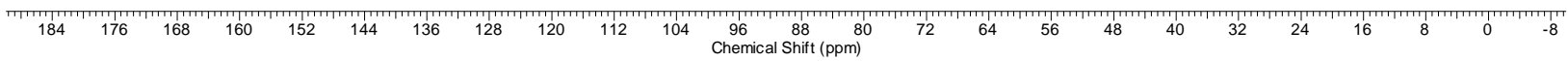



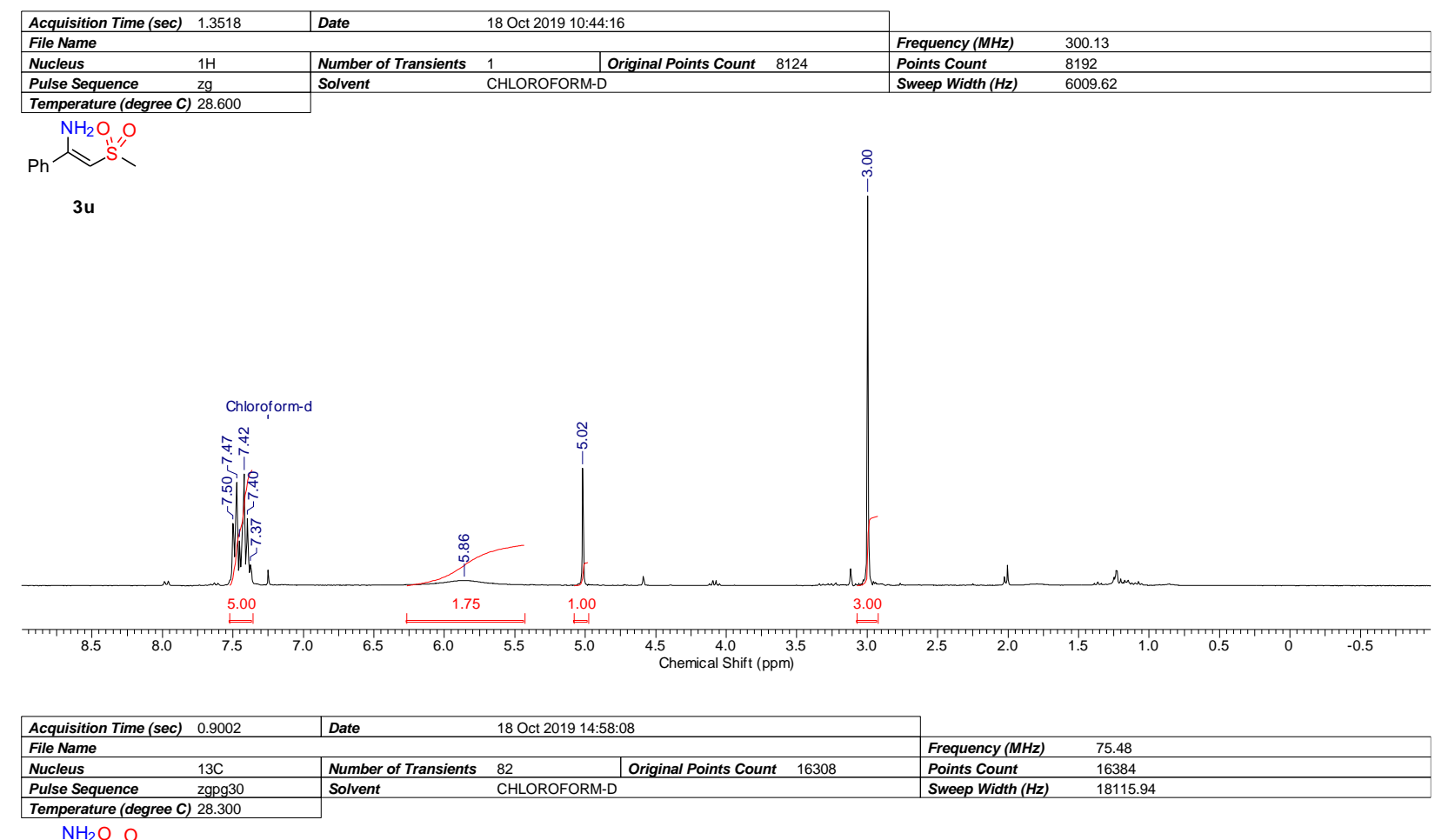
要"

$3 \mathbf{u}$

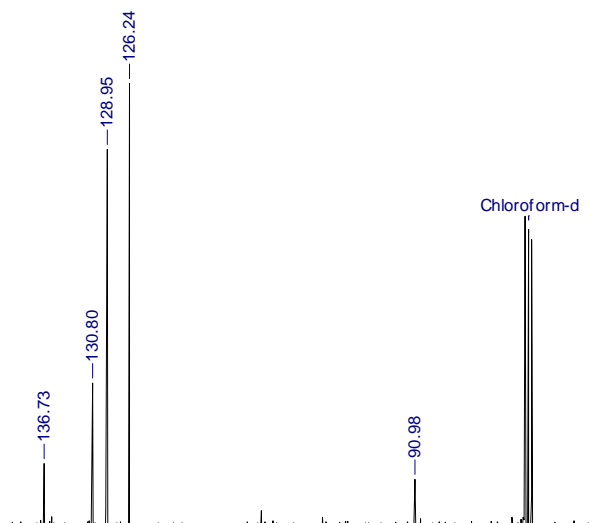

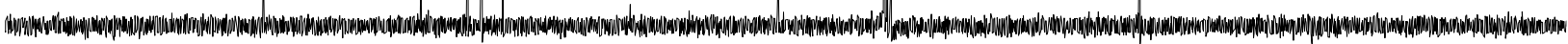

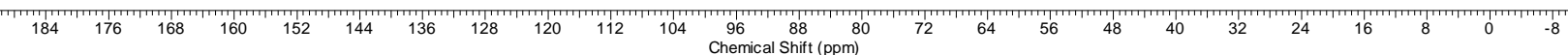




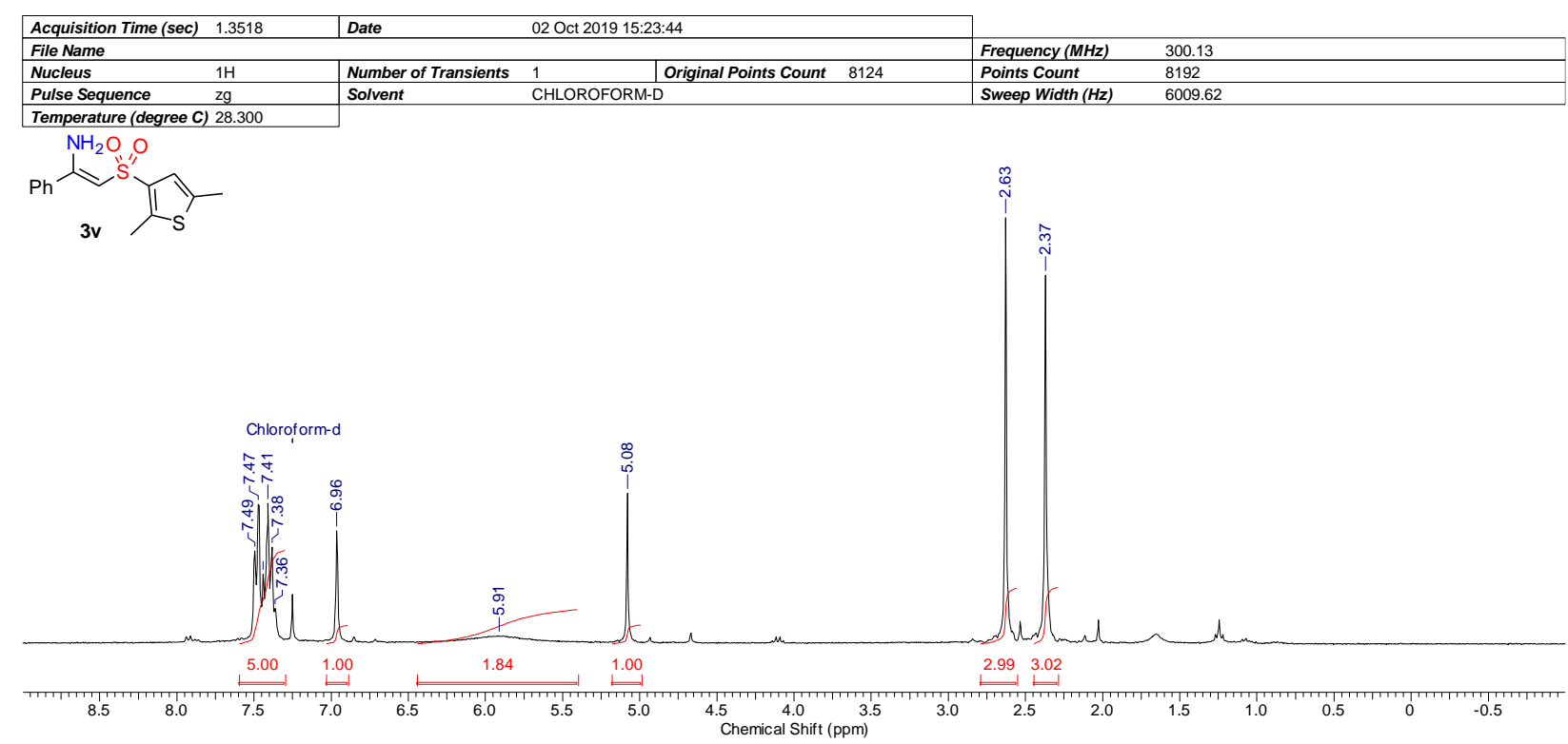

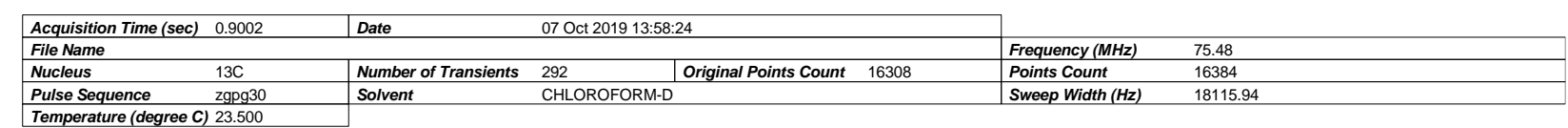
Temperature (degree C) 23.500

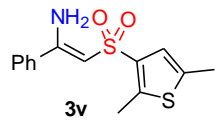

3v

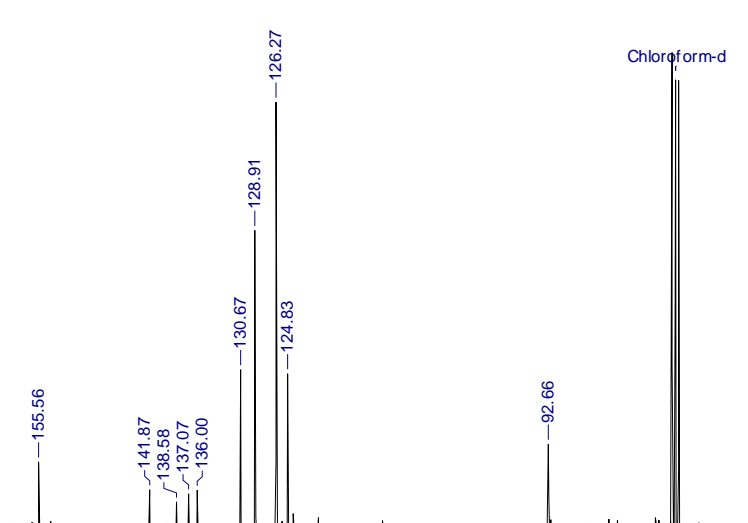

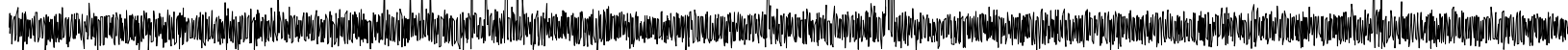

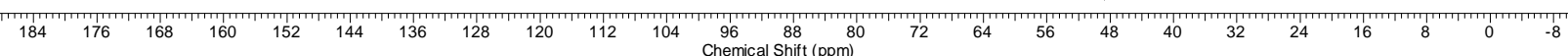




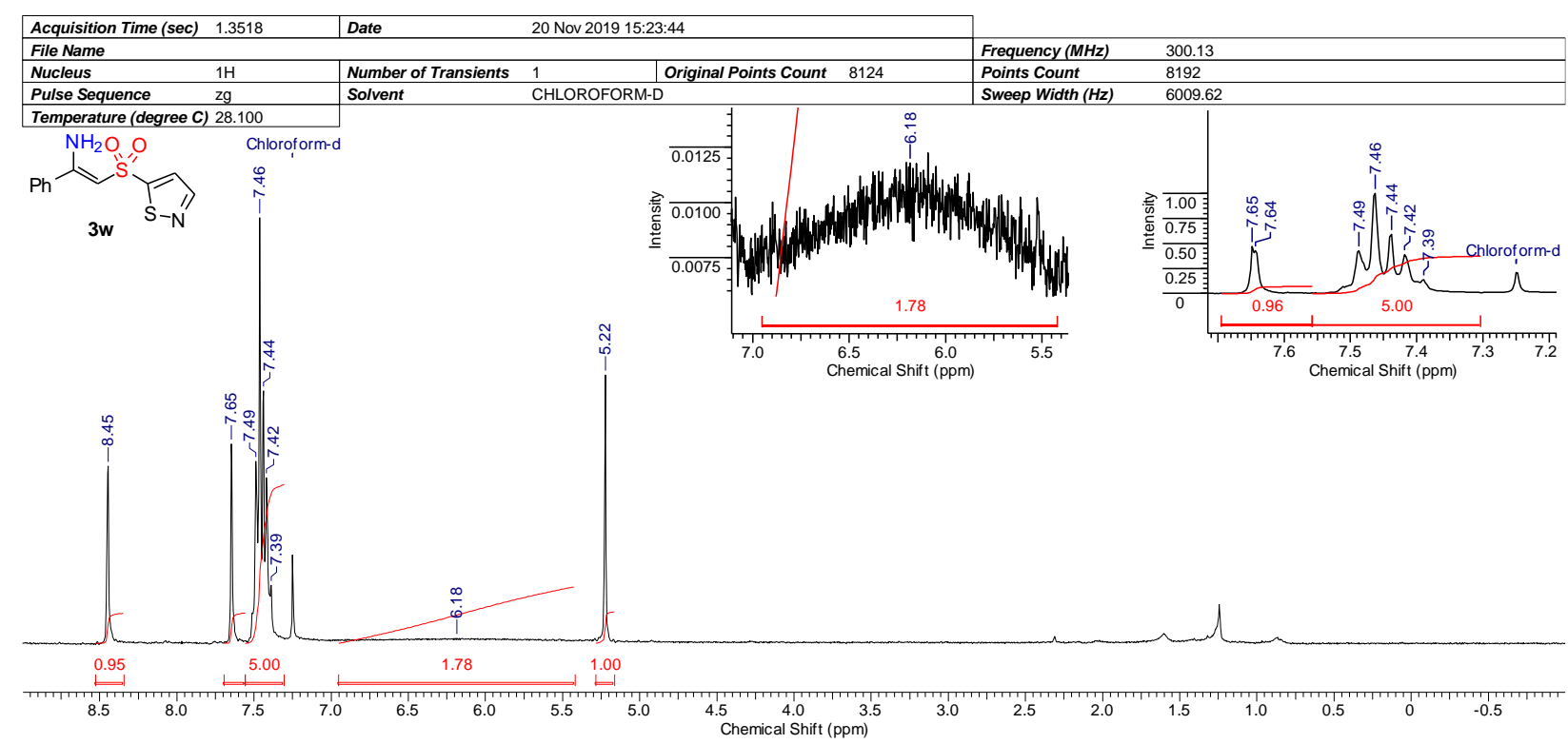

\begin{tabular}{|c|c|c|c|c|c|c|}
\hline \multirow{3}{*}{$\begin{array}{l}\text { Acquisition Time (sec) } \\
\text { File Name } \\
\text { Nucleus }\end{array}$} & \multirow{2}{*}{0.9050} & \multicolumn{3}{|l|}{ Comment } & \multirow{3}{*}{\begin{tabular}{|l|} 
Date \\
Frequency $(\mathrm{MHz})$ \\
Points Count \\
\end{tabular}} & \multirow{3}{*}{$\begin{array}{l}21 \text { Nov } 2019 \text { 06:53:52 } \\
75.48 \\
16384\end{array}$} \\
\hline & & & & & & \\
\hline & $13 \mathrm{C}$ & Number of Transients & 64 & Original Points Count 16316 & & \\
\hline Pulse Sequence & zgpg30 & Solvent & CHLOROFORM-D & & Sweep Width $(\mathrm{Hz})$ & 18028.85 \\
\hline
\end{tabular}
Temperature (degree C) 27.024<smiles>CN(C=C(N)c1ccccc1)c1ccns1</smiles>

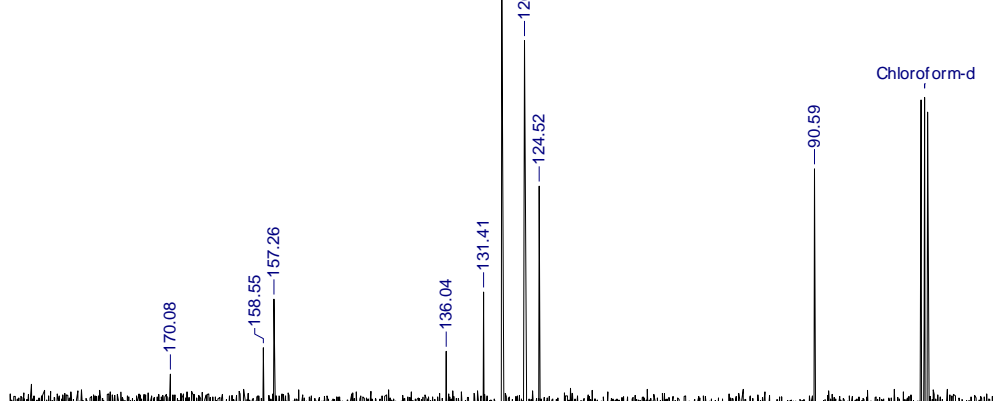

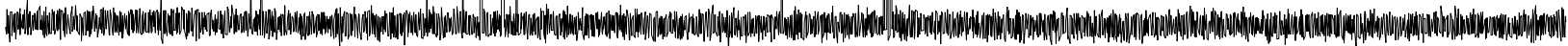



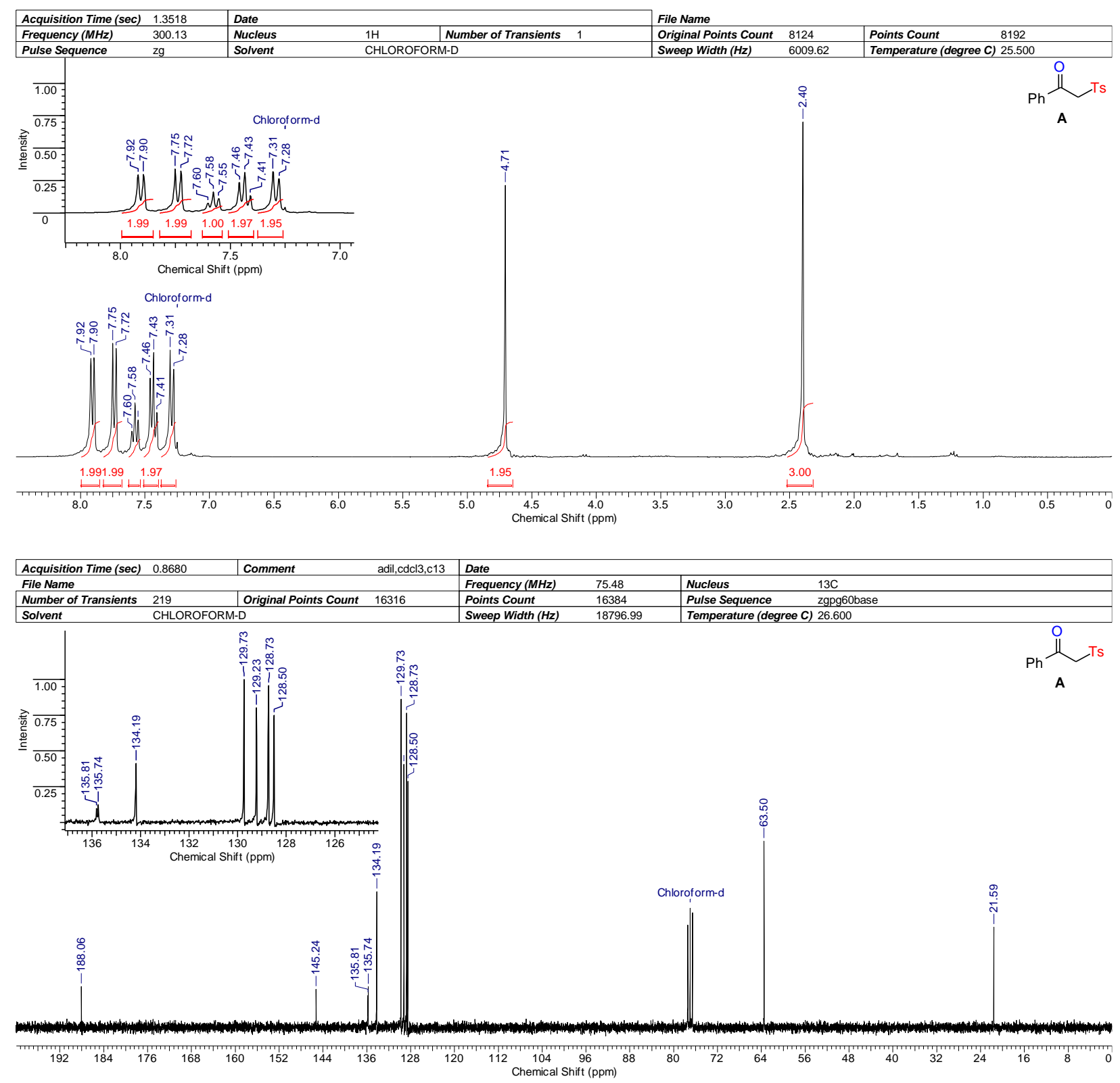